\title{
Money as tool, money as drug: The biological psychology of a strong incentive
}

\author{
Stephen E. G. Lea \\ University of Exeter, School of Psychology, Washington Singer Laboratories, \\ Exeter EX4 4QG, United Kingdom \\ S.E.G.Lea@exeter.ac.uk http://www.exeter.ac.uk/ SEGLea \\ Paul Webley \\ University of Exeter, School of Psychology, Washington Singer Laboratories, \\ Exeter EX4 4QG, United Kingdom \\ P.Webley@exeter.ac.uk http://www.exeter.ac.uk/ pwebley
}

\begin{abstract}
Why are people interested in money? Specifically, what could be the biological basis for the extraordinary incentive and reinforcing power of money, which seems to be unique to the human species? We identify two ways in which a commodity which is of no biological significance in itself can become a strong motivator. The first is if it is used as a tool, and by a metaphorical extension this is often applied to money: it is used instrumentally, in order to obtain biologically relevant incentives. Second, substances can be strong motivators because they imitate the action of natural incentives but do not produce the fitness gains for which those incentives are instinctively sought. The classic examples of this process are psychoactive drugs, but we argue that the drug concept can also be extended metaphorically to provide an account of money motivation. From a review of theoretical and empirical literature about money, we conclude that (i) there are a number of phenomena that cannot be accounted for by a pure Tool Theory of money motivation; (ii) supplementing Tool Theory with a Drug Theory enables the anomalous phenomena to be explained; and (iii) the human instincts that, according to a Drug Theory, money parasitizes include trading (derived from reciprocal altruism) and object play.
\end{abstract}

Keywords: economic behaviour; evolutionary psychology; giving; incentive; money; motivation; play; reciprocal altruism

\section{Why are people interested in money?}

This target article seeks to provide a biological explanation for one of the strongest motivations of humans living in modern societies: the desire to obtain money. We start by establishing some definitions. What do we mean by a "biological explanation"? What do we mean by money? And what do we mean by the motivation to obtain money?

\subsection{Biological explanation}

By the 1950s, the "grand theories of everything" that had emerged in early twentieth-century psychology seemed to have become extinct. But with the publication of Richard Dawkins' (1976) book The Selfish Gene, the strongly Darwinian approach that has been called, with slightly varying nuances, sociobiology or evolutionary psychology emerged as a new and potentially universal way of addressing the Why questions about human behaviour. If people do something, the sociobiological argument runs, it must be because (a) doing it confers a selective advantage; or (b) although doing it does not now confer a selective advantage, it did at some period in our evolutionary past, most likely in the early history of Homo sapiens, within the Environment of Evolutionary Adaptation; or (c) the tendency to do it is a by-product of some other tendency, which does or did confer such an advantage.
Stephen Lea is Professor of Psychology at the University of Exeter, U.K. He is the author of more than 150 publications spanning the areas of animal cognition, behavioural ecology, economic behaviour, and human visual perception. As well as being one of the founders of modern economic psychology in Europe, he is well known for his research on pattern recognition and concept discrimination in birds, and for bringing together ecological, economic, and psychological approaches in the analysis of both human and animal behaviour. Within economic psychology he has specialised in the study of debt and giving, as well as the psychology of money, but has also co-authored or edited several more general books with Paul Webley.

Paul Webley is Professor of Economic Psychology and currently Deputy Vice-Chancellor at the University of Exeter, U.K. His books include The Individual in the Economy (Lea et al. 1987), Tax Evasion: An Experimental Approach (Webley et al. 1991), New Directions in Economic Psychology: Theory, Experiment and Application (Lea et al. 1992), Children's Saving (Sonuga-Barke \& Webley 1993), and The Economic Psychology of Everyday Life (Webley et al. 2001). His current research is concerned with the economic psychology of personal money management (saving, debt, investment), tax compliance, and children's economic behaviour. 
Biological explanation does not imply that human behaviour is "innate," "hard-wired," or will inevitably take a particular form. Humans are social and cultural animals, and any observed human behaviour is the product of a particular social and cultural environment interacting with human nature: genetically adaptive instincts are always manifested in culturally specified ways. Selective advantage is not an alternative to social and cultural factors as a kind of explanation, but if an explanation is to be classed as "biological," then selective advantage must be part of it-even if the behaviour currently being explained, in current circumstances, confers no such advantage.

\subsection{The nature of money}

In talking about money, we mean just that - money itself, money as a distinctive economic institution and its physical embodiments in particular kinds of money stuff. We are investigating the psychology of money, not using it as a metaphor for property and possessions (for which see Rudmin 1991) or economic activity generally (for which see, e.g., Lea et al. 1987; Webley et al. 2001). It may well be that someone who seeks out money is seeking it out for the sake of what it can buy. Indeed, one of the two theories that we consider here supposes that this is always the case (we call this the Tool Theory). But the point of our target article is that this is not the only conceivable theory, because although the desire for money is undeniably closely connected to the desire for the things that it can buy, the two are logically distinct and need to be investigated separately. Part, but only part, of that investigation is to establish whether and how the psychology of possessions, and of other human motives, leads to a psychology of money.

Although we are talking about money in a narrow, concrete sense, our notion of money stuff is broad. We include the coins and notes that are at the core of people's concept of money in present-day societies (cf. Snelders et al. 1992), but we also include both the so-called primitive moneys (Einzig 1966) and more modern ones, such as cheques, credit cards, marks in bank ledgers, and memory states of bank computers. Any substance or medium is within the scope of our discussion if it fulfils or appears to fulfil the three basic functions of money: as a medium of exchange, a unit of account, and a store of value (discussed further in sect. 3.1).

\subsection{The motivation to obtain money}

By saying that people are motivated to obtain money, we mean that when people live in a culture where money is used, money enters into human behaviour in some of the same ways as commonly recognised motivators such as food or sex. More specifically, (a) money acts as an incentive: if people can perceive or understand that a particular action is likely to lead to them obtaining money, they are more likely to perform that action (though they will not inevitably do so, since there may be constraints from conflicting motivations); and (b) money acts as a reinforcer: actions that in the past led to a person receiving money are more likely to be repeated (though again, they will not inevitably be).
We treat these effects of money as "stylised facts." They could be questioned, but in this article we accept them without further discussion. Our aim is to explain them by reference to other known human motivations, known features of human nature, or particular features of the socialization of children.

\subsection{The problem}

Most strong human motivations have two characteristic properties, which make them easy to explain in evolutionary terms:

1. Adaptiveness: The motivations direct people towards, or away from, stimuli of obvious significance for the survival of individuals or the propagation of their genes. This is true not only of motivations such as hunger and thirst that are related to individual tissue needs, but also of such motives as the need for social companions, sexual drives, and parental care.

2. Darwinian continuity: The motivations are either exact homologues of motives that exist in all or many related species of animals, or (more commonly) they are obviously derived from such motives. Continuity does not require that human motives should be identical to those of other animals. Humans hunger for a wider and more culturally defined range of foods than do other apes (cf. Mennell et al. 1992); human sexual motivations are unusually independent of the biological need to reproduce (e.g., Symons 1979); human curiosity takes us into scientific explorations that are unparalleled by the exploratory motivations shown by many other species (cf. Berlyne 1960); human politics are much more complex than the socially motivated behaviours of, say, chimpanzees (cf. de Waal 1982; 1996). Many of these variations on motivational themes are informed by, and informative about, cultural differences. But we have no difficulty in understanding where these complex human motivations come from, evolutionarily speaking, and we can speculate in sensible ways about how they have become more complex over the five million years or so since the divergence of the ancestral lines that led to chimpanzees and bonobos on the one hand, and humans on the other.

Most human motives show adaptiveness and Darwinian continuity in an obvious way. It is therefore reasonable to talk about people as displaying a "hunger instinct" or a "sex instinct" or even a "political instinct" - though we must always recognise that the way in which those instincts play out in actual human behaviour is a function of culture and individual experience; they are not instincts in the sense of being inflexible, hardwired micromechanisms. The motivation to acquire money, however, is not directly adaptive, and has no obvious parallels in the behaviour of other animals. Furthermore, it cannot be imagined to result from some evolutionary process that has occurred within the hominid period: money has emerged only within the last 3,000 years or so (Davies 2002), too short a time for significant genetic adaptation to its existence; besides, individuals born into cultures that have never used money quickly come to use it if they move into a money-using culture. Money, therefore, is a problem for a biological account of human motivation. We cannot reasonably talk about a "money instinct."

It is possible that there is no biological basis at all for our attraction to money, that it is a pure creation of culture, 
with no connection to human nature at all. That would make it an exception, perhaps even a unique exception, among strong human motives. We do not consider this "pure cultural" hypothesis directly in this target article, but indirectly it is under test since our task is to offer the best account we can of the biological origins of the money motive. If that account fails to convince, the pure cultural option would be all that remained. However, we cannot leave culture out of our account, because human instincts are always manifested in a cultural context. Much empirical and theoretical work on the human interest in money has been done within the culture-dominated sciences of sociology and anthropology. We will draw on data from these sources throughout this article, and in particular we will return to those analyses when we come to offer a synthetic account of the money motive (sect. 5).

\subsection{Previous work}

Despite the obvious power of the money motive, money has been given little attention by psychologists writing about human motivation. There are no chapters devoted to it in general textbooks such as those by Mook (1987) or Weiner (1992), though extended accounts of specific psychological theories in relation to money can be found (e.g., Bornemann 1976). Conversely, although economics naturally deals with money, it has been so little influenced by evolutionary ideas (at least until fairly recently; cf. Boulding 1981) that economists have not recognized the problematic nature of the money motive. The questions we are interested in have mainly been addressed by writers who have crossed disciplinary boundaries and considered money from an economic but also from a more general point of view: these include economists (e.g., Maital 1982; Scitovsky 1976), but also anthropologists (e.g., Crump 1981), sociologists (e.g., Simmel 1900/1978; Zelizer 1989), cultural historians (e.g., Seaford 2004), and literary theorists (e.g., Shell 1982), as well as psychologists (e.g., Furnham \& Argyle 1998; Lea et al. 1987, Ch. 12; Van Veldhoven 1985). However, these sources offer general, comprehensive accounts of the psychology of money. The present article addresses a single more specific question: Is there a biological reason why money is such a powerful incentive? The question necessarily assumes that there is coherent set of behaviours that we can class as human reactions to money as an incentive, and that they have a single explanation. To the extent that we are able to find a biological reason for the strength of the money motive, we will be giving support to that assumption.

\section{Tool Theory and Drug Theory}

Although money is unusual among powerful human motivators in having no immediate adaptive origins, it is not unique. There are other examples, and between them they furnish two classes of theory that can be applied to the problem of money motivation. We argue that between them these exhaust the possibilities for a biological psychology of that motivation.

\subsection{Tool Theory}

Frequently, humans' advanced culture and technology provide us with biologically unprecedented means to familiar ends. For example, humans (and only humans) will use time and effort to acquire such modern artefacts as newspapers, radios, or television sets. The incentive value of newspapers is not biologically problematic. They are a means of gaining information about the environment, and most advanced animals can benefit from such information: dogs use time and effort to sniff lampposts and chaffinches use time and effort to listen to one another's songs. The biological value of information has been formally analysed in studies of group foraging in many species of vertebrate (e.g., Mesterton-Gibbons \& Dugatkin 1999; Ward \& Zahavi 1973), and operant psychologists have shown that information may function as an effective reward in nonhumans (e.g., Catania 1975; Hendry 1969b), though only when it is correlated with a reduction in the delay before reward (Case \& Fantino 1981). Similarly, many mammals seek out shelter to spend the inactive period of their daily cycles and to hide their developing offspring; many manufacture shelters for such purposes; badgers dig setts, beavers build dams, and chimpanzees weave nests. None use bricks, mortar, and timber to build themselves houses, but we do not regard human house building as a biologically problematic activity, or the incentive value of building tools and materials as a biologically problematic motivation.

The Tool Theory sees money in the same light. Economists have argued since the earliest days of the discipline that when two people exchange scarce resources, the exchange can increase the wealth of both parties (e.g., Smith 1776/1908). Money is the most efficient means yet discovered of making such exchanges possible. It is not the only means: among the other examples that have been analysed are the gift-mediated exchanges that were used by the Trobriand Islanders (Malinowski 1922), and the bartering systems by which tools were traded over quite long distances in New Guinea and Queensland (Sahlins 1974, Ch. 6). But these exchanges do not circulate goods anything like so quickly, nor do they produce such a large social gain in wealth, as money-mediated exchanges. On this view, money is not an incentive in itself; it is an incentive only because and only insofar as it can be exchanged for goods and services. Those goods and services are among that majority of incentives that do demonstrate adaptiveness and Darwinian continuity, and if money is a strong incentive, it is because the goods and services it will buy are strong incentives. According to Tool Theory, we do not need a psychology of money at all, or we need it only in a limited sense: we only have to understand the job that money does and the human cognitive system that enables us to use it. Cognitive psychology may allow us to understand why a system of a 100 cents to the dollar has replaced Charlemagne's system of 12 pence to the shilling and 20 shillings to the pound, but such understanding hardly deserves the name of a psychology of money. In the same way as a literal tool like a screwdriver mediates between our need to connect pieces of wood and the limited strength and dexterity of our hands and arms, so money mediates between our need to exchange commodities and the limited evaluating power of our brains.

Obviously money is a tool only in a metaphorical sense. You can use money as a literal tool - as when you use a coin to undo the battery compartment of a bicycle lamp or use a $\$ 100$ bill to light a cigar. Flaunting a well-filled 
wallet as a means of social display is almost as crude. But such aberrant uses of money are not what we are talking about in Tool Theory. Tool Theory accepts the metaphorical extension of the idea of a tool inherent in the word "instrumental"; it sees money as a means to an end. As we shall discuss in sect. 3.1, economic theory recognises that money has more than one function: it serves as a unit of account and a store of value, as well as a means of exchange. But that does not undermine the notion of money as a tool - it means that, like a screwdriver, it is a tool with a number of uses. Similarly, the possibility that money is used for purposes such as social display, social communication (Buchan 1997), or social protection (Doyle 1998) merely extends the range of uses for money as a tool. Furthermore, it would be a mistake to describe money, or anything else, as a "mere" tool; the idea of a tool is a potentially powerful one, and has been used by philosophers such as Heidegger (e.g. 1927/1962) and Innis (1984) to provide an account of basic phenomena of cognition and perception.

\subsection{Drug Theory}

Although Tool Theory is the obvious account of the motivation to acquire money, tools are not the only class of biologically unprecedented objects that can acquire strong incentive properties. A second class can be briefly described as "drugs." Just like the Tool Theory, the Drug Theory of money depends on a metaphorical extension of the core idea, but we start with the most literal idea of a drug.

2.2.1. Drugs sensu stricto. Certain chemical substances, such as alcohol, nicotine, caffeine, tetra-hydro cannabinol, cocaine, and morphine, can all become strong incentives, but their incentive power does not depend on their ability to produce other goods and services. Instead, they produce distinct physiological states by direct action on some part of the body, usually the brain. The nervous system contains numerous receptors for natural substances that play a role in the body's normal functioning, and the existence of these receptors is readily explained as adaptive. Drugs in the strict sense usually act on such receptors, changing a person's nervous state. But we do not explain the existence of binding sites for drugs as adaptive. We do not envisage early humans, or our pre-hominid ancestors, gaining a selective advantage by smoking marijuana. Instead, a psychoactive drug is thought of as a substance that by chance or by chemical similarity acts in the same way as a body chemical, and which is therefore able to intrude upon the normal functioning of the nervous system. By mimicking the action of some natural substance, it produces an abnormal response without being part of an ordered, functional sequence. The Drug Theory of money motivation asserts that money, too, intrudes on the normal functioning of the nervous system. Clearly, however, money is not a psychoactive chemical, so to develop the Drug Theory we need a metaphorically extended concept of a drug, just as the Tool Theory of money requires an extended concept of a tool.

2.2.2. Perceptual drugs. Alcohol, nicotine, and the other substances listed above are all familiarly recognized as psychoactive drugs. There are other substances, however, that meet the essential definition of a psychoactive drug as having a nonfunctional, direct, effect on the nervous system that affects our mental state. An instructive example is saccharin, which produces much the same motivational effect as natural sugars like fructose or lactose, without being a nutritive carbohydrate. It differs from alcohol or caffeine in that it produces an instant, perceptual effect instead of a longer lasting effect on mood, and in the fact that the receptors it acts on are in our sense organs, not in our central nervous system. But neither seems to be an important point of principle: we might reasonably call saccharin a "perceptual drug" to note that it has a drug-like action, but not directly on the central nervous system. The historian of sugar, Sidney Mintz, refers even to sucrose as a "drug food" (e.g., Mintz 1986), on the grounds that its psychological effects are disproportionate to those of the sugars found in unprocessed foods.

If we grant this extension of the notion of a drug, we can see that there are many other stimuli that produce the same perceptual effect as some natural motivator, but are not associated with any benefit to the perceiver. Early ethologists discovered many stimuli that resembled the Sign Stimulus for a Fixed Action Pattern sufficiently to trigger a response: for example, cardboard disks elicited sexual pursuit in Grayling butterflies, a striped knitting needle elicited begging in herring gull chicks, and an Easter egg elicited brooding in greylag geese (Tinbergen 1951). Although it is to a male Grayling's evolutionary advantage to court a female Grayling, the butterfly gains nothing in fitness terms by pursuing a cardboard disk. Furthermore, many natural sign stimuli will act as reinforcers or incentives (e.g., Thompson 1963), and in all cases that have been investigated, the artificial sign stimuli discovered by the ethologists have the same reinforcing or incentive effects as the natural stimuli they mimic. They therefore constitute a kind of functionless motivator. Like saccharin, they could be called "perceptual drugs." Any "dishonest signalling" system exploits this perceptual drug action, and there are many such systems in nature. Well-known examples include the chicks of cuckoos or other brood parasites eliciting feeding from the host parents by means of gaping behaviour and throat linings that resemble those of host chicks, and deceptive orchids eliciting copulatory probing from bumblebees and thereby achieving pollen transfer. There are also situations within human cultures that seem to work in the same way. Visual pornography, or the exaggerated drawings used in cartoons and advertising, can elicit and in some sense satisfy sexual or parental motivations (Lea 1984).

Such stimuli are only functionless in the strict, evolutionary sense of function. Within the life of the individual organism, they provide the same kind of gratification as the corresponding fully functional stimulus. But unlike that stimulus, they are not associated with the increment of biological fitness that, we assume, drove the evolution of the motivational system in question.

2.2.3. Cognitive drugs. Pornographic pictures mimic natural visual stimuli that are instinctually sexually arousing, for functional reasons that are well understood in principle even if the details are open to much debate. But what about pornographic text? Such material can undoubtedly be sexually arousing, but it does not mimic any stimulus 
that could be supposed to have an innate effect. Pornography here serves as an extreme example of a general fact: we can be emotionally engaged by many kinds of text, and therefore motivated to read them. Any such text must be thought of as a "cognitive drug." Its effect depends on what we know and understand, not on what we perceive; but like nicotine, like saccharin, and like the knitting needle that Tinbergen showed to herring gull chicks, it elicits a response without delivering the effects that make it adaptive for the organism to make that response.

2.2.4. The drug metaphor and Drug Theory. It may seem that we have extended the concept of a "drug" unreasonably, so let us recapitulate what we have discarded and what we have retained. We have discarded the idea of a chemical with an identifiable locus of action in the central nervous system. But we have retained the idea of a drug as a deceiver: a stimulus that is of no biological significance in itself, but which has motivational properties because it produces the same neural, behavioural, or psychological effect as some other stimulus that is biologically significant. A drug in this extended sense is any functionless motivator, obtaining its motivational effect by a parasitic action on a functional, evolutionarily adaptive system.

It is from this metaphorical definition of a drug that we derive our second biological account of the psychology of money, which we call Drug Theory. On this account, money acquires its incentive power because it mimics the neural, behavioural, or psychological action of some other, more natural incentive. Obviously, we are not suggesting that there are biochemical receptor sites in the brain on which, say, chemicals released by used fivepound notes react. Nor are we suggesting that money has a direct effect via the sense organs, like saccharin or visual pornography. But we do suggest that money can "act like" natural incentives at a cognitive level, and its motivational power flows at least partly from this. In describing money as a cognitive drug, however, we do not mean to disembody its action. Although the response to money must be mediated through the cognitive system, it is nonetheless an affective response, just as the response to pornography, or fiction, is not coldly cognitive. Cognitive drugs involve hot cognition (Anderson 1981). Furthermore, cognitive processes do imply correlated brain processes. The rapidly expanding research field of neuroeconomics (Glimcher 2003) has already shown, through brain imaging studies, that specific brain centres are activated in the presence of money (e.g., Zink et al. 2004), and immediate monetary incentives stimulate parts of the brain that are associated with immediate reward, not delayed reward (McClure et al. 2004). This is the opposite of what would be expected from Tool Theory, since on such a theory money is only interesting because of the biologically relevant rewards it can produce at a later time - a conclusion that is reinforced by the fact that in McClure et al.'s experiment, money was delivered in the form of tokens for an online bookshop, so the final reward could only be obtained after a delay of days.

Why should we use the drug metaphor for money, rather than some other alternative to Tool Theory? The core reason is that a drug is a functionless motivator, and that is what we want to assert that money sometimes is. But there are also other features of classic drugs that help make the metaphor persuasive. Drugs can be very strong motivators; they are often addictive; an attraction to them frequently has bad consequences for the individual; and they give immediate reward where "real" motivators can only do so over an extended period. As we discuss in section 4, all these features have been alleged of money. But while these additional features of the money motivation make the idea of "money as drug" attractive, they do not define it. Finding that money did not possess these additional drug-like properties would make the Drug Theory less attractive, but not useless; finding that money never acts as a functionless motivator would undermine it completely.

\subsection{Alternatives}

Could there be other accounts of the incentive value of money which do not fit within either Tool Theory or Drug Theory? Both assert that money gives access to biological rewards. Tool Theory covers cases where money gives real but indirect access to such rewards; Drug Theory covers cases where it gives direct access to the systems that subserve such rewards, but in an illusory, nonfunctional way. Given that we are looking for a biological understanding of money motivation, and given that we are taking as unarguable that there has not been time for the evolution of a direct, functional, brain system to detect and respond to the acquisition of money, the two theories seem to exhaust the range of possibilities between them. Tool Theory covers the cases where acquiring money is motivated by a real underlying function; Drug Theory covers the cases of functionless money motivation. It remains possible that an alternative, completely nonbiological, model could give a more economical account of the phenomena (see sect. 1.4). This means that only in a limited sense can we infer a role for Drug Theory from any failure of Tool Theory. If Tool Theory fails, Drug Theory is then the only possible biological theory, and vice versa. But that is not evidence that it is a satisfactory biological theory, only that there is no better biological alternative.

Money is neither literally a tool nor literally a drug. These are both metaphors, which we have used in an attempt to capture and contrast two distinct ways of explaining money within a biological approach to motivation. We believe that between them they do exhaust the field of human behaviour towards money, but clearly they are not the only conceivable way of partitioning that field. With sufficient sophistication, it is virtually certain that the tool metaphor could be extended to cover all the phenomena which we shall conclude are better explained by a drug metaphor, and vice versa. Our most fundamental aim in this target article, therefore, is not to establish the superiority of one of these metaphors over the other, but to deploy these metaphors in a relatively simple form to demonstrate the complexity of the phenomena of money psychology.

\section{Theories of money and money motivation}

Tool Theory and Drug Theory, as we have developed them here, are broad classes of psychological theories about the money motive. We now consider some particular theories 
that explicitly or implicitly specify psychological mechanisms for money motivation. We are not attempting an assessment of the plausibility of these theories, but rather characterising them as versions either of Tool Theory or Drug Theory. These categorizations are of course ours, not those of the original authors, who might well have disagreed with them.

\subsection{The economic theory of money}

A typical economic textbook account states:

whether money is shells or rocks or gold or paper, in any economy it has three primary functions: it is a medium of exchange, a unit of account and a store of value. Of these three functions, its function as a medium of exchange is what distinguishes money from other assets such as stocks, bonds or houses. (Mishkin 1992, p. 21)

All that matters, for something to function in these ways, is that all members of the relevant society should accept that it does so function. As Carruthers and Babb (1996) put it, money is a "self-fulfilling collective prophecy." Economists (and others) have divided sharply on what enables something to be accepted as money. On the one hand, there is the view - which, as Schumpeter (1954/ 1994) shows, goes back to Aristotle - that money must either have an "intrinsic" value, or at least be backed by a reliable promise from the issuing authority to exchange it for something of intrinsic value. Money that has this property is called "commodity" money, signalling that the substance that is used as money, or that backs money, would be sought for its own sake even if it were not used as money. It is also referred to as "convertible" money, signifying that the money substance can be converted into the underlying commodity. Because in complex economies the source of intrinsic or commodity value has usually been gold, the view that money must be convertible in order to be effective is known as "metallism" or "bullionism." It is by no means extinct; modern monetarist economic theory is its direct descendant (Bell 2001; Ingham 2001).

The alternative view claims that money becomes acceptable by government fiat, that is, by its designation as legal tender. Money with this property is called "fiat," "fiduciary," "chartal," or "nonconvertible" money. As Bell (2001) shows, this view, too, is ancient, but it first came to prominence with Adam Smith (1776/1908). Fierce political debates between bullionists and chartalists arose in Great Britain following a suspension of convertibility in 1797 (Perlman 1986), and in the United States after the end of the Civil War, during which both sides suspended convertibility (Carruthers \& Babb 1996).

Both commodity and fiat accounts of money face difficulties. The well-documented emergence of cigarettes as a money substitute in prisoner-of-war camps looks like excellent evidence for a commodity theory, but it poses two core problems: Why should people trade with a commodity instead of consuming it, and if they do use a commodity for trade, why does it generally circulate at a higher value than it is worth for consumption (Burdett et al. 2001)? To bullionists, on the other hand, fiat money poses two problems. First, why should people ever trust a purely arbitrary token? Second, if the value of money is created by the mere act of declaring it to be legal tender, what is to stabilise its value - especially as the government may well be motivated to change the value for policy reasons, to the detriment of economic affairs? Bell (2001) and Ingham (2001) trace from Adam Smith, through Keynes and other twentieth-century economists, the argument that government gives fiat money its value by declaring that it is acceptable in settlement of tax liabilities. Ingham extends the argument, suggesting (following Grierson; e.g., Grierson 1978) that the process of money creation has an older history in the use of money to settle other kinds of non-market debts such as brideprice and the compensations for injury (Wergeld) that were common in early Germanic societies. The creation of value through tax demands answers the metallists' theoretical questions, and the historical observation that governments often do interfere with the value of money is good evidence that modern money is in fact fiat money.

The chartalist account of money is an obvious Tool Theory. However, from our perspective, the metallist notion that abstract money must be backed by real goods is a version of Drug Theory. Gold and silver make good coinage because of their durability. But, according to metallism, nothing can work as money unless there is a market for it for non-money purposes. Such a market requires the substance to be scarce (which is true of gold and silver) but also desirable as a result of some human motive, which must therefore ultimately have a biological grounding. In the case of precious metals, their ultimate incentive value is aesthetic: the desire for beauty seems to be a biologically grounded motivation for our species, and gold and silver are useful in making beautiful and durable objects. According to the metallists, money backed by gold functions as a representation or symbol of that desirable thing, and though they were at pains to distinguish the symbol from the thing symbolised (see Carruthers \& Babb 1996), they were clear that it is because of the thing symbolised that money, the symbol, is desired. It is only because of this drug-like, mimicking property that money is able to function as a tool.

\subsection{Psychological theories of money}

We review briefly here some historically important accounts of the psychology of money; they have been surveyed in more detail elsewhere (e.g., Furnham \& Argyle 1998, Ch. 1; Lea et al. 1987, Ch. 12).

3.2.1. Depth psychology. Freud (1908/1959) commented explicitly on the question of money, and in his discussion of the anal character acknowledged that style of money management was one of the most obvious ways in which people differ. Like modern evolutionary psychologists, Freud recognized the need to provide a biological explanation of social behaviour. His explanation for the money motive was, characteristically, developmental. He suggested that psychological involvement with money must start with its most familiar form, coins, and that interest in these must derive by displacement from interest in faeces. Thus, for Freud, and for later psychoanalysts like Ferenczi (1914/1976) who developed Freud's ideas, the different individual behaviours and attitudes towards money, from the miser's hoarding to the spendthrift's self-destructive carelessness, represented varieties of anal eroticism. This is a basic Drug Theory: money acts on the developing human brain in the same way as 
faeces, with the important difference that it is acceptable to parents and society at large for a child to take a close interest in money.

3.2.2. Operant psychology. A very different kind of biological psychology provides a further example of a Drug Theory. Skinner (1953, p. 79) accounted for money within his radical behaviourism as a generalised token reinforcer. It is well established that stimuli paired with unconditioned reinforcers can acquire reinforcing power and are then called conditioned (or secondary) reinforcers; if the stimuli are tangible objects, they are called token reinforcers. Skinner argued (p. 77) that if a single kind of conditioned reinforcer was paired with many different kinds of unconditioned reinforcers, its reinforcing effect would become independent of deprivation of any of them. Operant psychologists have seen this process as providing a good account of the reinforcing power of money. To a cognitive psychologist, the token reinforcement would be seen as a means to an end, and a conditioned reinforcement theory of money would be a version of Tool Theory. But within a radically behaviourist account, the incentive power of tokens, and hence of money, derives from mere association with the goods and services it can buy; behaviour is not to be explained by supposing that organisms understand causal relations. Skinner is deliberately agnostic about the brain mechanisms of reinforcement processes, but it is clear that, however unconditioned reinforcers act, conditioned reinforcers must act in the same way, marking Skinner's theory as a pure Drug Theory. Skinner's is not the only behaviourist account of secondary or conditioned reinforcement (see the collections edited by Hendry 1969a and Wike 1966), though it is the one that has been applied most explicitly to explain behaviour towards money. However, other accounts share the essential feature of Skinner's, that the attraction to money develops through mechanistic principles of conditioning, and they too are therefore drug theories.

3.2.3. The functional autonomy of drives. A similar approach to money comes from social and personality psychology. Allport (1937) coined the phrase "functional autonomy" to describe motives that emerge from antecedent systems but become independent of them, so that the link with the original motive is historical and not functional and "'young” systems may become stronger than the older systems" (p. 363). Money can be seen as a good example of this process. This too is a kind of Drug Theory: though the motive to acquire money is a selfsustaining system, its origins are in more basic motives and it presumably acts on the brain in the same way as the comforts that it procures.

3.2.4. Cognitive development and money. As Webley (2004) explains, Piagetians have proposed that children's understanding of money passes through a series of stages. The number of stages proposed has varied, but in all cases the notion is that children are, step by step, learning how to operate within the economy of adults and how to use its institutions, especially money. This approach clearly focuses on the instrumental use of money, and thus qualifies as a Tool Theory.

\subsection{Money in other social sciences}

3.3.1. Classic sociology of money. The classic social science view of money was shaped by Marx (1867/1932, vol. 1, Chs. 1-3) and Weber (1904/1976, Ch. 5). Both linked the psychology of money to the capitalist mode of economic production. In Marx's view, tradable economic commodities are the products of human labour appearing as "independent beings endowed with life" (Marx 1867/ 1932, vol. 1, Ch. 1, sect. 4) through a process he describes as "commodity fetishism," in which certain compelling images come to eclipse the objects they portray. The conversion of labour into money requires a double transformation (Ch. 3, sect. 2), and therefore a double alienation (of labour into the commodity produced, and of the commodity into money). For Marx, this abstraction, or alienation, of perceived value from its origins in human labour is a necessary step in the historical development of a modern capitalist economy. Although lacking technical psychological input, Marx's account is plainly a theory about the psychology of money, and in our terms it is a clear example of a Drug Theory; a "fetish" is a very reasonable description of a "functionless motivation," and incorporates well the notion of deception that is at the core of the drug metaphor. Weber also saw the accumulation of money as essential to the development of capitalism, though in his account accumulation flows not from desire, but from the paradoxical way in which Protestantism equated working at worldly callings with virtue while disallowing consumption. This view leads to a Drug Theory more by default: since the tool use of money is disallowed, money can only be sought for its own sake, even though, as Weber recognised, it is not within human nature to do so (cf. Needleman 1994, pp. 143-44).

These classical views are capable of wider application than the specific economic historical settings in which Marx and Weber deployed them. The idea of commodity fetishism continues to be used in modern sociological and anthropological analyses (e.g., Carruthers \& Babb 1996; Desforges 2001; Snodgrass 2002), and the Protestant Ethic has acquired new significance in the psychometric analysis of behaviour towards money (Furnham 1990). But long before the recent period, a wider view of the sociology of money had been taken by Simmel (1900/1978) in his major work, Philosophie des Geldes (The Philosophy of Money). Simmel explored "just about every conceivable topic connected to money" (Deflem 2003). He agreed with Marx in seeing money as an instrument of alienation, but he did not see it solely in the context of the emergence of capitalism. For Simmel, it is money itself, not capitalism, that transforms goods into commodities. Money is both the means and the symbol of the process by which in modern society impersonal, quantitative social relations between autonomous individuals replace the determinant relations imposed by traditional society. Simmel was specific about money motivation: normally money is not a purpose in itself, but it has infinite capacities of application in exchange relations, and so it becomes desired for itself. In our terms, we can see here both an assertion of Tool Theory and an assertion of its inadequacy, and the need for some kind of Drug Theory. This is most obvious in the extreme case: "For the miser, all other goods lie at the periphery of existence and from each of them a straight 
road leads to the centre, to money. The whole specific sense of enjoyment and power would be misinterpreted if one were to reverse this direction and wished to lead it back again from the terminal point to the periphery" (Simmel 1900/1978, p. 245).

Although Simmel was a significant figure in the history of sociology, he had relatively little immediate influence; for example, Philosophie des Geldes was not translated into English until nearly 80 years after its first publication. The major development of social science thinking about money in the early twentieth century came instead from anthropology, with the work of Malinowski (e.g., Malinowski 1922) and, in particular, Mauss (1925/1954) on gift exchanges in non-Western cultures. These ethnographic studies supplied an empirical basis, lacking in the classic sociologists' work, for assertions about what exchange might be like in the absence of money. They showed that exchange can take place without moneybut also that it is distinctly different from exchange in a modern economy. They thus tended to confirm that money is not just a neutral tool, but an institution with a transformative potential.

Even from this brief survey, it can be seen that there are many different nuances within the classic sociological and anthropological analyses of money. However, these analyses share a rejection of a purely economic account not necessarily as wrong, but certainly as inadequate. In different ways, they see its invention or introduction as corrupting or transforming previous patterns of exchange; but even if money diminishes the social content of exchanges, it does not abolish it. As a result, money is sought for reasons that go beyond its instrumental function. To varying degrees and in differing ways, therefore, these classic sociological accounts are versions of Drug Theory.

3.3.2. Modern sociology of money. Recent decades have seen a revival of interest in the sociology of money, often involving a fusion of ideas from classic sociological theory (especially that of Simmel) with more recent anthropological data. Important contributors to the modern sociological theory of money include Carruthers (e.g. Carruthers \& Espeland 1998), Dodd (1994), Doyle (e.g., 2001), Ingham (e.g., 1996; 2001), Singh (e.g., 1996), and Zelizer (e.g., 1994). Less strictly academic accounts such as those of Buchan (1997), Millman (1991), and Needleman (1994) have also contributed to the modern view of the place of money in society.

These writings cover many aspects of money other than the motivation to acquire it, so a full review of them would be beyond the scope of this target article. A recurring theme within them, however, is the social interactionist perspective, resulting in a tension between two pervading ideas. On the one hand is the notion that money anonymizes social interactions, and on the other is the recognition that money is imbued with social meaning and thereby links things and people together (Newton 2003). Zelizer, who has taken a less hostile and pessimistic view of money's role in society than have many other modern social theorists, particularly stresses how money retains meaning beyond the particular transaction in which it is obtained or used (e.g., Zelizer 1989; 1996). Conversely, Ingham (2001) argues that the fundamental nature of modern money is the abstract recognition of a debt, so that its representation by a commodity is merely contingent; for him, money stuff always symbolises abstract money. But he is at one with Zelizer and other sociologists of money in rejecting the simple economic view that "money is what money does." From a different background comes the striking hypothesis of Seaford (2004) that it was the invention of coinage that enabled preSocratic Greek metaphysicians to conceive of impersonal universal forces: on this view, money can actually be said to give birth to abstract symbolic thought (see also Shell 1982).

The sense that money is essentially a symbol, perhaps multiply symbolic (cf. Lea et al. 1987, Ch. 12), seems hard to reconcile with any kind of biological analysis of money motivation; it leads, furthermore, to a cognitive rather than a motivational analysis of behaviour towards money. We will return later (sect. 5.2) to the question of whether there is a fundamental conflict between this kind of social-cognitive theory of money and our attempt to construct a biological account. Within the confines of our current account, however, we need to classify the modern sociological theories. Clearly they go beyond the simple notion of money as a tool for economic exchange, but they do not align in an obvious way with what we have called Drug Theory. Rather, modern sociology tends to see money as a tool, but as a tool for more than exchange, and, as we have already noted, that idea is explicit in several modern social accounts of money function; see, for example, Buchan (1997). In the final section of this target article (sect. 5.2), however, we shall argue instead that the modern sociological account should be classified as a Drug Theory, because its conclusions parallel those of the specific version of Drug Theory we develop there. At this point, we merely note that if money is sought for the meanings it carries, that allows for a disconnection between those meanings and the reality that is believed to underlie them, and thus creates an opening for the deceptive processes that characterize Drug Theories.

\subsection{Summary}

This brief survey has shown that a number of leading theories of money in psychology and other social sciences are, in terms of the metaphorical dichotomy we have drawn up, best classified as Drug Theories. However, we have not found a simple economics versus psychology opposition. Surprisingly, the most conservative economic theory of money (metallism) appears to be a Drug Theory, while at least one much-used psychological theory is clearly of the Tool Theory type, and modern sociological approaches may be best described as "sophisticated tool" theories.

\section{The empirical psychology of money}

Modern approaches to the psychology of money have been strongly affected by the emergence of the specialised subdisciplines of economic psychology and behavioural economics. A number of lines of investigation have proved fruitful within the empirical economic psychology of money, and these shed some light on the issue of Tool Theory versus Drug Theory. Several of them overlap with recent empirical work in the sociology and anthropology of money. Not surprisingly, these lines of investigation 
have shown that quite a lot of human behaviour towards money can be accounted for in terms of what we are calling Tool Theory, because this is the "obvious" account. In this section, we review several lines of evidence showing that something beyond the rational use of a tool is involved. We argue that many of these exceptional findings are well accounted for by a Drug Theory.

\subsection{Perceiving coins}

Bruner and Goodman (1947) found that children tend to overestimate the sizes of coins relative to other, physically similar, stimuli. This report caused considerable controversy, and a series of experiments by other authors clarified the result, without however shaking the basic claim that there is something special about money objects at the psychological level (Saugstad \& Schioldborg 1966). More recent research has supported that claim by looking at how the perception of money is changed by historical changes in the money system and the value of money. Lea (1981) found that pre-decimal British coins were remembered as larger than the identical coins under their decimal names, devalued by a decade of rapid inflation. Furnham (1983) found a similar effect for an obsolete design of pound note, and further research along the same lines has been carried out in other countries by Leiser and Izak (1987) and Brysbaert and d'Ydewalle (1989). A Drug Theory can account for these phenomena by asserting that the value of money gives it a special status, which interferes with normal perceptual/ cognitive processing. It is not obvious how a Tool Theory can accommodate these phenomena.

\subsection{Money illusion}

In the presence of inflation, economic events and choices that take place over time can be denominated either in terms of nominal values - the actual money amounts - or in terms of real values - purchasing power. If people are influenced to some extent by nominal rather than real values, they are said to be suffering from "money illusion" (Fisher 1928). Although the possibility of money illusion was for decades dismissed by theoretical economists, it has now been demonstrated in economic experiments (Fehr \& Tyran 2001) and survey studies (Shafir et al. 1997). It is also ubiquitous in ordinary economic life. At the population level, consumers demonstrate money illusion in relation both to the entire economy (e.g., Dowd, 1992) and to individual commodities (e.g., Franke 1994). Consumer money illusion can also be seen at the individual level, for example in price estimation in different currencies (e.g., Gamble et al. 2002) and in the effects of currency change on charitable donation (Kooreman et al. 2004). Money illusion can also be demonstrated in producers: for example, in the borrowing behaviour of small firms (Machauer \& Weber 1998) and in the response of independent professionals to changes in state-mandated fees (Mayer \& Rozier 2000). Investors, too, suffer from money illusion (e.g., Miller \& Schulman 1999; Modigliani \& Cohn 1979). The downward trend in the value of nonresident fathers' child support payments in the United States seems to be in part attributable to money illusion on the part of judges, lawyers, and parents (Hanson et al. 1996).
Money illusion disconnects the psychological impact of money from what money can do. Shafir et al. (1997) argue that the disconnection is only partial, and that money illusion in fact arises from people's struggles to work with both real and nominal values. But even a partial disconnection of the motive for money from its instrumental effect is evidence that a pure Tool Theory cannot be adequate.

\subsection{Money conservatism}

People frequently resist new forms of money, even when the innovation is quite trivial. When the U.K. pound note was replaced by a coin in 1983, reaction in the press was absurdly hostile; and Hussein (1985) showed experimentally that people did indeed behave differently with the coins, spending them more quickly than notes. In the United States, the introduction of the Susan B. Anthony dollar coin in 1979 largely failed because of public rejection (Caskey \& St. Laurent 1994). Current attempts to introduce a dollar coin are again meeting with hostility and very low levels of usage; the coins barely circulate, except for a few special purposes such as the purchase of subway tickets in slot machines, while dollar bills remain in widespread use. The reaction against the euro in countries such as the United Kingdom (see Routh \& Burgoyne 1998) is similarly disproportionate to any economic facts. Indeed, people are more agreed about their dislike of the euro than they are about the reasons for that dislike, a strong indication that their hostility is rationalised rather than rational. That is not to say, of course, that it is unreasonable: the euro is recognisable as both a means and a symbol in the ongoing project of "Europeanization" (Borneman \& Fowler 1997) to which many people in the United Kingdom remain opposed. Its rejection is the rejection of an institution that is literally foreign to them, and thus incapable of supporting the trust that money is required to elicit.

At first sight, money conservatism seems to give strong support to a Drug Theory. However, it is not an unlimited phenomenon, and its limitations tend to support a Tool Theory. Caskey and St Laurent (1994) produce an entirely instrumental analysis of the rejection of the U.S. dollar coins. When currencies lose their value because of economic or political change, people lose interest in them precipitately, as a Tool Theory would predict. Furthermore, not all new forms of money are rejected. Credit and debit cards have won wide acceptance quite quickly, though penetration varies greatly between countries (Humphrey 2004; Snellman et al. 2001). Nevertheless, some of the phenomena of money conservatism do seem to call for a Drug Theory. The loss of interest in superseded forms of money is rarely total. Anecdotes of people hanging on "irrationally" to foreign or devalued currencies are common, suggesting that money does not lose quite all its power when it loses its function. Furthermore, although dramatic devaluations certainly do cause people to lose confidence in a particular currency, they have much less effect on people's confidence in money in general. The high inflation that has characterised many Latin American and African countries for decades has certainly caused their citizens to lose interest in acquiring their local currencies, but they remain very interested in acquiring dollars (e.g., De Boeck 1998; Guidotti \& Rodriguez 1992). The collapse of the rouble following 
the end of the Soviet Union caused a return to barter in many sectors of the Russian economy (Woodruff 1999), for lack of any alternative. But in Central Europe, where other forms of money (dollars, Deutschmarks, and now euros) were more readily available, it was these rather than barter that filled the gap. Moreover, although some forms of "plastic money" have spread successfully, others have failed spectacularly. There have been a number of high-profile attempts to introduce "electronic purses", a kind of "smart card" where the record of money available is stored on the card itself rather than in a central bank computer; all have failed to gain public acceptance, despite apparent technical advantages (Truman et al. 2003). New forms of money are in general not less functional than old forms, indeed the reason for introducing them is that they will be better tools for exchange; but they seem to need to show a substantial advantage over old forms before people will adopt them. The reaction to them is often emotive rather than calculative. We conclude the people become attached to money objects themselves, as predicted by Drug Theory.

\subsection{Money attitudes}

Economic psychologists have developed a number of psychometric scales that assess attitudes towards money for example, the Money Attitudes Scale (Yamauchi \& Templer 1982), the Money Beliefs and Behaviour Scale (Furnham 1984), and the Love of Money Scale (Tang 1995). These scales are always multifactorial, yielding anything from three to eight factors. Although the details vary between scales and studies, the common experience is to find more or less orthogonal factors relating to power and prestige, to distrust and anxiety, and to retention and other temporal issues. Tang and his colleagues have found separate and virtually orthogonal factors for an affective component (assessment of money as good or evil), a cognitive component (money seen as an indicator of achievement, respect, and freedom or power), and a behavioural component relating to practical budgeting. Furthermore, these factors enter into different relationships with other variables of both economic and psychological interest, such as job satisfaction, business ethics, work motivation, and life satisfaction (Luna-Arocas \& Tang 2004; Tang \& Chiu 2003; Tang \& Gilbert 1995). These results demonstrate a dissociation between the instrumental and affective aspects of money. In our terms, therefore, they do not suggest that either Tool Theory or Drug Theory is correct and the other wrong; they suggest that money has both tool-like properties and drug-like properties, and the two are psychologically dissociated, so that neither kind of theory could give a complete account on its own.

\subsection{Restrictions on money use}

The primitive moneys of non-Western societies often could only be used for certain kinds of exchange, or there might be several different money systems, each confined to a particular class of commodities or a particular group of people. Such restrictions on use represent a failure of the tool function of money. It might be argued that special-purpose moneys correspond to specialpurpose tools, which are after all common in most kinds of technology. But money is, specifically, a tool for exchanging. Any limitation on its exchangeability is a restriction on its tool use. Economic psychologists have shown that money in modern society, like primitive money, has restrictions on its use, particularly in connection with gifts. In Britain, young adults do not feel it is appropriate to use money as a gift for their mothers (Webley et al. 1983), and identifiable social rules prohibit or allow using money as a Christmas gift, depending on the relationship, and relative age and status of the giver and recipient (Burgoyne \& Routh 1991; Webley \& Wilson 1989). For example, the person giving money as a gift must be of higher status, if only by virtue of being older (cf. Motel \& Szydlik 1999). Furthermore, the evaluation of gifts, whether by the giver or the receiver, does not depend only on their monetary value (Pieters \& Robben 1999). A related phenomenon is the partial taboo on the use of money to repay neighbourly help (Webley \& Lea 1993a). These particular social rules are not universal: there are cultures where to give money is a sign of respect (e.g., in Ghana: van der Geest 1997) or is socially required in certain contexts (e.g., in Cyprus: Hussein 1985). Whatever form it takes, however, there is a general tendency to maintain a distinction between market exchanges (where money is acceptable and usually required) and gift exchanges (where money may not be acceptable), to the point where some marketmotivated exchanges may be given the outward form of gifts in order to appropriate a different social meaning (Offer 1997).

A second sphere where money is often an unacceptable medium of exchange is within sexual relationships. Historically, cultures have generally provided ways of legitimising the exchange of money or money's worth for sexual access, whether through bride price, bride service, or the convention that husbands should be the "breadwinners" for their wives and families. But it is not socially acceptable for the exchange to be made too starkly, or in other than the conventional forms: to do so incurs the stigma of prostitution. The exchange has to be cast within the rhetoric of gifts and giving rather than as payment. Millman (1991) argues that this social convention acts to mask the real financial exchanges that do take place within close relationships and are exposed when relationships break down. Simpson (1997) takes a slightly different position, arguing that on relationship breakdown there is a shift of transactions from the nonmonetised gift sphere to the monetised sphere, and this causes many extra difficulties between divorcing couples - even as they seek that shift to symbolise the social distance that now exists between them. Zelizer (1996) has documented some of the ways in which people in Western cultures try to keep spheres of exchange distinct, using sex as a leading example; Wojcicki (2002) describes the ways in which South African women, with a very different cultural background, camouflage money-for-sex exchanges as social relationships; and Knauft (1997) reviews how the monetisation of extramarital affairs in both Amazonia and Melanesia has resulted in increasing stigma for the women involved. Converging evidence for the convention of separating sexual from monetary exchanges comes from situations where the monetisation of the transaction is actually sought, precisely because it removes sexual acts from any 
affectional context. Thompson et al. (2003) document how topless dancers in the United States use the fact that they are paid for what they are doing to help distance themselves psychologically and emotionally from it, and from their clients. Prasad (1999) shows that prostitutes' clients use similar mental strategies to distance themselves morally and emotionally from the women they use.

The sense that there may be exchanges that should not be conducted in money goes wider than gifts or sex. Developing ideas from Simmel (1900/1978), Holt and Searls (1994) list the family sphere, and consumption of religion, high art, and education, among the areas where people resist "the market's commodification of the good" that is mediated by money. Even this list is not exhaustive: Desforges (2001) documents how Western tourists sometimes feel that any monetary transactions at all between them and local inhabitants in "exotic" travel destinations render their travel experiences inauthentic. Fiske and Tetlock (1997) make the point that people do not just find it difficult to estimate the value of their children, their loyalty to their country, or acts of friendship: they find it morally offensive even to be asked to try. Zelizer (1996) makes similar points about bonuses given by firms. Thus, there are many situations where money is not the preferred tool for exchange, or even is not acceptable at all. Surprisingly, it is often much more acceptable if money is replaced by something that is clearly money's worth, even something with a precise monetary value such as a book token, a gift certificate of defined value that can be used only for the purchase of books (Webley et al. 1983).

These data suggest that money has special properties that are not captured by the Tool Theory. But do they give any direct support to the Drug Theory? What seems to lie at the root of these social rules is a perhaps-unformulated belief that to give someone money is to move the transaction out of the realm of ordinary social exchange into a different, economic, sphere, so that what should be a gift or a means of thanks becomes payment - and that is something quite different. The prevailing rhetoric of most societies is that gifts are given, and sex is shared, for reasons other than material benefit. Gifts and sex are the currency of the moral and romantic economy, and to confuse them with the currency of the material economy is somehow to contaminate them. These social rules restricting money use could be taken to suggest that money is different from "real" incentives, such as "real" praise, "real" affection, or "real" gratitude, and therefore that money is a mere tool, different from the real objectives it subserves - that though you can in a sense buy love, happiness, and truth, there remains a love, a truth, and a happiness you cannot buy (Needleman 1994, pp. $237 \mathrm{ff})$. We argue, however, that these results show precisely that money is not, or not just, a tool. If it was a tool, it would always be an acceptable surrogate for other objectives. From an instrumental point of view, money is the best gift of all because the recipient can use it to buy exactly what he or she wants. The empirical results show that this point of view cannot be complete. Money-mediated exchanges are different from other exchanges, and under at least some circumstances, people avoid them. Under a Drug Theory, this avoidance is easy to explain: such a theory asserts that money is psychologically special and that it acts on us in ways other than as a neutral medium of exchange, ways we sometimes want to avoid. It might be argued that the restrictions on money use can also be reconciled with a Tool Theory by taking the tool metaphor more seriously and pointing out that tools do not have to be universally useful. But the problem with exchanging money for sex, for example, is not that it cannot be done, but that it is not socially acceptable for it to be done because the effects of doing it are socially and psychologically destructive. It appears that money exchanges have side effects, and that these give it drug qualities.

\subsection{Money in relationships}

Sociologists and psychologists have shown that money often has as a special status within relationships and a special impact on them (e.g., Burgoyne 1990; Millman 1991; Pahl 1989; 1995; Simpson 1997). Within families, access to and influence over money is rarely distributed equally, and this inequality is frequently a focus for dissatisfaction, strain, and dispute. Money issues are reliable predictors of divorce (Amato \& Rogers 1997), and as Millman has shown, divorce courts (and also courts adjudicating disputed wills) provide many illustrations of the money problems that arise in close relationships.

Family financial disputes are not only about money. In part, they are about the real power that money gives to buy real goods and services, and in part they are about more general issues of freedom and constraint within the relationship (Vogler 1998). But they are also about money as such. Disputes about money within the family can concern the distribution of limited financial resources (e.g., Zelizer 1994), but they can also be triggered when one partner acquires new resources, disrupting the previous distribution of power. James et al. (1992) recorded how some wives of unemployed men in Britain withdrew from the labour market to avoid the marital strain that went with their acquiring the powerful position of the major earner. Money is a potent symbol and channel of the power relationships within a family, and because this is a direct impact of money rather than one mediated through what money can buy, we argue that it has a strongly drug-like quality.

\subsection{Sacred and profane uses of money}

The most systematic recent approach to the psychology of money is that of Belk and Wallendorf (1990). Using anthropological data, they draw a distinction between "sacred" and "profane" uses of money. In many ways this parallels our distinction between Drug Theory and Tool Theory. Belk and Wallendorf's profane uses are the mundane, functional uses of money that fit easily into a Tool Theory. But they put forward the hypothesis that even modern money can be sacralized precisely in order to explain "some of the more puzzling ways in which people behave towards money." Among such money puzzles they include the social bar on the direct use of money to buy slaves, brides, political office, or children; the distinction made between earned and unearned income; the restrictions on the use of money as gifts; gender and class differences in the uses of money; and the paradoxes and contradictions in the ethics of money use. In sections 4.4 to 4.6 , we construed many of the 
same money puzzles as evidence in favour of a Drug Theory. Like the data on money attitudes, therefore, Belk and Wallendorf's analysis supports the need for a dual theory.

Related research includes Oliven's (1998) examination of the social functions of money in the United States from the standpoint of an anthropologist from a less financially developed society, Brazil. Oliven argues that in America, money is what Mauss called a "total social fact." Oliven argues that whereas in a society like Brazil's money is seen as polluting, in the mature capitalist society of the United States it pervades all social relationships and takes over all metaphors, being associated with love, death, blood, semen, food, and God. Again in our terms, it is hard to see how money can be regarded only as a tool when it has become so involved in a society's expression of itself, though the dramatically extended conception of the importance of tools found in the views of philosophers of technology such as Innis (1984) might provide a viable approach. We argue, however, that it is easier to take these wide-ranging social phenomena as evidence of a drug dimension to the motivation for money.

\subsection{Money and social status}

Both classic and recent sociologists and social psychologists have stressed the importance of money as a marker of status within modern societies. To some extent money here serves as shorthand for general wealth, possessions, and consumption: Veblen's (1899/1979) original development of the idea of a status symbol was much more concerned with things that money can buy than with the possession of money itself. Status is established through consumption in non-monetised or weakly monetised traditional societies as well as in modern economies (e.g., in the potlatch ceremonies of Northwestern Native Americans; see Aldona 1991). Nevertheless, statements of people's wealth or income, in numerical money terms, are a common part of discourse about status; nineteenth century English fiction is rich in examples. People differ in the extent to which they interpret wealth as a sign of status, and indeed the extent to which they attribute value to objects on the basis of their financial cost; the tendency to do so is referred to as "materialism" and, from Belk (1984) on, reliable and valid scales to measure it have been developed [see Richins (2004) for a recent review]. People high in materialism seek happiness through wealth and possessions (and tend not to achieve it; see, e.g., Burroughs \& Rindfleisch 2002). This selfdefeating nature of materialism might lead us to claim this area as one that is well explained by a Drug Theory of money. However, it is probably better seen as calling for an elaborated Tool Theory in which money is used as an instrument to assess or obtain social status and happiness. This is not among the functions of money conceived of by economic theory, but it is different from the pursuit of money for its own sake.

\subsection{Money work}

Even in societies that are not as money-dominated as the United States, the ubiquity of money means that many people work directly and continuously with money they do not own. Jinkings (2000) explores some of the ambiguities that this produces in the lives of low-paid Brazilian bank employees, who face deteriorating pay and conditions under circumstances where the money they are processing is increasingly powerful. Given the contradictions inherent in their situation, it is not surprising that he found the Marxian concept of money fetishism useful in describing their psychological processes. More commonly, people's work has a direct financial dimension which can be given more or less psychological prominence. Schweingruber and Berns (2003) have analysed the behaviour and attitudes of U.S. students recruited as door-to-door commission booksellers, and show how they had to both involve themselves in and distance themselves from the financial rewards that would be associated with a successful sale. The idea of money acquired an almost magical content for them.

\subsection{Money addiction}

If money is to be thought of as a drug, we might expect to find addictive processes associated with it, though evidently they would constitute a "non-substance addiction" in the same way as compulsive gambling. The concept of non-substance addiction remains controversial, but it has been widely used. The idea of money addiction has been put forward to explain some of the oddities of people's financial behaviour (Boundy 1993; Cameron \& Bryan 1992; Forman 1987; Goldberg \& Lewis 1978; Needleman 1994, e.g., pp. 115ff; Slater 1980). Most of these sources are popular or semi-popular rather than academic, and the idea of money addiction has found little use in sociology or clinical psychology. Furthermore, many of the references to it in fact deal with more specific addictions or supposed addictions, such as "workaholism" (Harpaz \& Snir 2003), compulsive gambling (Dickerson 1984), or compulsive buying (Black 1996). It is an interesting possibility that all these are manifestations of a broader addiction to money, but there is as yet no evidence to support that proposition; and given our interest in understanding the motivation to acquire money as such, rather than the things that it can buy, compulsions to spend in various ways are not relevant to our argument.

Slater (1980) did consider one case that is more specifically relevant to our argument: the hoarding of money per se, or miserliness. Hoarding in Slater's sense is distinct from the accumulation of money for precautionary or investment purposes, though of course it is possible that at the mechanistic level there is overlap between these motivations, or indeed the many other recognised motives for saving (see Lea et al. 1987, Ch. 8). As we have seen in section 3.2.1, miserliness was historically a particular concern of psychoanalysts. Clinical and psychometric work gives some support to the Freudian notion that miserliness and hoarding are components of obsessive-compulsive disorder, and both seem to have some connection to compulsive shopping (Frost et al. 2002; Grilo 2004). As such, there does seem to be some support for a Drug Theory of money motivation from the evidence on money pathology. More recent clinical psychological approaches, such as cognitive behaviour therapy, have also been applied to money pathologies, and as these too would see the pathological interest in money as disproportionate the money's actual usefulness, they would also favour a Drug over a Tool account. 


\subsection{Summary}

A consistent theme emerges from these very different kinds of empirical research on money. The evidence is not that Tool Theory is wrong, but rather that it is inadequate, and inadequate in specific ways. In a range of situations, money is found to have a value and an emotional charge that is not predicted by its economic use. In some situations this leads to only marginal effects, such as the sentimental clinging to a few outdated coins. In other, closely related situations, the effects are strong enough to determine the economic policies of nations.

It is one thing to accept that money is not just a tool for carrying out the functions that economic theory prescribes for it. It is another to accept our suggestion that its additional psychological effects can be captured by categorising it as a cognitive drug. We argue, however, that this analysis is fruitful, on two grounds. First, because it captures the parasitic, functionless quality of money motivation that characterises many of the situations we have described. Second, however, it leads on to an evolutionary account of these phenomena, and of the incentive value of money in general, which we will set out in the final section of this article. If that explanation is accepted, the importance of the drug metaphor fades; it will have done its job in linking together phenomena and rephrasing the question about money motivation in a form that can be more readily answered.

\section{A synthetic theory of money}

\subsection{The need for synthesis}

Lea et al. (1987) tried to accommodate what was then known about the psychology of money within a loose theoretical framework in which money was seen as multiply symbolic. In evolutionary terms, this account is vague and underspecified: What is meant by a symbol, and what selective pressures does it respond to? What that analysis did capture was the notion that money in modern society has more forms, and more functions, than the simple economic Tool Theory would allow. In section 4 we showed that modern research in economic psychology is uncovering an increasing range of money phenomena that Tool Theory cannot account for. We have argued here that these phenomena call for some version of the Drug account: money seems to act on the human brain in ways that mimic more natural incentives, not just by being an instrument for access to them.

It would be foolish to deny the force of the Tool Theory. Money does have functions, and new forms of money are constantly being invented to fulfil those functions in new ways. The range of new forms that money has taken in recent decades, and the speed with which people have adopted some of them (see sect. 4.3), show that the instrumentality of money is fundamentally important: the only thing all forms of money have in common is their function (cf. Ingham 2001). But not all tools for a given function come equally easily to human hands or minds. All computer operating systems perform roughly the same operations on stored information, but the menu and pointer system used in modern operating systems is more efficient than a command line interface for all but the most skilled users (Card et al. 1983) because it relies on recognition rather than recall memory. The good tool always comes with overtones of drug, whether it is a tool for data processing or exchanging. Thus we argue that, though money certainly is a tool, it is too successful a tool for the Tool Theory to be entirely right.

But the Drug Theory is not without problems. First, the phenomena that we have identified as requiring some kind of Drug Theory are not a coherent set. They could easily be regarded as a mixed bag of marginal, second-order phenomena that all have different explanations. This argument, however, only carries force if we are implicitly persuaded that Tool Theory must be the correct explanation for most money motivation. If Drug Theory covers any phenomena at all, then it may also cover some of the phenomena that could be accommodated by a Tool Theory. It need not be confined to the margins.

More seriously, Drug Theory is feeble unless we can specify what the natural incentives are that money mimics, and in this final section we therefore seek to do that. For convenience, we refer to the incentive systems concerned as "instincts," though, as explained in section 1.4 , we mean that term only in the sense of a motivational system so widely observed that it can be taken to be culturally universal, like hunger or parenting. Those examples are sufficient to remind us that even when motivations are universal, the way they are manifested varies greatly between cultures and periods of history. Here, we suggest two motives that we believe are universal among humans, and argue that they manifest themselves in modern cultures as a desire for money. These are certainly not the only possibilities, but we are seeking to establish that there is at least some plausible means by which the drug-like effects of money could have evolved.

\subsection{Reciprocal altruism, trade, and money}

A prime use of money, considered as a tool, is to facilitate trade. Could trade itself be the incentive that money mimics? At first this seems an unhelpful suggestion, since it simply moves the problem from the evolutionary origin of money to the evolutionary origins of trade, which is also a uniquely human behaviour (see Lea 1994). Division of labour occurs in other species, but there is little doubt that its integration into a system of trade is uniquely human; chimpanzees may be induced to barter in the laboratory (Hyatt \& Hopkins 1998), but there is no evidence that trade forms any part of their natural social life. The problem of the evolution of a motivation for trade, however, may be tractable in a way that the problem of the evolution of a money motive is not. Ridley (1997, Ch. 10) has argued, from the archaeological evidence, that though trade originates with Homo sapiens, it must have done so early, in fact it must be as old as the species itself; he sees trade as one of the distinguishing marks of our species. So, whereas the use of money is too recent to allow the evolution of a money instinct, trade could be a human instinct on which the money motive might be built through drug action. But Ridley concedes that most anthropologists have thought of trade as a late development in human prehistory; and even if he is right in assigning it an early origin, we would still have to specify the more widespread instincts from which it could have evolved, because it does not occur in other apes. 
The most obvious such instinct is reciprocal altruism. Sociobiological theory came to prominence because it managed to reconcile the existence of altruistic behaviour with the neo-Darwinian concept of the selfish gene. Most altruism can be explained by kin selection - indirect selective advantage to an individual achieved through benefits to his or her kin (Hamilton 1963). Humans, who have long periods of juvenile dependency and tend to live in groups of related individuals, should show such kin altruism instinctively. But, in addition, Trivers (1971) showed that there were circumstances under which instinctive altruistic behaviour between unrelated individuals could be favoured by evolution, because of the possibility of reciprocation. Humans fit precisely Trivers' specification for a species within which such reciprocal altruism could evolve: we are long-lived, intelligent, and live in permanent social groups. But what Trivers and other sociobiologists describe as reciprocal altruism would usually, if it occurred in humans, be referred to as trade, because it depends critically on exchange: it is only sustainable if an organism that gives up fitness at one moment can expect to gain fitness in the future. Trivers' argument can thus be restated as implying that it might be adaptive for humans to trade with unrelated individuals. And if trade is adaptive for humans, and has been over a substantial period of time, it is reasonable to suppose that natural selection will have equipped humans with a motivation to trade, and ensured that we will enjoy doing it - in a word, that we might have an instinct to trade, in addition to our instinct for unreciprocated giving towards kin. Although this may sound an odd idea, there are both theoretical and empirical arguments in its support.

At the theoretical level, Trivers' (1971) argument sets minimum conditions under which reciprocal altruism can emerge. But once it is established, reciprocation has adaptive value over and above the goods or services a particular trade makes available, because it makes it possible to have with strangers at least some of the kinds of interactions that normally only occur between kin. Long before money came on the scene, humans developed networks of social relationships, involving individually known and at least partially individually trusted persons, that were larger than those of any comparable animal. In the Environment of Evolutionary Adaptation, a person whose extended social network was larger had many advantages - the primary one being that he or she was safer against both social and environmental threats. This added adaptive value should strengthen the instinct to trade. The implication is that there is not just a human possibility to engage in reciprocal altruism in case of need, but a motivation to do so whenever a reasonable opportunity presents itself. Margolin (1978/ 2003 , pp. 89-102) gives a graphic description of the motivation for reciprocal altruism and trade, and its adaptive value, among the Ohlone peoples of the Californian Central Coast. Studies of informal transactions in modern society, within the "black economy" (Henry 1978) or in consumer "swap meets" (Belk et al. 1988), have shown that this social function of trade remains strong. Interestingly, such informal transactions are often imperfectly monetised.

Empirically, much evidence supports the idea that there are two different motivational systems underlying human giving and receiving. Economic anthropologists such as Sahlins (1974) have shown that in societies without money there is a continuum of exchanges. At one extreme are truly altruistic exchanges within households, where reciprocation need not be exact or immediate, and may indeed never happen at all; at the other are exchanges with members of other villages, where reciprocation must be immediate and exact or no exchange will take place. Conversely, in modern societies, where there is repeated trading between the same individuals, for example, in a continuing employment relationship and particularly where employer and employee live together, the language of trade tends to be replaced by the language of kinship; for example, we hear of "paternalistic" employers - particularly where the reciprocation is in fact unbalanced.

The idea of a trading instinct allows for a much more precisely specified version of Drug Theory. Considered as a tool, money is used extensively to serve the trade motivation. In this role, it multiplies the reasonable opportunities for exchange by making it more instant, more sure, and easier; it removes the need for an exact reciprocal return of action for action, good for good. Considered as a drug, however, it seems to be capable of giving the illusion of trade and reciprocation even when it is absent. If trade is a human instinct, we would expect there to be a specific region of the human brain that has an innate tendency to be active when the opportunity for trade arises - a suggestion that once would have seemed outlandish but, in the light of recent developments in neuroeconomics, seems merely obvious (cf. Glimcher 2003). Money, we argue, acts like a drug on that centre, activating it even when there is no real possibility of trading, or no real advantage in it. And just as an artificial sweetener like saccharine can stimulate our sweetness receptors far more than the natural substances it mimics, so money can overstimulate our trading receptors, with the effect that, as Wordsworth put it, "getting and spending we lay waste our powers."

This specification of Drug Theory fits perfectly with the social rules that constrain the use of money as a gift. The data surveyed in sections 4.5 and 4.6 show that money is, in a range of ways, socially awkward. The idea that money is a trade-based drug explains that awkwardness from the fact that trade is socially awkward, because it is in tension with a different but overlapping instinct. Within the circle of close kin, reciprocation need not be insisted on - indeed, to insist on it would be to label the interaction as taking place outside that circle. Within the circle of slightly less close kin, where some reciprocation is needed, too speedy reciprocation is equally a solecism. Although it might be advantageous to mislabel a trade relationship as kinship, to mislabel kinship as trade could be a biologically fatal mistake, since it would be to relinquish the claim of kinship, a much more powerful and reliable source of altruism than reciprocation.

As would be expected from its close fit to the data on money as a gift, the idea of money as a trade-based drug also fits well with modern sociological and anthropological accounts. From a theoretical perspective, Newton (2003) has argued that modern money and credit create increasingly extended "dependency networks" of the sort implicated in the civilising process as it is described by Norbert Elias (e.g., 1994). Much modern empirical sociology of money has aimed to uncover the social meanings money acquires from the exchanges by which it is obtained and in which it is spent, and the social meanings that are 
created when money is used to facilitate an exchange that might have taken place by other means. Thus, Granovetter (1985) insists on the "embeddedness" of economic action within social structure and social relations; Offer (1997) argues that where it is important to establish mutual "regard," money is avoided even when reciprocation is needed; and Zelizer (e.g., 1989; 1996) shows how money from different sources is used in different ways because of its different social meanings. From the symbolic interactionist point of view, money has symbolic value that both derive from and help construct the social interactions in which it is used, sometimes helpfully and sometimes destructively (Schweingruber \& Berns 2003). The nature of its symbolic value varies between societies, and van der Geest's (1997) cautionary reminder that in West African societies money can be a symbol of happiness and security, and a vehicle of love and respect, needs to be set against the generally corruptive symbolism of money in European-derived cultures. Knauft (1997) similarly emphasises that in previously non-monetised societies, money often symbolises modernity, undercutting earlier cultural values - a tendency that can be so extreme that dollars are animized as wild, undomesticated items that behave in unpredictable or even demonic ways (De Boeck 1998). There is also theoretical dispute about exactly what money symbolises in the modern economy: Ingham (2001) argues that previous sociologists of money, such as Zelizer, have paid too little attention to money's symbolisation of the promise to pay. But the idea of money as a vehicle of some kind of symbolic meaning, and therefore as more than a neutral tool in the economy, is universal among both theoretical and empirical sociologists of money. The language of sociology differs from the sociobiological approach we have taken here, but in different terms both are saying that money has value - which may be positive or negative - over and above its usefulness.

\subsection{Play and money}

A second human instinct on which money might act as a drug is object play. Considered as mammals, and even as primates, humans are remarkable both for the length of time we spend in a juvenile state and the strength of the motive to play among juveniles (and even adults). Object play is particularly well developed, as the extraordinary scale of the toy market testifies. Lea and Midgley (1989) argued that this might be one of the factors that have allowed the evolution of money use. We agree with Freud in seeing the interest in money developing first out of the instinct to play with objects that can be held in the hand, though we reject the Freudian belief (see Bornemann 1976, p. 17) that faeces constitute a privileged class of such objects. The plausibly instinctive human liking for carrying around a few easily handled objects provides a natural setting within which a money system can develop. Money may be a drug partly because it provides something of the same kind of stimulation as a plaything.

The trading and play accounts of money motivation are not in competition, but complementary. If playthings are valued because of an instinct towards object play, they would make natural props in our first hesitant steps onto the stage of economic exchange: having learned to manage playthings as children, we are better equipped to manage plaything-like money as adults. We have argued elsewhere (Webley \& Lea 1993b; Webley \& Webley 1990) that playground exchanges of toys are a more realistic scene of economic socialisation than the limited exposure young children have to the formal economy of adult shopping. Money might be an especially potent drug because it can mimic the satisfaction both from the instinct to play and from the instinct to trade, as children first begin to play at trading or to trade their playthings.

\subsection{Synthesis}

We explained at the beginning of this target article that there cannot be a "money instinct." If we are to fit money motivation into the framework of biological explanation that applies to other strong human motives, then we must explain how money gets its incentive power through its action on other instincts. If we cannot do so, we would be faced with a situation that would be scandalous within the terms of a biological psychology - a powerful human motivation, perhaps even the most powerful, with no real biological roots.

Reviewing a range of phenomena and theories of human behaviour towards money, we have reached three conclusions.

1. Although money is an efficient tool, and so gains incentive power by enabling us to fulfil a wide range of instincts, a Tool Theory of money motivation is inadequate. The majority of non-economic accounts of money (and even some economic accounts) either take this view or require a more elaborated Tool Theory than is usually assumed. Modern empirical work has uncovered substantial evidence in favour of this conclusion, and we believe that it would be widely if not universally accepted.

2. The inadequacies of Tool Theory can be overcome, and the phenomena that it fails to explain can be integrated, by asserting that money also acts as a drug. That is, we conclude that money derives some of its incentive power from providing the illusion of fulfilment of certain instincts. This argument has formed the core of the present article, and although we believe it is well grounded in the data we have reviewed, it will inevitably be more controversial. In particular, the alternatives of a more elaborate Tool Theory, or an entirely different way of partitioning the possible kinds of theory, cannot be ruled out at this stage, and perhaps they never could be.

3. The incentive power of money depends partly on the illusory fulfilment of the human instincts for reciprocal altruism and object play, though there may well be other instinctive systems that money can also parasitize. This conclusion is more speculative, and is likely to be the most controversial of all. However, insofar as it is persuasive, it would provide the best evidence in favour of the Tool/Drug analysis, since it would show that the analysis had been deployed fruitfully.

Thus, we are arguing that the scandal of a non-biological motivation for money can be avoided, but not by the most obvious means, which is a Tool Theory. We are not arguing that Tool Theory is wrong, but that it needs to be supplemented by a Drug Theory, and a Drug Theory of a particular type. This is not a sloppy "much to be said on both sides" argument. Rather, we argue that the extraordinary effectiveness of money depends on a synthesis between its two modes of action. One of the striking facts 
about money is its cultural dominance: it is taken up irresistibly by any human society that encounters it. Other equally functional social inventions are much less immediately attractive. In both developed and less-developed countries, governments have to engage in extensive and expensive promotional campaigns to get beneficial health, education, or birth control practices widely adopted, because those practices are not so readily compatible with human instincts and therefore with perceived immediate self-interest.

A prediction follows from this analysis. If, in the future, money is presented in forms that fit less well with the instinctual structure of the human brain, it may be a less effective tool. An obvious example is the representation of money by abstractions such as the totals in bank or credit card accounts, or the amounts in microchips on smart cards. Such abstractions would not stimulate humans' instincts towards object play, and therefore our management of them will not benefit from our early learning, through play, of how to manage objects effectively. It is consistent with this view that each new form of money seems to bring in horror stories of people who cannot control their spending with it (see Prelec \& Simester 2001; Schor 1998). Our argument, therefore, is that if money had not been an effective drug, it might never have emerged as an efficient tool. It is because it is both tool and drug that it is such a strong incentive.

\section{ACKNOWLEDGMENTS}

We thank the Department of Psychology, University of California Berkeley, and the CentER for Economic Research, University of Tilburg, for providing the authors with visiting research positions that made the writing of this paper possible. We also thank Carole Burgoyne, Lesley Newson, and Jana Vyrastekova for their helpful comments on earlier drafts. Earlier versions of this paper were presented at the British Association Festival of Science, Cardiff, U.K., September 1998, and at the conference of the Society for the Advancement of Behavioural Economics and the International Association for Research in Economic Psychology, Philadelphia, PA, U.S.A., July 2004.

\section{Open Peer Commentary}

\section{The biology of the interest in money}

\section{Joseph Agassi \\ Department of Philosophy, Tel-Aviv University, Tel-Aviv 69978, Israel, and Department of Philosophy, York University, Toronto, Ontario, Canada M3J $1 P 3$. \\ agass@post.tau.ac.il http://www.tau.ac.il/ agass/}

Abstract: Why are people interested in money? This question is too broad: there are many kinds of money, interest, and people. The biological approach of Lea \& Webley (L\&W) makes them seek the roots of this interest, and they contend that tool making and addiction qualify as the roots. Curiosity and the quest for power, however, qualify too. As $\mathrm{L} \& W$ rightly admit, other approaches supplement their biological one.

Lea \& Webley (L\&W) ask "Why are people interested in money?" They expand on the concepts of "people," "interest," and "money," but these are too broad for their concern. They mention different kinds of money, from unfamiliar primitive kinds to plastic money, only to ignore the differences between them. In its diverse manifestations, money reflects a variety of phenomena rooted in diverse aspects of diverse societies. These are of no interest to L\&W. Looking for the universally human, biological roots of the interest in money (no matter what counts as roots and why), they deliberately overlook social diversity. They center only on consumers' attitudes towards money. And, when they refer to people, they exclude those who do not know what money is, or who live in small communities or communes, or who are otherworldly. Thus, L\&W set the scene for discussion of their question sufficiently narrowly so as to lead to their biological, universalistic answer. Are leading questions permissible in research? It depends on how interesting the discussion is.

The program of $L \& W$ is acceptable, then, on the condition that we remember that their question is set towards a biological bias, leaving the sociological and psychological biases for another day. It is an error to claim more than that, in line with the "grand theory of everything," in what is known as intellectual imperialism (the claim that only one approach fits). L\&W agree: they stress in the opening of their article that a "biological" approach (involving "selective advantage") "is not an alternative to social and cultural factors as a kind of explanation" (sect. 1.1; see Agassi [1977], pp. 184, 281, 320, and 326). So they merely sketch a few alternative theories - psychological, cultural, economic - that they legitimately put aside.

Let me go along with the attitude of $\mathrm{L} \& \mathrm{~W}$ and follow the bias that leads them to seek the biological roots of the attraction of money. They take for granted that what comprises such biological roots is conduct, specifically the use of tools and of drugs. They view money, first, as a tool (for those who intend to use it) and, second, as a drug (for misers and for those who play with money in the widest sense that includes all sorts of social games). The tool that money is, however, is a means for the acquisition of other tools - all those goods and services that are on the market for sale. Hence, money always denotes sets of options that are available for sale on the market. It is these options, and not the money itself, that most people desire. This desire - for a range of options as wide as possible - has deeper biological roots than money. Nor is "interest" the same as attraction: people in the capacity of researchers, including $\mathrm{L} \& W$, have an interest in money different from what they have as consumers, as do entrepreneurs, politicians, economists, economic journalists, gossip columnists, and so forth. So we should include curiosity among our root biological drives. As to the idea of money as a drug, L\&W use the word "drug" loosely, and include pornography as a drug though it usually functions otherwise. Some people use pornography - and any other item that stands for sex - as sex objects proper, in a kind of fixation on them, as a diversion of the sex drive from the normal sex object. These (and other fixations) are then often called (inadequately) fetishes. And fixation is nearer to biological roots than addiction. (Addiction is a fixation of sorts.) In addition, money helps in the acquisition of power and other abstract qualities that are not commodities on the market. And the desire for power or the wish to lead others is generally deemed as having deep biological roots. Perhaps.

\section{What good are facts? The "drug" value of money as an exemplar of all non-instrumental value}

\author{
George Ainslie \\ Veterans Affairs Medical Center, Coatesville, PA 19320. \\ George.Ainslie@va.gov http://www.Picoeconomics.com
}

Abstract: An emotional value for money is clearly demonstrable beyond its value for getting goods, but this value need not be ascribed to human preparedness for altruism or play. Emotion is a motivated process, and our temptation to "overgraze" positive emotions selects for emotional patterns that are paced by adequately rare occasions. As a much- 
competed-for tool, money makes an excellent occasion for emotional reward - a prize with value beyond its tool value - but this is true also of the other facts by which we pace our emotions.

Lea \& Webley $(\mathrm{L} \& \mathrm{~W})$ demonstrate well that money is often valued for more than what it can buy. Among other things the target article should warn experimental psychologists that when they reward their subjects with money, the rewards have two components: the value of possible purchases, which are necessarily delayed, and an emotion attached to acquisition, which is immediate and imperfectly correlated with the amount and timing of possible purchases. L\&W have documented many situations in which money takes on value beyond that of its potential to be exchanged for goods. They point out that this value comes from emotion, and they liken it to that of "being emotionally engaged by many kinds of text" (sect. 2.2.3). In doing so, they have identified a gap in motivational theory, a gap which, I argue, affects far more than the theory of money. Since social constructivists have pointed out the extensive role of motivation in determining those beliefs that are not shaped by the risk of failure, it has been unclear what distinguishes belief from make-believe, and texts $^{1}$ that can support belief (which get called facts) from texts that cannot. From the question of how money takes on value beyond its tool value it is a short jump to ask how any facts that do not help you get goods or avoid "bads" - non-instrumental facts, those that are not tools - are worth attending to. And after that, what about text that is not factual at all - pornography to be sure, but also fiction in general? I agree that text is valuable beyond its instrumental usefulness insofar as it is emotionally engaging. I agree also that conventional motivational theory lacks a rationale for this engagement, not just for the case of money, but for all non-instrumental texts.

The authors look for specific underlying instincts that might be energizing money's drug effects. ("Drug Theory is feeble unless we can we specify what the natural incentives are that money mimics"; sect. 5.1, para. 4) This search seems unnecessarily specific, like the early behaviorists' attempts to trace each emotion to a conditioning experience (Watson 1924). Nor does the authors' suggestion that money in its drug mode provides "the illusory fulfillment of the human instincts for reciprocal altruism and object play" (sect. 5.4) stand up well in application to their own list of the anomalies that make drug theory necessary: What is it about reciprocal altruism or object play that should make coins appear larger than they are, nominal values be impervious to changes in real purchasing power, new forms be unwelcome, or the purchase of some social relationships be taboo? All that these two instincts supply is a nonspecific rationale for the value of money to have an emotional component, and this can be done at a more general level.

I have suggested that, instrumentality aside, the usefulness of externally supplied texts comes from their pacing the consumption of emotional reward; the usefulness of factuality comes from its selecting adequately rare texts for this purpose (Ainslie 2001 , pp $175-79 ; 2005)$. The motivational power of moneyas-drug is then an especially potent example of the power conferred by factuality itself. To briefly summarize the theoretical background: Emotion is well known to be a strong motivator, but there is also substantial evidence that emotion is itself motivated. Granted that emotions are only marginally voluntary, the voluntary control that is possible argues for their motivational basis, for their being selected by expected reward rather than elicited peremptorily by trigger stimuli. However, the lack of a rationale for how a process that both motivates and is itself motivated can avoid collapsing into positive feedback has confined us to the theory that emotions are unmotivated responses to external turnkeys (Ainslie 2001, pp. 65-70, 164-71). Why not pig out on positive emotions and simply withhold negative ones? The answers to these questions reveal a motivational role for events that do not necessarily have either instrumental value or a connection to an innate instinct.
It has now been widely reported that there is a basic tendency to discount delayed reward in a hyperbolic rather than an exponential curve (Green \& Myerson 2004; Kirby 1997). This lets us conceive of emotions as rewarded processes, with positive feedback restrained as follows: An occasion for negative emotion offers an immediate reward for participating in it, but the prospect of its brief reward lasts only long enough to seduce; it is experienced not as pleasure but as an urge. The dynamic I propose is the same as that for a binge, except that each cycle of seductive high and non-rewarding hangover is condensed into the fraction of a second (Ainslie 2001, pp. 51-61; 2005). For an acrophobic on a cliffside path, say, each moment of giving in to the urge to panic is followed not by relief but by a renewal of the urge, and by a growing inhibition of all other sources of reward.

But L\&W are talking about a positive drug effect. If positive emotions are indulged in ad lib they become attenuated into mere daydreams through habituation. This process cannot be controlled voluntarily because of the hyperbolically weighted overvaluation of small, immediate satisfactions relative to larger, delayed ones. As a result, only patterns of generating emotions in the presence of adequately rare occasions remain robust. This contingency creates the familiar gambles that seem to govern our positive emotions: Feats in sporting events, news items, objects of collection, and, notoriously, victories in romance incite feelings in proportion to their perceived rarity. The rarity factor is what makes factuality important: Texts that qualify as facts (by any stringent selective process, including communal folklore) are more potent than a story, and the facts we have reason to seek are more potent than facts in general. In this manner, instrumentality, the value of facts for getting other goals, confusingly becomes a source of non-instrumental value. Gambling for money has more kick than gambling for points, even when we gamble for money purely as recreation. In the United States, at least, the variability of gasoline prices among stations makes the search for cheaper gas a challenging game; several acquaintances have admitted to a temptation to drive uneconomically far out of their way just for the sensation of winning at this game, even though they would not be playing it if it did not ostensibly save them money. Once we authenticate money as a prize, it becomes a tool for occasioning emotion; that is, it becomes a drug.

Some of money's drug value may come from how it fits into specific hardwired preparednesses, among them not only L\&W's altruism and playfulness but also competing, gloating, envying, and especially hoarding. But all that is necessary to give money emotional power is for it to serve as a sufficiently hard-to-get goal that is set apart from equally hard but arbitrary goals by its peerless tool value. As a tool it has many uses, but that very fact makes it a unique pacing device in our quest for positive emotions per se. When a currency loses its tool value it loses its uniqueness and hence its pacing value, but this usually occurs, as the authors point out (sect. 4.3), after a lag. When McClure et al.'s (2004) subjects won an "immediate" Internet token, they consumed the prize emotionally on the spot, even though the token as tool would take some days to provide a "reward." There are many situations where tool and drug value are clearly separable, not the least of which arises when income becomes so predictable that it loses its value as an emotional prize even though its tool value remains unchanged (Ainslie 2003). But the "drug" value of money does not differ in kind from the emotional pacing value of anything else that has some claim to be a prize.

\section{NOTES}

The author of this commentary is employed by a government agency and as such this commentary is considered a work of the U.S. government and not subject to copyright within the United States.

1. An irreplaceable term, despite abuse by deconstructionists, for patterns of information that might or might not be factual. 


\section{Scarcity begets addiction}

\section{Giorgio A. Ascoli ${ }^{\mathrm{a}}$ and Kevin A. McCabe ${ }^{\mathrm{b}}$ \\ aKrasnow Institute for Advanced Study, Psychology Department, and Neuroscience Program, George Mason University, Fairfax, VA 22030-4444; ${ }^{b}$ Krasnow Institute for Advanced Study, Economics Department, and School of Law, George Mason University, Arlington, VA 22201. \\ ascoli@gmu.edu http://krasnow.gmu.edu/L-Neuron \\ kmccabe@gmu.edu http://www.neuroeconomics.net}

Abstract: As prototypical incentive with biological meaning food illustrates the distinction between money as tool and money as drug. However, consistent neuroscience results challenge this view of food as intrinsic value and opposite to drugs of abuse. The scarce availability over evolutionary time of both food and money may explain their similar drug-like non-satiability, suggesting an integrated mechanism for generalized reinforcers.

In their discussion of the reinforcement power of money, Lea \& Webley $(\mathrm{L} \& W)$ use the biological value of food to distinguish between tools (useful to eventually obtain a biological incentive) and drugs (parasitizing the biologically meaningful incentive system). This opposition between intrinsically valuable food and addictive drugs of abuse, however, may be less innocuous than it appears on the surface.

As a source of metabolic energy, regulation of food intake could be expected to be controlled by the hypothalamus, the brain region that monitors and manages the neuroendocrine system, ultimately modulating the blood concentration of glucose. Instead, the subjective feeling of "hunger," as meant in the industrialized world, does not seem to correlate primarily with hypothalamic activity. Brain imaging showed that, in human subjects craving food after skipping one or two meals, it is instead the dopamine system that lights up (along with the orbitofrontal cortex), with an activation pattern similar to that recorded in drug addicts awaiting their fix (e.g., Pelchat et al. 2004; Volkow \& Wise 2005). However, in subjects fasting for 36 hours, the hypothalamus does show increased activation (Tataranni et al. 1999). This protracted fasting period correlates with considerable metabolic changes and subjective reports nearly opposite to the feelings of people waiting to be seated at restaurants (depressed state as opposed to unrest).

A converging (if on the face unrelated) line of evidence indicates that caloric restriction significantly increases longevity in laboratory animals. In particular, rats whose daily caloric intake is limited to approximately $60 \%$ of ad libitum controls have a life expectancy about 30\% longer (Hadley et al. 2001; Mattson 2005). If confirmed in humans, these findings would complement the recent recognition of obesity as one of the most lethal preventable diseases in the United States (Allison et al. 2001; Goldin 2005; Volkow \& Wise 2005). Moreover, irregular diet (normal meals alternated with fasting periods) is more beneficial in rats than regular feeding (consistently light meals). Several mechanisms have been proposed to explain these observations, including reduction of oxidative stress, strengthening of the shock-absorber systems, and stimulation of growth factors (Mattson 2002; 2005; Mobbs et al. 2001). Taken together, brain imaging and caloric restriction studies invite the provocative hypothesis that humans with virtually unlimited access to food do not normally eat to gain a biological advantage, but rather because they are addicted to food.

Now let us consider barter, which operates on the principle of mutual advantage (McCabe 2003): each party has something the other wants, and, by trading, both parties can be made better off. The tool theory of money emerges from the observation that the value from barter can be greatly expanded by using money to (1) reduce the search costs of finding a potential trading partner, (2) reduce the default risk of trading with a partner by getting money in return, (3) define the relative value of goods and services by pricing them in terms of money, and (4) allow greater specialization of human activity (North 1990). However, money can lose value either through oversupply, as when governments print money to cover their debts, or in competition with other monies, as seen in international exchange rate fluctuations.

In experiments, people continue to trade money (McCabe 1989) even when it is losing value, thus providing evidence that money itself is seen as valuable (consistent with the money as drug hypothesis). A plausible explanation is that even as money itself loses value, the barter it is producing continues to be valuable. So the built-in desire for money may be a secondary reinforcer for barter. The anticipation and realization of earning money is known to activate the same dopaminergic pathways as drugs and other rewards (Knutson et al. 2001b), and contingent management strategies use monetary rewards as a substitute for drugs in drug treatment programs (Higgins et al. 2000).

Food and barter exchange have interesting correlates in that both were scarce (meaning hard to obtain) over evolutionary time, and yet both contributed strongly to the inclusive fitness of humans. Because they were scarce, it is reasonable to assume that the biological system would recognize them as rewarding. As suggested by reinforcement learning models (Sutton \& Barto 1998), it is important to encode these rewards (including money as a secondary reinforcer for barter) as values, which can then act as inputs into the actor-critic circuitry in order to learn experientially about better action sequences. Since the ecology makes the future availability of these rewards uncertain, it seems advantageous that the value systems associated with seeking behavior would evolve as non-homeostatic and non-satiable (i.e., linear or non-depreciated) and thus have drug-like properties.

Paradoxically, then, the dopaminergic system underlying drug addiction might have evolved precisely to incentivize mammals, whenever possible, to eat above and beyond the minimal, and in fact ideal, amount of food. Offsetting this impulse must then be inhibitory systems of control, which seem to be more variable across humans. Scarcity thus constitutes a powerful evolutionary explanation for the addictive feature of money, food, and in fact any scarcely available generalized reinforcer.

Research suggests that there are two systems competing for behavioral control. The first system locks in behavioral responses to predicted rewards using temporal difference learning (Shultz et al. 1997). This system allows for habituation and may be the primary route for a drug theory of money. Much of the processing in this system involves the dopaminergic neurons in the striatum (O'Doherty et al. 2004). The second system uses contingent goals to build the value of representative pathways for decision-making, and may be the primary route for a tool theory of money. Much of this processing occurs in the prefrontal cortex (Cohen et al. 2000). Recent theories attempt to explain the arbitration of these two reinforcement learning systems (prefrontal and striatal) in terms of the cost/benefit ratio of each system in different circumstances. Such models can help clarify the neurobiological bases of the tool-drug distinction (or at this point, integration), and at the same time extend it to the broader domain of reinforcement learning with scarce resources.

\section{The desire to obtain money: A culturally ritualised expression of the aggressive instinct}

\section{Ralf-Peter Behrendt}

MRC Psych, The Retreat Hospital, 107 Heslington Road, York, YO10 5BN, United Kingdom

rp.behrendt@btinternet.com

Abstract: Social behaviour is but an expression of instinctive mechanisms whereby the aggressive instinct is of particular importance, having given rise to most of the complexity of social behaviour through processes of phylogenetic and cultural ritualisation. The role of the aggressive 
instinct is to dynamically maintain the ranking order in a group, and much of social interaction is concerned with this, including monetary exchange.

What is certain, is that with the elimination of aggression, ... the tackling of a task or problem, the self-respect [in] everything that a man does from morning till evening, from the morning shave to the sublimest artistic or scientific creation, would lose all impetus; everything associated with ambition, ranking order, and countless other equally indispensable behaviour patterns would probably also disappear from human life.

— Konrad Lorenz (1963/2002, p. 269)

One can agree with Lea \& Webley (L\&W) insofar as "we must explain how money gets its incentive power through its action on other instincts" (sect. 5.4). Of course, money has "a value and an emotional charge that are not predicted by its economic use" (sect. 4.11), but affect and cognition that accompany the pursuit of money do not testify to an underlying trading or altruistic instinct, if ever one existed, but portray an attitude of envy, greed, or quest for status or security. Money is indeed "an indicator of achievement, respect, and freedom or power" (sect. 4.4) and a potent symbol of "power relationships" (sect. 4.6). It may be money's ability to mediate satisfaction of the instinct of intraspecific aggression in a culturally conditioned way, not its supposed "strongly drug-like quality" (sect. 4.6), that explains some of what Belk and Wallendorf (1990) describe as the "puzzling ways in which people behave towards money" (as quoted by $\mathrm{L} \& W$ in their sect. 4.7) and why it is "taken up irresistibly by any human society that encounters it” (sect. 5.4).

Lorenz (1963) observed that adaptive behaviour is commonly determined by impulses of several instincts, often one inhibiting the other. Phylogenetically, ritualisation creates new instinctive motor coordinations by welding together conflicting impulses. Social behaviour is dominated from a drive-motivational point of view by successive impulses of "aggression, fear, protectionseeking and renewed aggressiveness" (Lorenz 1963, p. 55). Norms of social behaviour that developed by cultural ritualisation started to play an important part in human society "when invention of tools was beginning to upset the equilibrium of phylogenetically evolved patterns of social behaviour" (p. 249), the "equilibrium between the ability and the inhibition to kill" (p. 242). As Lorenz remarked, on the basis of "the instincts of animals," "human culture has erected all the enormous superstructure of social norms and rites whose function is so closely analogous to that of phylogenetic ritualization" (Lorenz 1963, p. 240).

Ranking order is an essential principle of organisation of social life in higher vertebrates; it is maintained dynamically by individuals' aggressive impulses, although it has the effect of inhibiting aggression within a society and limiting fighting between its members (Lorenz 1963). Interaction between members of a group, particularly in highly fluid forms of society, like ours, involves frequent symbolic and paralinguistic display of each individual's potential for aggression and submission. Money is but one symbol for self-esteem and self-respect, which are reflections of social ranking, particularly in modern society. Money has become an increasingly important mediator of social organisation as traditional networks of social reference became fragmented and transient in modernity. As L\&W summarise Simmel (1900/ 1978) in section 3.3.1 of the target article: "Money is both the means and the symbol of the process by which in modern society impersonal, quantitative social relations between autonomous individuals replace the determinant relations imposed by traditional society." L\&W themselves acknowledge "the importance of money as a marker of status within modern societies" and recognise that references to wealth or income "are a common part of discourse about status" (sect. 4.8). Indeed, money is a tool to obtain social status, allowing the aggressive instinct to be expressed in accordance with our culture.
Psychoanalysis provides another vantage point. As the infant starts to crave a particular mental state that he senses in his caregiver ("object"), namely admiration and devoted interest, he starts to become sensitive to any threat to the exclusivity of this relationship. To the competitive presence of a third person, the infant starts to respond with a particular kind of anger - that is, envy directed at the third person's admirable qualities that attract the caregiver (Oedipus complex). The origins of envy and jealousy lie in the infant's loss of complete control over his object. It is the realisation of his dependence on his object and the development of object-relations that turns constitutional anger and aggression into envy, hate, and jealousy. Not only may envy arise when there is a threat to the exclusivity of one's object-relation, but also when others' qualities, being perceived to be more attractive than one's own, prevent one from establishing such a relation. Competitive aggressiveness derived from the Oedipal complex is a nonpathological and constructive force in human relations (e.g., Wolf 1988, p. 78). Competitiveness is a defence against unacceptable feelings of envy (e.g., Joseph 1986; Spillius 1993), which accords with Lorenz's notion of cultural ritualisation of conflicting impulses. Thus, the function of money may be related to suppressed but unconsciously omnipresent envy (being an expression of the aggressive or "death" instinct).

Much of psychopathology can be related in one way or another to failings of this ritualised interplay of aggressive impulses and reciprocal fear impulses that normally maintains us in social hierarchies, including compulsive gambling, hoarding, and other problems subsumed by the authors under "addiction to money" but with which money essentially has very little to do. The "miser's hoarding" and the "spendthrift's self-destructive carelessness" are both ways of dealing with interpersonal anxieties that abound in groups and societies organised by ritualised aggression with the omnipresent threat of rejection.

What is there to suggest that money "seems to be capable of giving the illusion of trade and reciprocation even when it is absent" or that money "acts like a drug on that centre, activating it even when there is no real possibility of trading" (sect. 5.2, para. 5)? In its social dimension, trade may not be altruistic but yet another culturally ritualised expression of intraspecific aggression aimed at organising hierarchies in social groups. McDougall (1924) argued that the parental instinct is the only truly altruistic instinct in man. One should not postulate a "trading instinct" just because trading is ancient and adaptive, in as little as one can speak of a tool-making instinct. We are not endowed biologically with a specific disposition to trade, although we do have various physiological needs for which trading is primarily a culturally conditioned strategy through which to ensure their satisfaction. There is no difference in principle between trading and foraging.

If Tool Theory suggests that money "is an incentive only because and only insofar as it can be exchanged for goods and services" (sect. 2.1), then this should be true for its social function too: Money is an incentive because it can be exchanged for social status (if only in one's fantasy), thus satisfying intraspecific aggression in a culturally ritualised manner. As L\&W acknowledge: "the possibility that money is used for purposes such as social display, social communication ..., or social protection ... merely extends the range of uses for money as a tool" (sect. 2.1). It seems the drug metaphor had to be invoked to make acceptable the otherwise unfeasible argument that our desire to obtain money is related to a trading instinct. The fact that money acquisition is not obviously adaptive to such instinct had to be reframed as deceit ("parasitic action on a functional evolutionarily adaptive system"; sect. 2.2.4). In contrast to the authors' assertion that money "gives direct access to the systems that subserve ... rewards ... in an illusionary, nonfunctional way" (sect. 2.3) (money as a "functionless" drug), it can be summarised here that, unlike drugs of abuse, money's access to these systems is real and functional because it is linked to the culturally adaptive satisfaction of an instinct - that of intraspecific aggression. 


\section{Money as civilizing ritual}

\section{Russell Belk}

David Eccles School of Business, University of Utah, Salt Lake City, Utah 84112.

mktrwb@business.utah.edu www.business.utah.edu/ mktrwb

\begin{abstract}
Although theorizing the non-tool motivations for desiring money is a worthwhile goal, Lea \& Webley $(\mathrm{L \& W})$ offer a view that is too individualistic, too biological, and ultimately too linked to a toolbased view of money motivation. I argue that our fascination with money is social, learned, and ritualistic. Through the magic of money rituals we overcome biological motivations and become civilized.
\end{abstract}

Lea \& Webley's (L\&W's) contention that money is a tool with which to accomplish objectives is hardly surprising, new, or a challenge to existing thought. It might have been more so if, rather than as a utilitarian tool, money had been regarded as a metaphor for possibility. It frees and stimulates our imagination. As Sartre (1943) observed, "Stop before a showcase with money in your pocket; the objects displayed are already more than half yours" (p. 753). It is this imaginative hedonism (Campbell 1987) that leads to consumer culture. That money is a drug is a more novel contention, but it is sketched out so roughly that no implications or predictions can be drawn. That is, the present account offers little theoretical understanding of money as drug.

The non-tool, "drug uses" of money discussed are especially centered around restrictions on money usage (sect. 4.5), or what McGraw and Tetlock (2005) call taboo exchanges. L\&W explain that "Gifts and sex are the currency of the moral and romantic economy, and to confuse them with the currency of the material economy is somehow to contaminate them" (sect. 4.5 , para. 4). This is an important observation, but it is illexplained without invoking ritualistic notions (e.g., Belk 1996; 2005; Belk \& Coon 1993). Recognizing that gifts and romance are key ritual motifs in contemporary society is necessary for understanding these "magical" non-tool uses of money by individuals.

Ritual money magic is also found at the institutional level. While U.S. monies proclaim "In God We Trust," in using money we express our trust in social institutions including money-coining governments, lending, savings, and credit institutions, merchants, stock markets, insurers, and retirement funds. These are the social institutions that "magically" safeguard, multiply, and guarantee the worth of our money. The rituals that these institutions perform, and in which we participate, are civilizing rituals that express our shared peaceful and cooperative intent, without which our lives would be solitary, poor, nasty, brutish, and short.

Seeking a non-ritualistic, non-cultural, biological basis for money motivations is misguided. As $L \& W$ point out, money is too recent a human development to have direct evolutionary bases. Their attempt to link it to other supposed instincts with presumably evolutionary bases is not useful. That such links might be speculated offers no evidence of their merit. It would be similarly specious to speculate on biological motivational links for other recent strong incentives like television viewing, Internet usage, or fashion purchasing. Such behaviors are more likely socially motivated and learned. They too are part of our cultural rituals. Any connection of these acts to biological motivations is tenuous, superficial, overly speculative, and quite probably fallacious.

Even if it were worthwhile speculating on biologically linked money motivations, the choice of reciprocal altruism and play as underlying "instincts" is problematic. Reciprocal altruism is a cynical view of human nature based on problematic sociobiological analogies. Non-reciprocal genuine altruism also exists (e.g., Rachlin 2002), and not just among close kin. Learned motivations better explain our exchange-related money behaviors. Children have no inherent attraction to money and must instead learn to desire it, use it, and thus become "civilized."
Play is a more likely a basic human motivation, but its link to money motivations is very weakly developed by L\&W. Based on their reference to children exchanging toys on the playground, it appears that L\&W see play as a tool facilitating trade rather than as an end in itself. Like reciprocal altruism, this conception of play is ultimately described by L\&W as more tool-like than drug-like. Contrary to assertions by L\&W, children's play with toys is initially more possessive than exchange-based (e.g., Furby 1978). Like shopping, (e.g., Falk \& Campbell 1997), children's exchange of toys is another socialized, imitative, civilizing, ritual behavior that must be learned.

Alternative underlying non-tool motivations for money-related behaviors are more likely than reciprocal altruism and play. They include the drive for power, the need for distinction, and the desire for social acceptance. Money is a means to power. Money and the things it can buy can bring prestige and status. Certain things money can buy make us more attractive to others and help us fit in with similar others. Within these social realms, accumulated money can become a means of "keeping score." However, because we learn civilizing rules not to directly tell people how much money we have, we indirectly make claims to wealth, power, and taste via our possessions and expenditures.

Money motivations are learned in the same way that manners are learned. This learning includes "civilizing" social rituals that facilitate mating and social relationships (e.g., rituals of romance and gift-giving), that announce or claim individual or group status (e.g., conspicuous consumption, consumption communities, and displays of cultural capital), and that curb envy (e.g., tipping, staging banquets, and other forms of wealth redistribution involving either real or symbolic sops; cf. Foster 1972), thereby reducing the threat of violence by the have-nots of society toward the haves. Most of these civilizing rituals overcome rather than indulge more basic motivations. They are social and cultural in nature rather than purely psychological or biological. They are what make us most fully human.

\section{Money as tool, money as resource: The biology of collecting items for their own sake}

\section{David A. Booth}

School of Psychology, University of Birmingham, Edgbaston, Birmingham, West Midlands B15 2TT, United Kingdom.

D.A.Booth@Bham.ac.UK http://psg422.bham.ac.uk/staff

Abstract: Money does not stimulate receptors in mimicry of natural agonists; so, by definition, money is not a drug. Attractions of money other than to purchase goods and services could arise from instincts similar to hoarding in other species. Instinctual activities without evolutionary function include earning a billion and writing for BBS.

Stephen Lea and Paul Webley (henceforth L\&W) spoil a strong case for a biologically based desire for money itself by inventing the incoherent concept of a "cognitive drug." They fail to recognise the hoarding instinct as a likely evolutionary origin of enjoying accumulated money for its own sake. More broadly, they do not allow that an inherited capacity can provide the basis for nonfunctional activities. Most generally of all, they seem to presuppose that, to have a biological basis, behaviour must be reducible to operations on material entities such as nicotine, saccharin, and coins; as a result, they miss the realities in social institutions and culture, and indeed of conscious and unconscious mental processes.

Many species collect items of food, in stocks far larger than needed at the moment or anticipatable from past individual experience (Morgan et al. 1943). Size of cache is not tightly regulated by selective value to ancestors, such as duration of seasonal lack of food or of torpor while hibernating (Munro et al. 2005). Ageing affects hoarding in mice nonfunctionally (Chen et al. 
2005). Laboratory rats even hoard blocks of wood. That is, adaptive behaviour is not always functional. Indeed, evolution could hardly work without useless activities becoming functional in new ecologies. A hoard of flints knapped by hominids (Wynn 2002) need not be evidence of an instinct for armouries among survivors of battles between groups; the collecting instinct could have run free in makers of axes for butchering or hunting.

Thus, adaptive capacities for hoarding could account for accumulation of coins. The gold or silver need not be felt to be beautiful to look at or delightful to touch (as reductionism disposes L\&W to suggest). The miser may simply be scrabbling through his hoard. The cop-out of invoking play is unnecessary, gambling is not analogous and it is unhelpful to relate drug addiction to obsessive-compulsive disorder (Grisham \& Barlow 2005).

Hoarding needs no coins (nor money-processing chips, as L\&W revealingly invoke twice), nor marks on a screen or in a ledger; the miser can go through his fortune in his head. Some people find entertainment in mining caches of data. Selfishness or incompetence about potential for knowledge from one's own database is a serious problem in the information industry (Lai et al. 2005).

Just credit information can be "a functionless motivator," although the strength of a delight in money as such is likely to come from its use to acquire immediate or delayed access to goods and services. It adds nothing to claim that money activates the brain's bump for collecting (or the cultural role of a collector). Like any mental processes, thoughts and feelings about money activate neural pathways and also pathways through the economy when overt in social activity. Hence, locating critical brain areas for people's normal or abnormal collecting of useless objects (Anderson et al. 2005) in no way substantiates the "metaphor" of a drug; it merely provides a starting point for characterizing the cellular expression of genes for the instinctual capacities that develop into accumulation of resources - or of junk. The irreducibly social system of an economy is also necessary for the hoarded resource to be the tool for collecting any purchasable resource.

So why do L\&W start with the idea of a psychoactive drug's mimicry of neurotransmitters at receptors in the brain and then stepwise empty it of all content, even metaphorical? The only necessity is if money's power has to be physical, in cause and in effect. Psychoactive drugs are substances that alter ion movements at synapses. What L\&W call "sensory drugs" are material stimuli to sensory receptors of the rare sort that elicit greater and greater reactions as the stimulation becomes extremely strong. This monotonic relationship is peculiar to unlearned reflexes however; liking for sweetness becomes contextualised socially or nutritiously to the particular level familiar in a food or drink, for rats (Booth et al. 1972) as well as for people (Booth et al. 1983; Conner et al. 1988). Furthermore, this may be the only piece of appetitive behaviour that is innate in human beings. (The baby-like rounded profile does not elicit particular movements.) The game is up when the only example of a "cognitive drug" (the metaphor for money) is pornographic pictures and text. Contrary to $\mathrm{L} \& \mathrm{~W}$, there is little or no evidence in human beings for innate sexual arousal at the sight of the real thing: the power of pictorial erotica results from acculturation, not genetically programmed wiring between inferotemporal cortex and autonomic efferents to the genitalia. The clincher is textual erotica, and indeed spoken words: linguistic capacities may be instinctive but not English or French verbiage, about sex or food.

Sexy sights or sounds are not "illusory" either. What's missing when they are bought rather than freely offered, in the flesh or just by photo or phone, is the other person. Even intense sweeteners are not illusions: their sweetness conveys what the consumer wants them for (Freeman et al. 1993). Similarly, it is not an illusory quality of money that makes monetary gifts "socially awkward," nor is it a trade instinct somehow separate from reciprocal altruism. A gift is expected to be attractive to the particular recipient: resorting to money instead of a personally appropriate object shows lack of empathy, which is poor acculturation of the biological capacity for altruism.

In summary, the capacity to develop the cooperative or individual activity of collecting items for their own sake is likely to have selective advantage in ecologies where resources are much more limited at some times than at others. In a species with much nonmaterial culture and activity, resources hoarded to no extrinsic purpose can include artefacts of society that are also nonmaterial, such as a balance at the bank that others only dream of. Money may derive all its attractions from services and goods it buys. Then (contrary to L\&W) money can fulfill the hoarding instinct in biosocial cognitive actuality - no illusion and not dependent on brains that can use coins as neurotransmitters.

\section{Hoarding behavior: A better evolutionary account of money psychology?}

\section{Paul Bouissac}

Department of French Linguistics, University of Toronto, Victoria College, Toronto, Ontario, M5S 1K7, Canada.

paul.bouissac@utoronto.ca http://www.semioticon.com/bouissac.htm

Abstract: The target article authors have been drawn into two metaphoric models of attitudes toward money that have prevented them from developing a convincing evolutionary theory able to account for the various behaviors they list and categorize as either tool-type or drug-type. Instead, hoarding could provide an evolutionary model that is better supported by behavioral and neurological evidence and could account for the whole range of behaviors they review. Moreover, the authors' focus on money as the common denominator of these behaviors brings an ideological bias to their inquiry.

Metaphors play an important role in scientific heuristics. The spontaneous or systematic identification of common properties across distinct categories of objects and the transfer of models across phenomenal modalities may indeed reveal essential similarities that were not obvious in the first place. This is often the first step toward the construction of a hypothesis which may eventually lead to a scientific theory that explains a set of previously unrelated observations as resulting from the same general laws. Metaphors are nevertheless double-edged because there is always a risk that they trap the imagination of scientists and preclude further advances. Niels Bohr's planetary model of the atom provides an example of this phenomenon. Lea \& Webley $(\mathrm{L} \& W)$ select two metaphors among the many that may bear upon money in contemporary Western cultures. Mindful of the limits involved in the heuristic use of metaphors, they nevertheless embrace drug and tool as the most likely to provide insights into the biological significance of the behavior of contemporary humans toward money. The case they make is persuasive, but in the rhetorical rather than scientific sense, as it is difficult to see how their dual theory could be falsified. Of course, as topologist René Thom used to say, a metaphor cannot be false. But the point is: how much trust can we place in such intuitions and for which purpose? All that glitters is not gold. At best, the authors' two root metaphors can help classify the other metaphors which have been propounded in the past to explain money-oriented behaviors.

It is surprising that $\mathrm{L} \& \mathrm{~W}$ have not taken into consideration hoarding behavior, also called collecting behavior, as a possible evolutionary ground to account for the various forms of attitudes toward money that they review. From the beginning of modern psychology, hoarding has been considered a human "instinct" (e.g., James 1890, Ch. 24); and the continuum between this self-preservation strategy and the behavior of many animals (mammals, birds, and insects) that hoard food or collect 
nonfood items that may be displayed in courtship is well documented (e.g., male bower birds). The adaptive value of storing nonperishable food in caches when seasonal variations bring scarcity is obvious (e.g., Sherry 1985; Smith \& Reichman 1984). Likewise, the adaptive value of demonstrating fitness by flaunting collections of nonfood items can be construed as a behavioral "handicap," in the evolutionary sense of the term (Zahavi \& Zahavi 1997), similar to phenotypic features such as oversized feathers or other conspicuous and costly ornamental appendages. In archaeology, hoarding is also considered to be an expected behavior in past cultures at least from the Neolithic on (Hamon \& Quilliec 2005). However, hoarding behavior appears in L\&W's article only marginally in association with the term "miser," perhaps because it has come to designate in contemporary psychology a behavioral dysfunction, usually associated with cluttering, and often connected with senescence. But this is a recent semantic change particular to clinical psychology. As noted above, it has kept its functional value as an adaptive strategy in other fields of inquiry.

Anderson et al. (2005) offer a neurologically based model of hoarding behavior that could explain more economically within a single evolutionary theory the two types of behaviors toward money contrastively described by $\mathrm{L} \& \mathrm{~W}$ in the target article. Anderson et al.'s investigation of patients with mesial prefrontal lesions who show compulsive collecting behavior suggests that the drive to collect and hoard, which "primarily originates from subcortical bioregulatory nuclei" (p. 208) (i.e., limbic subcortical and mesolimbic cortical structures), is modulated by selfregulatory functions associated with mesial prefrontal regions. Anderson et al. tentatively submit that "the drive to collect would be assisted in part by a weighting system, whereby the neural representation of a stimulus item would be associated with a particular signal value, which would serve as an index of the relative worth of the stimulus" (p. 208). This is all the more relevant to the case of money attitudes in that it does not appear that "the targets of acquisition behavior are specified at a genomic level" (p. 207).

In view of such evidence and plausible assumptions, it is possible to formulate a hypothesis: Natural selection both favored (1) a drive to collect and hoard a broad range of items, as this behavior enhances self-preservation and reproductive fitness; and (2) an inhibitory system that monitors the process and decides when this drive runs the risk of reaching a maladaptive threshold either by overloading the carrying capacities of the organism at the expense of other vital functions, or by collecting and hoarding indiscriminately. The latter could be explained by the fact that the properties of the stimuli should not be too narrowly specified, since excessive specialization would not be adaptive with respect to changing environments. It can also be expected that, if both behaviors are indeed genetically controlled, it will ensue that there will be variations among individuals in congruence with the emerging structural variation theory of the human genome (Check 2005). Therefore, it is not necessary to hypothesize a maladaptive addictive model (the drug metaphor), but simply natural variations and occasional dysfunctions that cause a more or less drastic disinhibition of the hoarding drive. As frontal cortical functions are associated with cognitive competences, such as the representation of the context and the comparative evaluation of stimuli, it is natural that they would appear to constitute the rational norm that is captured by the tool metaphor. From this point of view, money would not be a specific object but a mere cultural index for resources, and the intellectual conundrum created by the discrepancy of the two attitudes identified by L\&W would result from the incompatibility between the two root metaphors rather than from the attitudes to which they refer.

But there is more. By using the abstract notion of money as the common denominator of all the forms of behavior they take into consideration, L\&W operate a conceptual reduction by creating a kind of epistemological commodity that tends to erase all cultural, ideological, and socio-economical differences. Thus, they remain within the universalist discourse of the political economy that regulates contemporary globalization, construing capital as a tool to generate profit but ignoring the immediacy of salaries (or food coupons) as a scarce index of threatened livelihood. Hence, their surprising notion of money as a "functionless motivator" (sect. 2.2.2) that can "mimic...natural incentives" (see Abstract, sects. 2.4, 5.1) - a case that may perhaps apply to Monopoly type of games or extreme financial speculations, but not to everyday experiences in the greater part of the world.

By shifting the focus toward the evolution of the behaviors concerned and their neurological substrates (which could not have evolved with respect to the too-recent institution of money), the hoarding model seems to be more apt for explaining in evolutionary terms, and more economically, the range of behaviors L\&W address in their article. Confronted with this somewhat baroque, two-headed theory, one cannot help thinking that the authors could have made a better use of Occam's razor.

\section{Money, play, and instincts}

\section{Gordon M. Burghardt \\ Department of Psychology, University of Tennessee, Knoxville, TN 37996-0900. \\ gburghar@utk.edu http://web.utk.edu/ gburghar/}

Abstract: The metaphor drug model of money slights the possibility that money may literally tap into and exploit brain systems underlying motivational systems, and it also ignores growing evidence on the common neural substrates of behavioral and "physiological" addictions. Additionally, many objects other than money can gain such drug-like properties. The treatment of play in the evolutionary explanation for the unique role of money in people ignores key conceptual and empirical issues.

One of my professors at the University of Chicago back in the 1960s, the brilliant David Bakan, was very pleased with his definition of money as "a medium of exchange accepted by strangers.” Lea \& Webley (L\&W) realize, however, that money does not just have an instrumental or tool function; there are constraints on its use. They point out that money is not considered an appropriate gift in some contexts (though, of course, that is also true of any other object). L\&W invoke money as a drug, mimicking human instincts, to deal with all those aspects of money that their "tool theory" cannot accommodate. They argue that money readily comes to act as a motivator similar to biologically based instinctive drives.

Skinner and his followers viewed money as the ultimate generalized reinforcer developed through instrumental (tool) conditioning. That the ultimate bedrock of even the most artificial and arbitrary training regimes for rats, pigeons, and people was access to primary or secondary reinforcers (or "drives") was assumed as obvious, though uninteresting and not in need of an evolutionary explanation beyond the connections made in Skinner (1966). Now we find out that the operant approach was based on money (tokens) as drugs. I rather thought that token economies, when instituted in mental hospitals, were means to wean people from unproductive, destructive, incompetent, impulsive, compulsive, or self-injurious (e.g., drug-like) behaviors we now know to be largely due to malfunctioning neurotransmitters resulting from genetic and developmental events. Are we now to consider token economies as just another drug therapy, a trading of one addiction for another?

Although L\&W make much of the fact that money developed late in human history, automobiles appeared even more recently. Like David Bakan, my major professor at Chicago, Eckhard Hess, was also very pleased with one of his definitions: an automobile is merely a means to get from point A to point B safely 
and efficiently. To him a car was totally a tool, confirmed by the fact that he rarely drove except to travel out of town. But he, nevertheless, bought his wife, Dorle (a stylish and artistic matron from European wealth), a Mercedes convertible. As she zipped around Hyde Park with the top down and her blond hair blowing in the wind, Hess realized that for his wife a car was far more than a means of transportation, and he felt obliged to humor her "drug" habit. Fast sporty cars are fun, even exhilarating, to drive, and a Mercedes in the 1960s was still an uncommon status symbol as well. Obviously, there were constraints on what one could do with such a vehicle. It was not very useful for transporting more than two persons, had limited trunk space, and insurance and repairs were costly. So, I guess the way to understand automobiles is to invoke both the tool and drug metaphors. But wait, any use of food that does not just provide nutrition and calories should be looked at in this way also - as a drug. Food was also one of the first mediums of exchange and the spice trade a most important early part of international trade.

The point of these examples is to argue that, as formulated, I find this proposed drug metaphor an "emperor" theory of money that has no clothes. Oops, clothing also is both instrumental and a drug of choice for shopaholics, and has been an important means of exchange (cloth, silk, cotton, wool, not to say boutique "rerun" shops).

Does money act as a drug on dopamine receptors in the basal ganglia and related structures or is the drug idea merely a metaphor? The authors opt for the latter, but much of the article seems to argue the former. To them money "intrudes on the normal functioning of the nervous system" (sect. 2.2.1) by mimicking substances involved in basic instincts that are, in fact, centered in these same brain areas. Although still somewhat controversial, these areas seem to contain often overlapping systems involved in basic motivations, cravings, feelings, compulsions, conditioning, and both behavioral and drug-based addictions, including excessive running, gambling, and so forth (references in Burghardt 2001; 2005). I think that the drug word may have shock value, but essentially adds nothing since any behavior not based on rational or instrumentally adaptive behavior is, for $\mathrm{L} \& \mathrm{~W}$, acting as a drug. This dichotomy is just another learning- instinct contrast that neglects the biological processes connecting instrumental and instinctive behavior.

$\mathrm{L} \& \mathrm{~W}$ also assert that money is unique in having no intrinsic drive-reducing or instinctive properties based on current or past environments, and thus is an entirely new phenomenon that needs formal incorporation into an evolutionary account of behavior. In doing this they have to deal with the origins of money in our evolutionary past. This they view as a challenge since they claim that money is unique to our species (an interesting assertion itself since tool use, tool making, language, counting, altruism, even moral behavior have fallen by the wayside as qualitative distinctions between humans and other species). So what to do? After going through the first four sections of the target article, I awaited the new ideas that were going to emerge from their evolutionary analysis. Surprisingly, the critical heart of the paper on the origins of money is in but a fraction of the text (sects. 5.2 and 5.3) where we find that reciprocal altruism and play are the roots of the origins of money as drug.

Insofar as altruism as a source of money is concerned, I will focus just on the claim that, while altruism is old, the trading instinct is unique to our species; an assertion that cannot be sustained. We have known for decades of gift-bearing flies and gift exchanges among birds (see Judson 2002). Indeed, these gifts may become divorced from their original reinforcer (food) and become symbolic. Although ethology (Tinbergen 1951) is cited, the seminal concept of ritualization is not. While such "gifts" in other species may not always be explicit payoffs or serve as generalized reinforcers, they certainly are trades. Furthermore, exchanges are the essence of many social insect societies, even interspecifically (aphids pay for protection with secretions).
Mutualism, symbiosis, and similar "trading" phenomena are endemic in organic life. The roots of trading may run deep in our phylogenetic heritage, and the evolution of money may have been a small evolutionary step, albeit with major consequences.

The second instinct that is invoked to explain the origins of money is play. Having just written a treatise on this topic (Burghardt 2005), I was anxious to see how L\&W deployed the concept. I was surprised that play is invoked without any consideration of what it is or the nature of its instinctive origins. In fact, the only topic discussed is toy exchange, based on the authors' own studies published in economic venues. To end their paper on such a thin two-paragraph thread of support is disappointing. First, whether play, even object play, is a separate instinct (or behavior system) or is derived from other systems (such as predatory or fighting), is still an open issue in many species. Second, whether exchanging toys is a means of learning how to manage resources rather than a behavioral relic or a precocial performance of adult behavior with no important "practice" component, is largely unknown. A just-so story does not constitute data, especially when the adaptive function of play in juvenile animals has rarely been demonstrated experimentally (Burghardt 2005). If play exchange is training for money management, as L\&W assert, the problems so many people have with money management makes such play quite ineffective.

Finally, the loose use of the term "instinct" is disturbing and shows that the new style of evolutionary psychology, by largely eschewing engagement with data on other species, is in danger of losing any claim to be a naturalistic evolutionary science. The classical ethologists, along with their critics, made remarkable progress in conceptualizing instinctive behavior and motivational systems. I fear that articles such as this one will make the current incarnation of evolutionary psychology problematic to both evolutionary biologists and social scientists.

\section{Money as epistemic structure}

\section{Sanjay Chandrasekharan \\ Centre for Behavioural and Cognitive Sciences, University of Allahabad, \\ Allahabad, Uttar Pradesh, 211002, India. \\ sanjayen@gmail.com http://www.sce.carleton.ca/ schandra}

Abstract: A testable model of the origin of money is outlined. Based on the notion of epistemic structures, the account integrates the tool and drug views using a common underlying model, and addresses the two puzzles presented by Lea \& Webley $(\mathrm{L} \& W)$ - money's biological roots and the adaptive significance of our tendency to acquire money.

Epistemic structures (ESs) are structures that organisms add to their environment to lower the cognitive complexity associated with tasks (Chandrasekharan 2005). For instance, wood mice (Apodemus sylvaticus) distribute small objects, such as leaves or twigs, as points of reference while foraging. Such "waymarking" has been shown to diminish the likelihood of losing interesting locations, and is exhibited even under laboratory conditions, using plastic discs (Stopka \& MacDonald 2003). The male bower bird builds colorful bowers (nest-like structures), which are used by females to make mating decisions (Zahavi \& Zahavi 1997). Bacterial colonies use a strategy called "quorum sensing" to know that they have critical mass to attack a host. Individual bacteria secrete molecules known as auto-inducers into the environment; when the chemical breaches a threshold, the colony attacks (Silberman 2003).

We have developed and implemented an evolutionarily plausible model of the origin of such external structures, using artificial agents that possess only reactive behaviour (the agents just sense and act, they do no internal processing). The model uses cognitive load reduction in a recursive fashion: it is an effect of 
ES generation, but it is also the cause that drives generation. We make two assumptions: (1) organisms sometimes generate random structures in the environment (pheromones, leaf piles, etc.) as part of their everyday activity; and (2) organisms can track their physical or cognitive effort (i.e., they get tired), and they have a bias to reduce tiredness. The term "tiredness" indicates the "felt" quality of the feedback, which allows tracking of cost using affect - that is, without using a separate computational module.

Some of the randomly generated structures in the world are now encountered by the agents, and in some random cases, these structures make tasks easier for the organisms (following pheromones reduces travel time, avoiding leaf-piles reduce foraging effort). In other words, these structures shorten paths in the task environment (see Kirsh 1996). Given the postulated bias to avoid tiredness, these paths get preference, and they are reinforced. Since more structure generation leads to more of these paths, structure generation behaviour is also reinforced. We have implemented this model using both genetic algorithms (evolutionary learning) and the Q-Learning algorithm. The latter implementation shows that reactive agents can learn, within their lifetime, to add ESs systematically to their world to lower cognitive load (Chandrasekharan \& Stewart 2004). Such withinlifetime learning to reduce cognitive load has recently been shown in homing pigeons. They follow railways and highways to reach their target, even taking exits (Guilford et al. 2004).

The tiredness model explains the process underlying the generation of two of the three ES types possible (structures for oneself, structures for oneself and others, structures exclusively for others). It only partially explains the third. The second type is explained by appealing to the similarity of systems: if a structure provides congeniality for me, it will provide congeniality for other systems like me. The similarity of agents led to them forming structures that were useful for everyone, even though they were just concerned about reducing their own tiredness.

A similar learning system could explain the first of Lea \& Webley's (L\&W's) puzzles: the origin of money. The tiredness approach is suited to modeling money because, given a barter system, money lowers both physical and cognitive effort, as it helps lower the number of physical transactions, and reduces the computational complexity of tracking branching transactions (agent X has Good B and she wants Good A, but agent Y, who has Good A, doesn't want Good B. Agent X now needs to find an efficient and guaranteed path from her Good B to Good A.). With multiple goods, the branching transaction problem becomes extremely complex, particularly with added constraints like perishability, security, and so forth. Money can be seen as an epistemic structure that emerged to shorten such complex paths in the barter environment, by providing a common structure that can connect any path, reducing both cognitive and physical load.

Applying our model of ES generation to such a view of money, given any barter environment with sufficient cognitive load and transaction costs, and agents that seek to lower their tiredness, a commodity that is in demand by most agents (salt, sugar, spice, gold, etc.) would be used to connect branching paths efficiently. The commodity would acquire this money role the same way pheromones acquired an epistemic role in our simulation. In this view, money emerges not because of evolutionary or genetic advantages, but because of a central survival advantage - the lowering of energy utilization. To test this hypothesis, we are currently designing a network-based barter experiment and a parallel simulation model.

What about L\&W's second puzzle: the tendency to acquire money? In the model above, this could be explained by including dopamine as a second reinforcement factor, acting in tandem with tiredness. So, once the use of money is learned by agents in a barter environment, a dopamine-based system takes over. This system "extends" the use of money as a path-connecter - to a tendency to acquire money. Schultz (1992; reported by Braver \& Cohen 2000) has shown that dopamine responds initially to a rewarding event, but with training this response "migrates" to predictive cues. This behaviour, where learning chains backwards in time to identify (and reinforce) successively earlier predicators of reward, has been modeled by Montague et al. (1996) using a temporal difference learning algorithm (similar to Q Learning). Such a dopamine-based model would explain the tendency to acquire money (and the pleasure it provides) as an adaptive extension of money's role in lowering tiredness.

Besides cognitive load, two other factors could drive this migration. One, epistemic structures like money significantly expand the space of actions possible (see Kirsh 1996). Being the connector of all possible paths in a trading system, money expands the action space of agents exponentially. Two, epistemic structures make a system more robust, by raising task-success in noisy and high processing load environments (see Chandrasekharan 2005). These two advantages, combined with lowered energy use, make the tendency to acquire money a highly adaptive response.

\section{Money and the autonomy instinct}

\section{Siegfried Dewitte \\ Marketing Research Center, K.U.Leuven, Naamsestraat 69, Leuven, 3000 Belgium. \\ siegfried.dewitte@econ.kuleuven.be \\ http://www.econ.kuleuven.be/siegfried.dewitte}

Abstract: Applying the reciprocity instinct to monetary transactions implies that the reaction to monetary debt and monetary credit are similar. However, evidence suggests an asymmetry. I suggest that the "autonomy instinct" fits better with human behavior towards money. I show that people value autonomy, and I show how money can serve this instinct.

I concur with Lea \& Webley's (L\&W's) analysis that human behavior towards money is consistent with Drug Theory rather than with Tool Theory. I also concur with their claim that this implies that money should hinge on a pre-existing instinct. I do not concur with L\&W's claim that money mainly parasitizes on humans' reciprocity instinct.

Applying the reciprocity instinct to monetary transactions requires two cognitive tools: a sensitivity to what others owe you (cf. cheater detection module; Tooby \& Cosmides 1992) and a sensitivity to what you owe others (cf. the reputation concern; Axelrod 1984). The function of both is to bridge the time lag between the two transaction phases (i.e., giving and receiving) that define an exchange situation. $\mathrm{L} \& \mathrm{~W}$ claim that money fills the gap between giving and receiving. Money removes the temporary imbalance between giver and receiver and the negative affect related to that imbalance.

It is critical to L\&W's claim that people are willing to fill the time lag between the two transactions with money in both directions. They should be motivated not only to get the money they deserve but also to pay the money they owe. Credit cards should be equally as aversive as prepay cards. However, common intuition and recent findings suggest that people do not want to pay their debts as quickly as possible to get rid of the feelings of obligation. People are willing to live on credit and use simple heuristics to decide how much they can borrow (Soman \& Cheema 2002). Credit cards are very popular (turnover in Europe in 2004: €617.3 billion), whereas prepaid cards remain marginal and often remain tied to one retailer (e.g., B+S Card Service GmbH 2005), although there is no practical reason why people would not be willing to prepay their expenses. There just seems to be no demand for such a product, although prepay cards would be an efficient way to self-regulate expenses (Trope \& Fishbach 2000). Further, there is evidence that living on credit does not hurt when durables are involved (Prelec \& 
Commentary/Lea \& Webley: Money as tool, money as drug

Loewenstein 1998). Finally, the mental accounting framework (Shefrin \& Thaler 1988) does not fit nicely with the reciprocity principle: People borrow money even when they have money available on different (mental) accounts. By borrowing, they increase the amount they owe without increasing what others owe them. Borrowing increases the imbalance between giver and receiver, which is inconsistent with a reciprocity instinct.

My claim is that money either (1) parasitizes only on the receiving part of the reciprocity instinct (cf. cheater detection) or (2) parasitizes on another instinct. A candidate alternative instinct is the need for autonomy (Deci \& Ryan 1985). I first present a series of human behaviors that suggest the existence of this instinct. I proceed by explaining how money might hinge on this instinct. I finish by reviewing several money phenomena that fit better with the autonomy instinct than with the reciprocity instinct.

The value of autonomy can be inferred from several human behaviors. I here define autonomy as independence from social influence. Autonomy reduces the likelihood that others can exploit the agent for their own benefits, and therefore increases survival. Is there evidence that such an instinct exists? Brehm (1966) showed that people are willing to forgo their favorite option in order to establish that they are in charge. Bown et al. (2003) showed that people prefer options that allow further freedom of choice. People also prefer a larger option set for its own sake (Suzuki 1997). Iyengar and Lepper (2000) replicated this finding but added that people are less likely to come back to the same choice situation, which suggests that choice has a cost. Together, these findings support the notion that people are willing to incur costs to preserve their freedom of choice.

How might money serve this instinct? Money may provide a buffer against dependency. In times of scarcity, poor people have to sell their labor or their bodies to survive. Rich people manage to acquire the means and the labor they need to survive. As a result, people might value money for its own sake, even in times of plenty when they cannot spend all the money they possess.

I sketch four observations suggesting that money might be a drug fitting the autonomy instinct rather than the reciprocity instinct. (1) Parents are allowed to give money to their offspring, but not vice versa. Although parent-offspring relationships become reciprocal later in life and are reciprocal in the long run (e.g., when children care for the elderly), this monetary asymmetry survives adulthood. Gaining autonomy from parents is an important step in life, which suggests that the monetary asymmetry between parents and offspring is related to the autonomy instinct. (2) Intrinsic saving motives (Wärneryd 1999) do not make much sense from a reciprocity perspective because they reduce reciprocity. Money that is not spent is removed from the social dependency network and does not build reputation in a reciprocal interaction. However, intrinsic saving motives do make sense from an autonomy perspective. Saving leads to accumulation, which increases independence. (3) Borrowing money from third parties while owning money is difficult to understand from a reciprocity perspective. In fact, borrowing increases the amount you owe others (which is aversive if reciprocity underlies behavior towards money), without increasing what others owe you. However, borrowing from third parties distributes social dependency and hence increases average autonomy. (4) According to the autonomy instinct, money should function as a signal of some hidden intrinsic quality of the owner. Money may signal that the owner managed to become independent from the environment. According to the reciprocity instinct, however, accumulated money should raise concern of cheating. Money reflects that the owner received more money than he gave away. Probably both evaluative reactions to wealth exist, but I found evidence only for the first one (Christopher et al. 2005).

To conclude, I submit that human's behavior in the context of money fits better with an autonomy instinct than with a reciprocity instinct. Money might reduce interpersonal dependency rather than organize interpersonal dependency.

\section{Individual differences, affective and social factors}

\author{
Adrian Furnham \\ Department of Psychology, University College London, London, WC1 OAP, \\ United Kingdom. \\ a.furnham@ucl.ac.uk
}

Abstract: The target article overestimates the power of money as a motive/incentive in order to justify trying to provide a biological theory. A great deal of the article is spent trying to force-fit other explanations into this course categorization. Lea \& Webley's (L\&W's) account seems to ignore systematic, individual differences, as well as the literature on many negative affective associations of money and behavioural economics, which is a cognitive account of money motivation.

The authors are to be congratulated on an interesting, innovative, and thoughtful paper on a woefully neglected topic. The understanding of how people think about and use money seems at once the concern of all disciplines and of none. Economists have been consistently wrong in asserting that money is the measure of all things but is itself unable to be measured. The everyday meaning and use of money may be a neglected topic in the behavioural sciences but that situation is thankfully changing (Furnham \& Argyle 1998).

Perhaps the first point to be addressed and one that is completely overlooked in the target article is the extent to which money is a powerful motivator, particularly at work. Although both psychologists and lay persons hold the view that money is indeed a powerful motivator, the psychological research is far more sceptical about the power of money as a work incentive. Important experimental (Deci et al. 1999) and popular (Kohn 1993) literatures have demonstrated that money has paradoxical and negative effects on work motivation. In the old Herzbergian terminology, money is a hygiene factor, not a motivating factor: it prevents dissatisfaction rather than causing satisfaction. Money, in short, is over-rated as an incentive. It seems not be a powerful incentive, instinct, or motivator except under specific circumstances

Indeed, Lea \& Webley (L\&W) overlook the literature which suggests that social comparison in terms of money earned is a much more important source of satisfaction and motivation than absolutes earned (Furnham \& Arygle 1998). It is unclear how either Tool Theory or Drug Theory copes with that. Moreover, the literature on what people are willing to trade-off money for (e.g., time) seems at odds with either theory.

Further, there is a literature on the affective associations on money - that is, on what people associate with money (see Furnham \& Argyle 1998). For money to be a positive cognitive drug one would imagine that nearly all associations would be positive. The results suggest precisely the opposite: Money is a major source of anxiety, worry, and depression for manyhardly an incentive.

It seems that $L \& W$ want to start with a powerful motive so that they can offer a novel biological or evolutionary psychological explanation and theory that parsimoniously explains the processes and mechanisms for money motivation better than all the other theories. But what is the nature of those theories? Are they any better than simple metaphors? The authors seem happy to dismiss Tool Theory as such but want to supplement it with Drug Theory. The ideas are novel but I believe the authors fail on three counts.

First, half of the target article is dedicated to showing how all the other theories in areas as diverse as classic psychoanalysis, economics, and developmental psychology can be fully accounted for by either the tool or drug metaphor. So we get many sections (Depth psychology; Cognitive development) in which, after a short description, the authors suggest that the area fits into one or other metaphor. This is woefully overplayed and often not well argued. Depth psychology is categorized as a 
Drug Theory and cognitive development is categorized as a Tool Theory, yet it seems pretty simple to suggest a way in which it is the opposite way around. The authors seem far too eager to "scoop up" all the explanatory processes and mechanisms from all areas of behavioural science in terms of their two metaphors.

Second, there are many characteristics of a good theory apart from its heuristic appeal: parsimoniousness, consistency, validity, and so forth. A good theory both explains the current data and leads one to be able to derive clear testable hypotheses to verify the theory. It seems unclear as to how tool/drug theory does this. For instance, whence money pathology and the whole issue of individual differences? How does tool/drug theory explain pathological and irrational money hoarding or spending or gambling any better or differently than psychoanalysis? And what is the source of gender differences in money use (which should not be particularly problematic from an evolutionary perspective)? In short, what is the incremental validity of the theory/metaphor from what has gone before, or is it merely a classificatory device for all other theories in the area?

Third, the question must be asked: Is L\&W's theory only one theory of why people seek out money as well as of how and when and why they save and spend it? Is the theory aiming to be a new, overarching, universalist theory of money usage which supplants all earlier "partial and inadequate" theories that ignore all important biological factors, or simply a corrective taxonomic challenge to those working in the area? I would suggest it succeeds as the latter but not the former.

\section{Metaphysics of money: A special case of emerging autonomy in evolving subsystems}

\section{Robert B. Glassman \\ Department of Psychology, Lake Forest College, Lake Forest, IL 60045. \\ Glassman@lakeforest.edu \\ http://campus.lakeforest.edu/ glassman/}

\begin{abstract}
There is "something more" to money, as this incisive review shows. The target article's shortcoming is its overextension of the "drug" metaphor as a blend of features that do not fit the rationalistic economics and behavioral psychologies summarized as tool theories, but this may be resolved by viewing money as a particular case of the more general evolutionary phenomenon of emergent subsystem autonomy.
\end{abstract}

Money is not alone. Examples of robust, "drug-like" phenomena other than money include humor and music. How did these things originate and become widespread and varied? To what degree can these pervasive human phenomena be explained in terms of exaptations or present adaptiveness? Another possible analogy to the emergence of money: How do humans come by the remarkable aptitude and brain circuitry for reading written words and passages, given that the history of writing seems to be only several thousand years old?

When a fleeting occurrence in living systems repeats itself, and then becomes frequent and widespread, it may achieve its own "entification" or "thinghood." Entification entails further opportunities to accumulate additional raisons d'être. Sufficient robustness may then be achieved to abet new evolutionary branches, and proliferation of forms. Gradually increasing autonomy in subsystems of complex systems (either living or engineered by humans) is a much more general phenomenon than is captured by Allport's personality theory principle of "functional autonomy," which Lea \& Webley (L\&W) cite (target article, sect. 3.2.3; Allport 1937). ${ }^{1}$ This crucial aspect of complex systems (Glassman 1973; Glassman \& Wimsatt 1984; Simon 1996) underlies the fact that every evolved entity or feature of every living system originates as something else.

The biological and social living world is always in motion. Features that had served a particular function within one species of complex system, come to serve other functions in descendents of that system, while still retaining sufficient resemblance to their precursors to be recognizable as homologs. There are innumerable examples. Engineering examples include the modification and reuse of subroutines in the development of computer programs (perhaps especially "object-oriented" programs; e.g., Kehtarnavaz \& Kim 2005), and the "evolution" of large buildings and bridges (Petroski 1985). Natural examples include the evolution of the human hand and the bird's wing from the primordial vertebrate forelimb; also, the evolution of innate components of behavior, such as the patterns of rhythmgenerating circuitry in the spinal cord that serve swimming in fishes and walking in terrestrial animals, and the emotions underlying greeting behavior in diverse species of social animals. Enhanced depth perception, attending overlapping binocular visual fields, is another robust phenomenon with diverse uses; it serves largely to increase the accuracy of traveling among tree limbs by monkeys and the accuracy of predatory pouncing by cats. For only the past 100 years or so, this complex neurobiological apparatus has been subject to a new form of natural selection, as humans try to accurately drive cars at highway speeds, and often live to tell the tale.

Related to emerging autonomy, the concept of "modularity" is widely used in present-day biological and social theorizing. This concept is now also deeply rooted in cognitive science theorizing, whose beginnings, circa the 1960s, happen to be coincident with those of evolutionary grand theories. However, typical uses of the concept of modularity do not sufficiently capture the degree of autonomy of evolving subsystems. Money, for example, virtually has a life of its own. L\&W note that it has quickly taken root in every society that has discovered it. The ferment of multiple ongoing changes in every complex evolving system means that even when none of these dynamics is internal to a particular subsystem, the subsystem's buffeting about among other subsystems is tantamount to a process of "seeking." This point, approximately the same insight that led Darwin to use the term "natural selection," has been explained particularly well by Donald T. Campbell in his works on evolutionary epistemology. Campbell discusses the ubiquity of "unjustified variation and selective retention," or "blind variation and selective retention" (Campbell 1974a; 1974b; Kim 2001). I would push L\&W's history of the origins of biological "grand theories of everything" to earlier in the mid-twentieth century, certainly at least as far back as E. O. Wilson's grand tome Sociobiology (Wilson 1975), which, by the time of Dawkins' The Selfish Gene (Dawkins 1976; cf. target article, sect. 1.1), was in its fourth printing. Campbell (1976) announced it vigorously in his presidential address to the American Psychological Association.

L\&W provide some important examples from ethology (sect. 2.2.2), but their use of these examples, particularly in regard to dishonest signaling, parasitism, and other "drug-like" phenomena, seems inherently conservative in its emphasis on a seamy side of evolution. L\&W also cite Thorstein Veblen (1899), who offered a delightfully droll and cynical view of the seamy side of the social evolution of uses of wealth, while describing the sheer, showy nuttiness of some of those familiar uses (also see Brooks 1981). But new evolutionary branches may also be "good" ones. Yes, human archetypes are often exploited in advertising or for other selfish ends; however, they are exploited as well in great literature, which helps its human consumers to better orient themselves and to find new adaptations as they face civilization and its discontents.

Citing Campbell, Konrad Lorenz perceptively argued that a high degree of subsystem autonomy, coupled with internally generated spontaneity, is crucial in any living system, for reliability and continued survival (Lorenz 1969; Eibl-Eibesfeldt 1970). It is unfortunate that the more speculative aspects of Lorenz's work elicited polemics that have led to the neglect of many of his ideas by English-speaking behavioral scientists. For example, Lorenz compellingly explains the vital importance of 
spontaneity of the heart's atrioventricular node, which ordinarily, but not always, remains subordinate to the sinus node, as a model instance of the much more general phenomenon of subsystem spontaneity and semi-autonomy (Lorenz 1966, p. 86). These ideas about subsystem spontaneity also seem related to William James's argument that "Man has more instincts than any other mammal" (James 1890, pp. iv-v, 383-441).

Whether the spontaneous "motion" of a subsystem is generated internally or by the "chaos" of its surroundings, the principle of natural selection implies that when the subsystem encounters an opportunity in its environment, it may exploit that opportunity, and will then persist in its new form or behavior, so long as any costs or risks of its new functionality provide a net increase in its "inclusive fitness," or longer-term probability of survival in itself or the copies it generates. Taking a few steps back from such individual cases to better conceptualize "the forest" over and beyond its individual swaying "trees," we can envision the larger ecology of a living environment comprising autonomously "entified" loosely coupled components and features of components. All of these are engaged in the same general game of seeking new opportunities for exploitation of each other or for mutualism. In human social systems such ferment is extremely rich because our exquisitely developed abilities to learn, remember, and imitate make it particularly easy for a feature to decouple from its host entity and jump to a new vector. In other cases, instead of such decomposition and recomposition, an entity or feature of an entity simply accumulates additional functions, thereby achieving greater and greater robustness. In much of their argument for "money as a drug" I think this is what $\mathrm{L} \& \mathrm{~W}$ are getting at.

NOTE

1. I thank the fourteen undergraduates in my Psychology 325 class ("Persuasion and truth in sales communications") for their enlivening discussion of the L\&W target article during our September 26, 2005 evening meeting.

\section{Keeping up with the Joneses: The Desire of the Desire for money}

\section{Paul Jorion \\ Interdepartmental Program in Human Complex Systems, University of California at Los Angeles, Los Angeles, CA 90095. \\ pauljorion@ucla.edu http://pauljorion.com}

Abstract: The biological basis of money lies in a three-term relationship between one subject and some others, with money acting as a mediator. The drive to acquire money is a special case of a desire for recognition. What is aimed at by subjects is their desire for the desire of some others: the former derive satisfaction from representing to themselves the admiration, or envy, of these others. This raises reproductive advantage.

The object of Lea \& Webley's (L\&W's) inquiry is to find a "biological basis" for money, meaning a basis reducible to a Darwinian trait such as reproductive advantage. Both their "tool" and "drug" approaches refer to a two-term relationship where a subject experiences cognitive and emotional states linked to a representation centred on money. The most obvious instance of this, which the authors unfortunately fail to mention, is sustenance. For anyone below the poverty level, cash remains foremost the means to the essential end of subsistence. The "biological basis" of money needs therefore to be understood in the authors' analysis as meaning "when cash as a tool for straightforward biological survival has been discounted." Examples of such a two-term relationship would then be those of Harpagon, Molière's Miser, clinging to his cherished casket, or Uncle Scrooge, diving and tunnelling through gold coins and hundreddollar bills in his pool-designed vault. In such cases, cash has been "fetishized," adulated as such, as a symbol of wealth.
One can talk of a "biological" response to gold because of its shininess and hue, and its feature of being rust-proof, leading to its universally evidenced function as a symbol for immortality. Paper banknotes and coins of vile metal are of a different nature and their link to riches is conventional; in financial parlance, their nature is "fiduciary," requiring an act of trust that a central bank will honour cash of this sort, guaranteeing it will maintain it in its role of a universal equivalent of worth. L\&W mention times (such as in the aftermath of the American Civil War) when convertibility of cash into precious metal gets suspended. When this happens, precious metal is restored in its role of a depository of value, confirming that money as such might very well be - as the authors hint - an entirely cultural phenomenon, impossible to analyze profitably within any alternative framework.

Analyzing money as a cultural phenomenon, beyond immediate survival concerns, does not preclude tracing it back to its "biological basis." It requires, however, an extension from a two-term relationship between a subject and money to a three-term relationship between one subject and at least one other, with money acting as a mediator between the two. In the two-term model, a subject holds a representation of money (as with cash as a "fetish"); in the three-term model, a subject owning money holds a representation of another subject's representation of him/herself owning that cash.

The three-term nature of money is best illustrated in a "Keeping up with the Joneses" example: Let's buy a 70" flat screen TV because the Joneses own a $50^{\prime \prime}$ ! The drive behind the purchase is not improved viewing (only a secondary benefit here) but competition: the satisfaction obtained derives from representing to oneself the Joneses' envious state of mind. By out-competing them we've made ourselves the centre of their own attention: their attention has been captured by us; they are, literally speaking, captivated. Money is used as a tool to achieve this effect and its drug-like quality lies in the altered state of consciousness we reach when subordinating some other subjects' attention to our persons, meaning that we've altered at the same time their own mindsets.

L\&W say of their tool/drug dichotomy that "the two theories seem to exhaust the range of possibilities between them" (sect. 2.3 , para. 1). This is correct but, as we've just seen, not in the simple "either/or" way they imply: the complexity of the relationship requires a more sophisticated model combining both tool and drug within a three-term model. In that perspective, the drive to acquire money amounts to a special case of a desire for recognition. A psychological theory of recognition has been proposed before; its source lies in philosophy where it was initially formulated by G. W. F. Hegel as the "desire of desire" - that is, my desire for another's desire, either of an object or, in the case of love, of my own person (Hegel 1807/1949, pp. 225-27; Roth 1988, p. 97). The theory was further developed in the twentieth century by Alexandre Kojève (Kojève 1969, pp. 6-7; Roth 1988, pp. 97-99), then given a psychiatric/psychoanalytical formulation by Jacques Lacan (Wilden 1968, pp. 83-85, 192-96). In Lacan's interpretation, the "desire of desire" becomes the linchpin of a theory of the Self where the sole foundation for my own Self - my proper identity - is the attention other subjects are paying to me, that is, it is constituted of my own capacity for captivating others. What constitutes the subjects' Self is therefore not internal to them but distributed among a network of other subjects, although centred on them.

When applied specifically to money, the "desire of desire" model means that what is aimed at by subjects through their possession of money is their desire for the desire of some others: the satisfaction they derive from representing to themselves the admiration or the envy of others. The theory is instrumental (it has a "tool" quality), in that money is in truth sought after to obtain something, but that something is not of a material nature: it is the altered state of consciousness achieved (hence the "drug" quality) through captivating the attention of a number of other subjects. One example presented by the 
authors, that of playground exchanges of toys, confirms a desire of desire interpretation much more convincingly than it does a "trading instinct" hypothesis of a drug-like nature, as it is the simple fact that another child holds an object that makes it desirable for a second one.

As for the Darwinian fitness advantage that money confers, subjects who are admired extend the range of their potential partners, gaining access in particular to those who are themselves objects of admiration. The overall benefit of admiration is fitness or reproductive advantage. Cash is a universal tool to this aim. In other words, the psychological function of money turns out to be precisely what the popular press assumes it to be.

\section{Operant contingencies and "near-money"}

\section{Simon Kemp and Randolph C. Grace}

Department of Psychology, University of Canterbury, Christchurch, New Zealand.

simon.kemp@canterbury.ac.nz randolph.grace@canterbury.ac.nz

\begin{abstract}
We make two major comments. First, negative reinforcement contingencies may generate some apparent "drug-like" aspects of money motivation, and the operant account, properly construed, is both a tool and drug theory. Second, according to Lea \& Webley (L\&W), one might expect that "near-money," such as frequent-flyer miles, should have a stronger drug and a weaker tool aspect than regular money. Available evidence agrees with this prediction.
\end{abstract}

Lea \& Webley $(\mathrm{L} \& W)$ describe an interesting and provocative framework for the analysis of money-related behaviour. Their goal is to provide a biological account of money motivation, and they claim that, if their attempt fails, the alternative would be a purely cultural explanation. But they overlook the role of conditioning and learning processes that operate within an individual's lifetime. An operant theory of money, properly construed, may be difficult to distinguish from L\&W's drug/tool theory, although money-related behaviour is so varied and complex that all three levels - biological, individual learning, and cultural - are probably necessary for a full understanding.

In their discussion of the operant theory, $L \& W$ do not mention the role of negative reinforcement or avoidance contingencies. It is well known that avoidance responding is highly resistant to extinction; dogs that learn to jump over a hurdle in a shuttlebox to avoid an electric shock continue to respond vigorously long after the shocks have been discontinued (Solomon et al. 1953). Neo-liberal economic reforms that create "incentives" to work by reducing social welfare expenditure can be viewed, at least in part, as massive avoidance contingencies. Thus, it is possible that some apparent "drug-like" effects of money, such as workaholism, reflect the resistance to extinction of responding maintained by negative reinforcement. Although the aversive event-joblessness, poverty - may never be experienced, the workaholic individual, like the unfortunate dogs in Solomon et al.'s experiment, lives in fear of an unhappy future.

According to L\&W, traditional operant theory, based on the idea that money functions as a conditioned reinforcer, is a "pure Drug Theory" (target article, sect. 3.2.2). But it has long been recognized that stimuli that function as conditioned reinforcers have discriminative as well as reinforcing (i.e., hedonic) properties (Rachlin 1976). For example, a keylight that signals transition from a lower- to a higher-valued situation in terms of reward rate comes to act as a conditioned reinforcer for pigeons (i.e., discriminative function; Baum 1974a). And recent research has found that single dopamine neurons show a spike in activation following the onset of a stimulus that predicts subsequent reward that is similar to the spike following the reward itself. This phenomenon provides neurophysiological support for the traditional view, dating back at least to Pavlov (1927), that conditioned stimuli have hedonic value (Fiorillo et al. 2003; see Schultz [2004] for review). Therefore, the operant account is not easily categorized as either a tool or drug theory, because it combines aspects of both. Moreover, because the tool/drug distinction is closely analogous to that between the discriminative and hedonic properties of conditioned reinforcers, ultimately it may be difficult to distinguish L\&W's account from the operant theory.

Nevertheless, we outline one approach to testing L\&W's theory, and show that some existing data are consistent with it. We are not attempting to distinguish their account from the operant theory, but rather to test the idea that money has both tool and drug properties.

Money is understood to resemble a drug with "the idea of a drug as a deceiver" (sect. 2.2.4). The implication is that, insofar as money operates as a drug rather than a tool for a particular individual or in a particular situation, it will be overvalued, in the same way that, for example, the taste of saccharin promises a food value that it does not actually have (sects. 2.2.2, 5.2). Misers can be thought to fall victim to this deception (sect. 4.10); however, as a general test of the theory, misers are unsatisfactory since their behaviour is counterbalanced by that of spendthrifts, who, in the eyes of most of us, do not attach sufficient value to money. Is there any phenomenon that suggests that the average person might generally overvalue money?

One approach is to examine the way that people value "nearmoney" (the phrase is from Lea et al. 1987, p. 328). Nearmoney, like primitive money, is a currency that can be used to buy a limited variety of services. One prominent example of near-money in Western societies is frequent-flyer miles. Frequent-flyer miles have many of the attributes of money and, indeed, airlines often set up "accounts" for their customers. We suggest that, in terms of L\&W's theory, frequent flyer schemes are set up so as to retain as much as possible of the drug nature of money, while having rather little (although still some) of its tool nature. Given this assumption, we would expect to find even more overvaluation of a near-money such as frequent-flyer miles than of regular money. Or, alternatively, because of this greater drug component, near-money should be overvalued relative to regular money.

This possibility has not been rigorously researched, but two recent studies have produced results suggesting it might be true. Liston-Heyes (2002) found that respondents in the United Kingdom were willing to pay more for 100 air miles (about 23 pound sterling) than the air miles were apparently worth (around 7 to 12 pound sterling). Kemp (2005) found New Zealand respondents were willing to pay a median NZ $\$ 50$ for 1,000 Air New Zealand frequent-flyer points. Estimates of the real cost of these were NZ $\$ 12.50$ (based on cheap ticket cost) and NZ \$3.61 (Air New Zealand company estimate of the marginal cost). Moreover, members of frequent-flyer programs were willing to pay more than non-members (median $=\$ 20$ ), as might be predicted from the drug theory.

Thus, at least one independent test of L\&W's tool/drug theory seems to support it.

\section{Show me the status: Money as a kind of currency}

\section{Kevin M. Kniffin}

Department of Anthropology, University of Wisconsin-Madison, Madison, WI 53706.

kmkniffin@wisc.edu

Abstract: Currencies that are recognized as money cannot be easily distinguished from alternative currencies such as status. Numerous examples demonstrate the need for status to be recognized as a motivator alongside, at least, money. Lea \& Webley (L\&W) acknowledge the roles of status; however, a closer focus is warranted. 
To the extent that we can commonly recognize "money," we can also agree that it is not a category that is carved at Nature's joints. Although Lea \& Webley (L\&W) acknowledge some examples, it is worth clear recognition that money coexists as a currency alongside a range of alternatives that includes meat, frequentflier miles, collectibles (e.g., special coins or clothing), and status. Indeed, the way in which frequent customers of airline and hotel companies are recognized with redeemable credits that can accompany "elite" (or "gold," "silver," or "platinum") "status" provides an entertaining juxtaposition of currencies.

Illustrative of the reasons why money and other currencies need to be considered alongside each other, Frank (1985) notes that people who work closely with others often appear willing to make trade-offs between salaries and status. Frank reports a pattern of within-firm salaries in relatively interactive or social organizations where high-performers are paid less - and lowperformers are paid more-than would be predicted by traditional economic, pay-for-performance models. Frank concludes that (1) high-performing individuals who work closely with peers accept lower-than-predicted salaries in exchange for higher within-firm status while (2) lower-performing co-workers endure lower within-firm status in exchange for higher-than-predicted salaries. This notion that people can buy and sell status is similarly illustrated by the willingness of hotel and airline "frequent-users" to narrow their shopping of competitors and sometimes pay above-competitor prices and consume more in pursuit of increased "status." Loyalty programs, in general, rely on this incentive to build their associated businesses.

Adopting one of L\&W's models, status has many "drug"-like features and, in fact, has been shown to affect individuals' biochemistry. When considering the evolutionary basis, or origin, for their Drug theory, L\&W accept that "trade could be a human instinct on which the money motive might be built" (sect. 5.2). While the authors' recognition of the social nature of commerce (and childhood play) is interesting and relevant, it is also true that status could be a human instinct on which the money motive might be built. Research showing drug-like changes in human biochemistry after changes in status (e.g., Mazur \& Booth 1998) provides material support for this argument.

More consequentially in the genetic domain, Smith (2004) shows that relatively successful hunters in hunter-gatherer communities tend to have relatively greater reproductive fitness. Similar to L\&W's observation that "we cannot reasonably talk about a "money instinct" (sect. 1.4), it would be incorrect to infer from Smith's findings that hunter-gatherers have an instinct for dead animals. Instead, it is helpful to recognize the fact that status can motivate individuals (e.g., to be among the best hunters) and, when acquired in sufficient quantities, relatively high status can translate into material benefits (e.g., relatively high reproductive fitness).

L\&W ably show that money cannot be reduced to some universally liquid currency of status; however, the use of money can, and should, be recognized in large part as a consequence of individual "status instincts." Predictably, just as money, meat, and furs carry different values across individuals, we should expect variation among individuals with regard to the importance of personal status. Schwartz et al. (2002) report a series of studies in which they find individuals vary according to whether they tend to be "maximizers" or "satisficers." Maximizers strive to be the best, to complete perfect projects, and get the best deal, while satisficers are more easily accommodated and less demanding of themselves and others. This dimension of individual differences might profitably guide future research on money as drug or tool.

Good examples of the importance of status regularly originate with professional athletes since their contract negotiations are so deeply open to media coverage. When professional athletes who are already earning millions of dollars and are dominant members of their team argue that they are underpaid, they and their agents are staking claims on the need for maximized status (independent of how closely they consider their relationships with teammates). The leapfrogging that happens in this and other contemporary environments (Gerhart \& Rynes 2003) is driven in part by a concern for status in which salary is interpreted as a reflection of one's relative standing. In the movie Jerry Maguire (Brooks et al. 1996), when a dominant football player and his sports agent celebrate their goal of a superior contract and exclaim "Show me the money!," they might as well be shouting "Show me the status." L\&W acknowledge the roles of status in parts of their paper; however, (1) the distinction between money and status cannot be neatly made, and (2) the importance of concerns about status over the course of human evolution warrants closer focus.

\section{Sacredness in an experimental chamber}

\section{Vladimir A. Lefebvre \\ School of Social Sciences, University of California, Irvine, CA 92697. valefebv@uci.edu}

Abstract: I focus on the problem of whether a specific biologic basis exists for reinforcing the power of money. I argue in favor of its existence based on a new interpretation of data obtained in experiments with pigeons and rats in an experimental chamber. The experiments demonstrated that in the animals' behavior we can observe some features that had been considered pertinent to human beings only, such as making certain sources of utility "sacred."

We all know cases in which people agree to receive lower payment for work related to higher values than for equal work unrelated to such values. For example, a person requires smaller salary for participation in building a cathedral, than in commercial construction. Thus, some "agencies" where a person exchanges his labor for money possess a special quality that will be called sacredness (Lefebvre 2003). A person agrees to work for these agencies for smaller reward than for other agencies. Something similar can be observed in the behavior of rats and pigeons

Experiments with rats and pigeons were conducted in a chamber with two pedals (left and right keys), each connected to its own food-hopper from which food bits were distributed according to a special schedule (Baum 1974b). Animals were studied individually in a series of sessions; in each session a schedule of reinforcement was fixed for the pedals. An important detail is that the frequency of reinforcements could be regulated by the animal itself by means of multiple pushes on the pedals. In analyzing the animal behavior in the experimental chamber, we use the metaphor of an "agency": the left key with its food-hopper being the first agency, the right key with its food-hopper being the second agency. The animal behavior consisted of "addressing the agencies" and performing "work" by pushing a pedal, and this was reinforced with a scarce food supply.

For a time it seemed that in these experiments the animals chose a specific line of behavior which is described by the Generalized Matching Law (Baum 1974b), but recently Baum put forth a hypothesis that this law only approximately describes the behavior of animals and in reality there are two different behavioral patterns (Baum 2002). Analysis of these patterns allows us to suppose that in each session the alternatives (pushing a left or a right pedal) were polarized by the animal's cognitive system, and one of them started playing the role of the positive agency, and the other that of the negative one. By using the reflexive model of bipolar choice (Lefebvre 2004) we obtain the following correlation describing the behavior of the animals:

$$
N_{2} / N_{1}=\exp (-S) n_{2} / n_{1}
$$


where $N_{1}$ and $N_{2}$ are numbers of addresses to the positive and negative agencies, and $n_{1}$ and $n_{2}$ are numbers of reinforcements received from the positive and negative agencies during one session. The value of $S$ is constant on the entire set of sessions and $S \geq 0$.

Correlation (1) indicates the existence of the analogue to sacred behavior in animals. Let us demonstrate this.

It follows from (1) that

$$
n_{1} / N_{1} \leq n_{2} / N_{2} \text {. }
$$

Ratio $n_{1} / N_{1}$ can be interpreted as the mean payment for one appeal to the positive agency and $n_{2} / N_{2}$ as the mean payment for one appeal to the negative agency. We can see from (2) that, on average, the subject never requires more payment for one appeal to the positive agency than for one appeal to the negative one. Is it possible that in these experiments, we observe behavior evolutionarily preceding the sacral behavior of human beings? If it is so, then the sacral aspect of money has deep biological roots.

\section{Money and motivational activation}

\section{Arthur B. Markman, Serge Blok, John Dennis, Micah Goldwater, Kyungil Kim, Jeff Laux, Lisa Narvaez, and Jon Rein \\ Department of Psychology, University of Texas, Austin, TX 78712. markman@psy.utexas.edu

Abstract: Different aspects of people's interactions with money are best conceptualized using the drug and tool theories. The key question is when these models of money are most likely to guide behavior. We suggest that the Drug Theory characterizes motivationally active uses of money and that the Tool Theory characterizes behavior in motivationally cool situations.

Money acts as a drug or as a tool in different circumstances. We suggest that money acts like a drug when there is a strongly active current goal that may or may not relate to money. In contrast, money is treated as a tool in motivationally cool states, such as those for which there is significant psychological distance between the individual and the choice situation. To illustrate this point, we refer to specific data.

Research on mental accounting suggests that people set up mental accounts for different kinds of money to protect active short-term goals from desired long-term goals (Brendl et al. 1998; Shefrin \& Thaler 1992). This view is consistent with the drug theory of money. When people are faced with tempting short-term alternatives, they are likely to spend money without recognizing that money spent in the present has opportunity costs in the future. Thus, people create both mental accounts and physical forms of money that are hard to spend in order to create barriers that protect long-term goals, precisely because they cannot treat money as a tool (see also Zelizer 1994b).

Consistent with this interpretation, we have data suggesting that people do not recognize the general value of money as a tool in motivationally hot states (Brendl et al. 2003). In one study, we approached German college students who were cigarette smokers after they had completed a long lecture class (in which they were not permitted to smoke). Half of the students were kept in the classroom and were given a cup of coffee (which stimulated their need to smoke). The other half were brought outside the classroom, were encouraged to smoke, and were also given a cup of coffee. Thus, the participants inside the classroom had a high need to smoke, and those outside the classroom had a low need to smoke.

Participants were offered the opportunity to purchase raffle tickets for 25 pfennigs apiece. For half of the subjects, the prize was three cartons of cigarettes. For the other half, the prize was an amount of cash about equal to the cost of three cartons of cigarettes. Participants were only aware of the raffle they were offered. The students were told that the raffle drawing would be held the following week, so any prize could not be used to satisfy their current goals.

Those offered the raffle to win cigarettes were slightly more likely to purchase tickets when they had a high need to smoke than when they had a low need to smoke. This greater preference for a goal-related item when the goal is active than when it is inactive is called valuation. Of importance, students who were offered the raffle to win cash purchased tickets at a reasonably high rate when they had a low need to smoke, but rarely purchased tickets when they had a high need to smoke. This lower preference for a goal-unrelated item (cash) when the goal is active than when it is inactive is called devaluation (for more discussion, see Brendl et al. 2003; Markman \& Brendl 2005).

This finding suggests that cash is not considered relevant to the goal of smoking when people have a high need to smoke. This result is consistent with the drug theory of money, for money is being treated as a specific entity that is relevant in particular circumstances. Other needs, such as smoking, can lead to devaluation of money. Had money been conceptualized motivationally as a tool, then it should have been perceived to be relevant to any situation in which it could be used to purchase an object that would satisfy an active goal. On the basis of evidence like this, we believe that money is treated as a drug in motivationally active states.

There are also cases in which money is conceptualized as a tool. One area where this view of money is obvious is in studies of taboos and social exchanges. As an example of a taboo, Tetlock et al. (2000) showed that people find it morally repugnant for a hospital to consider denying an expensive treatment to a patient in order to save money for another hospital project. Even considering the proposal taints the decision maker.

As a second example, McGraw and Tetlock (2005) describe varieties of social exchanges. Most transactions in our culture permit money to be used freely. Indeed, currency is the basis of our day-to-day purchases. Nonetheless, we have certain special relationships for which money is inappropriate. If a neighbor helps us to fix a flat tire, we can reciprocate by helping him or her to rake leaves in the yard, but not by paying them money. An offer of money for help from a neighbor would likely be seen as an insult. As another example, parents perform duties for their children without keeping track of the effort spent and with no expectation that the effort will be returned in like kind. Again, the idea that parents would receive payment for their services is strange.

Determining that it is inappropriate to offer money directly in exchange for human lives or in certain close social relationships rests on money being recognized as a tool. A significant component of the negative reactions to these situations arises because people do not wish to place these dimensions into the market economy where they can be traded against other goods and services for which money can be used.

These moral and social exchange situations involve psychological distance between money and the situation in which money is used. Most considerations of the taboo uses of money involve situations in which one is not actively engaged in the choice process itself. Indeed, most of the evidence obtained by Tetlock and his colleagues is done using vignette studies that assess people's reactions to hypothetical situations. Likewise, our social relationships are maintained in situations that do not have strongly active goals relating to exchanges. Thus, it is easier in these contexts than in motivationally active contexts to treat money conceptually as a tool. 


\section{The investigation of neural correlates of monetary reward by using functional neuroimaging techniques}

\author{
Harold Mouras \\ Inserm, U742, Paris, F-75005 France; Université Pierre et Marie Curie-Paris 6 , \\ UMR S 742, Paris, F-75005 France and Socio-Affective Development Group, \\ Department of Psychology, University of Geneva, CH-1205 Geneva, \\ Switzerland. \\ harold.mouras@snv.jussieu.fr
}

Abstract: Money is a specifically human incentive. However, functional imaging techniques bring striking evidence that neural circuits pertaining to more "natural" addictive and rewarding processes are involved in response to monetary reward. Main results are evoked here, with specific brain responses demonstrated along the different stages of the process.

With regard to a drug theory of money, Lea \& Webley (L\&W) address the question: "Is there a biological reason why money is such a powerful incentive?" (sect. 1.5). Interesting results related to this question have emerged from modern neuroimaging techniques, and these results have converged with studies about decision processes in fields such as neuroeconomics (Glimcher \& Rustichini 2004).

Studies developed by Breiter and colleagues are of primary interest. After a focus on the effects of cocaine on brain circuits in a cocaine users sample (Breiter et al. 1997), neural circuits involved in monetary gain and losses were investigated (Breiter et al. 2001). A game of chance performed in the scanning session included an "expectation" phase where different possible monetary amounts were presented and an "outcome" with the presentation of the gain or loss. A striking result of this study was that an incentive unique to humans (i.e., money) induced brain activations in areas such as the nucleus accumbens, the sublenticular extended amygdala, and the orbital gyrus (in the prospect and outcome phases) that overlap brain activations observed in response to cocaine infusions in addicted subjects (Breiter et al. 1997) or to low doses of morphine in drug-naïve individuals (Breiter et al. 2000). Such an overlap could partly explain that a dysfunction in this cerebral network could contribute to impulse disorders, such as compulsive gambling.

The study performed by Breiter et al. in 2001 identified an overlap between cerebral areas involved in monetary rewards and those involved in drug addiction, but few differences were recorded in brain activations for different stages (e.g., the prospect and outcome phases) of cerebral processes related to monetary reward. The growing development of neuroimaging techniques has allowed several studies to focus on specific properties of the cerebral networks involved in response to monetary stimuli, and some results have identified brain activation differences occurring during different stages of the process. Based on primate work, Knutson et al. (2001a) used a parametric task that elicited anticipation of monetary reward or punishment. Within a sample of eight healthy volunteers, this study was the first to demonstrate a selective recruitment of the nucleus accumbens (a part of the ventral striatum) for monetary gain but not for loss; moreover, the activation was proportional to the amount of the reward. Most often, neuroimaging studies on the neural correlates of monetary reward have used tasks that involve prospect, choice, and outcome phases. As theses phases can be temporally close, the event-related functional magnetic resonance imaging (fMRI) method with a good temporal resolution should allow identification of specific brain activations related to these phases.

On this topic, a recent study by Ernst et al. (2004) brought very interesting results: whereas the prominent recruitment of the ventral striatum was confirmed, the choice phase involved more "cognitive" areas such as parieto-occipital ones (visuospatial attention), the dorsal part of the anterior cingulate cortex (conflict monitoring), parietal (manipulation of quantities) and premotor areas. This study also showed that high risk/reward conditions are associated with greater neural response during the choice phase but not the prospect phase. Likewise, were there specific brain activations that characterized the outcome of a monetary reward? With the same parametric task described earlier, Knutson et al. (2003) showed that a particular region of the mesial prefrontal cortex is activated when an expected reward is obtained, and a previous study (Knutson et al. 2001b) showed that this particular region is deactivaed in response to reward omission. Thus, the use of fast neuroimaging techniques would allow demonstration of a dissociation between ventral striatum areas involved in the prospect phase of the reward and more prefrontal ones involved in the outcome phase.

Clearly, neural circuits involved in the prospect and the outcome phases, although partly distinct anatomically, should be functionally linked. This point has been addressed in studies seeking to identify the reaction of monetary reward circuits when a difference occurs between the expected value and the real value of the monetary reward obtained. Still using eventrelated fMRI, Ramnani et al. (2004) examined cerebral activity related to the failure of expected rewards and the occurrence of unexpected rewards, independently of any goal-directed actions or decisions. Principally, this study showed that each type of prediction error evokes activity in a distinct frontotemporal circuit: whereas unexpected reward failure evokes activity in the temporal cortex and frontal pole (Brodmann area 10), unpredicted rewards evoke activity in the orbitofrontal cortex, the frontal pole parahippocampal cortex, and the cerebellum. The study also showed that the activity time-locked to prediction errors in frontotemporal circuits is involved in encoding the associations between visual cues and monetary reward. For the purpose of this commentary, this result is very important because it shows that neural mechanisms are not only temporary and activated either during the prospect phase, the stimulus presentation, or the outcome phase, but also that networks are devoted to the association between these successive phases.

Since 1999 several neuroimaging studies have explored the neural circuits involved in other goal-directed behaviors such as human sexual motivation (Mouras \& Stoléru, in press; Stoléru \& Mouras, in press). Following these reviews, several brain areas have been shown to be related to both monetary reward and sexual motivation. For example, most studies on neural correlates of sexual motivation have identified anterior cingulate cortex activations (often interpreted as involved in action preparatory processes), and a recent study by Williams et al. (2004) reported a similar role for monetary reward processes.

ACKNOWLEDGMENT

I would like to thank Naia Silveira for the correction of this manuscript.

\section{Avoiding drug dependency}

Paul Romanowich, Edmund Fantino, and Stephanie StolarzFantino

Department of Psychology, University of California, San Diego, La Jolla, CA 92093-0109.

promanowich@ucsd.edu efantino@ucsd.edu

sfantino@psy.ucsd.edu

Abstract: If Tool Theory is buttressed by fundamental concepts of conditioned reinforcement and extinction, a dependence on Drug Theory may not be necessary.

Lea \& Webley (L\&W) insist that a Tool Theory of money, which encompasses only purely ontological behavior, is inadequate to deal with the profound motivational power displayed by human behavior in relation to money. In their provocative analysis, the authors depend much on the notion that money "can mimic the satisfaction both from the instinct to play and from the 
instinct to trade" (sect. 5.3). Without a biological (evolutionary) basis, such motivators would be seen as "scandalous" from certain subsets of psychology. However, empirically based theories of motivation, such as the Premack Principle, explicitly state that any desirable behavior or tangible item can serve as a basis for motivation. Within this framework what qualifies for a motivator does not depend on its biological or adaptive value, but rather on the item or behavior's value in relation to all other possible behaviors or items. This idea about primary and secondary reinforcement is consistent with Skinner's behavioral position and suggests that it is unnecessary to consider Skinner's view as Drug Theory. Money has an important place in the hierarchy of value because of its flexibility. Not only can it be used to make other reinforcers available, but-like a good tool-it extends their reach, making them available at future times when they may be even more desirable than they are at present. It can be argued that computers, too, are extremely desirable tools because of their extraordinary flexibility; one notebook computer can replace a roomful of equipment. And, like money, computers are the objects of a great deal of preoccupation on the part of their users.

L\&W also assert that token reinforcers maintain their motivational power without explicit pairings with unconditioned reinforcers. Indeed, such reinforcers can exert motivational influence even when devalued or when presented in a different context (e.g., Fantino 2000; O'Daly et al., in press). However, such influence is typically fleeting. In fact, the authors point out that in many historical societies where rapid devaluation of currency occurred, the old devalued currency was abandoned and either money with a stable value was used or bartering ensued. This devalued money could then be used as a more literal "tool" as in Figure 1, which shows a woman in postWWI Germany using a pile of devalued Marks as kindling.

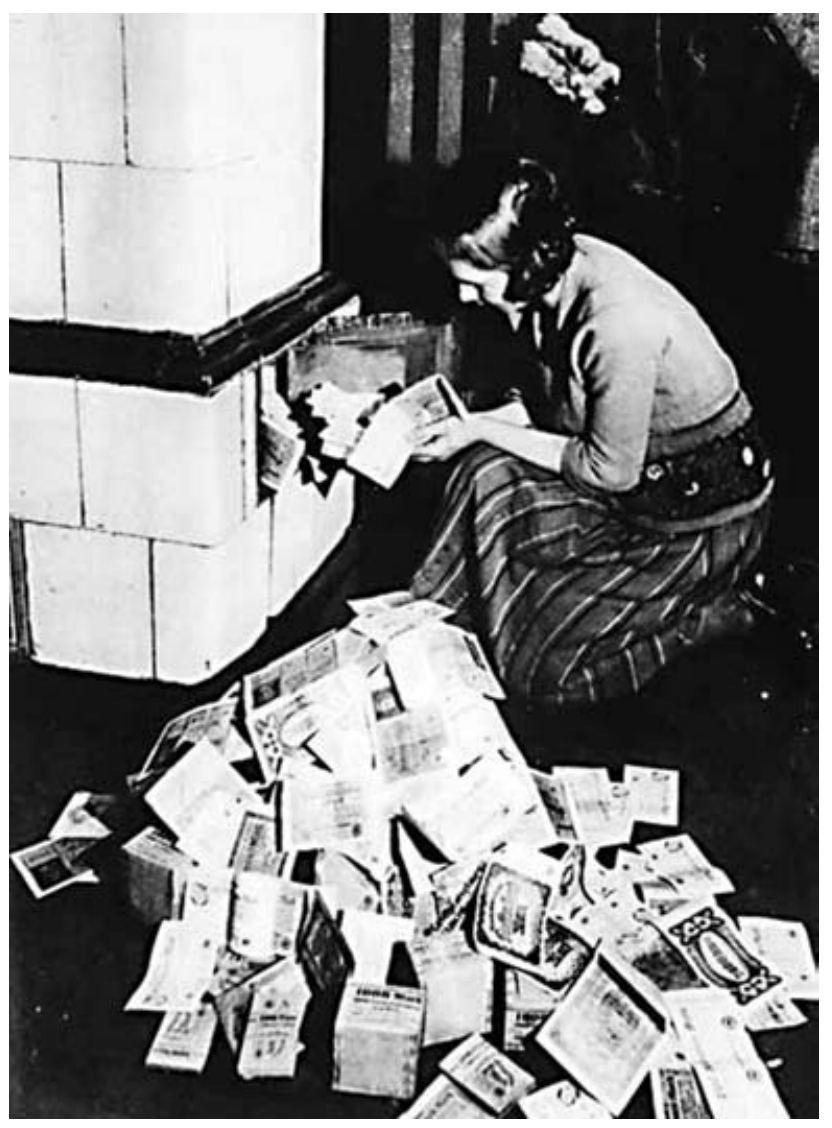

Figure 1 (Romanowich et al.). Inflation-1923. Devalued Marks are used as kindling in post-WWI Germany.
Extinction is a key component in the process of operant conditioning. When one tangible item or behavior leads to unconditioned or conditioned reinforcers, those tangible items or behaviors will be motivators. Other equally tangible items or behaviors that do not, or no longer, lead to reinforcers will not be motivators. This means-ends relationship is identical to Tool Theory. Drugs are no different in this respect. Once a drug no longer offers any physiological satisfaction, its use stops. This chemical action is biological, but obviously has no evolutionary advantage to the individual. In most cases, as the authors point out, the opposite effect can be observed. But, other conditioned stimuli may still elicit the craving for the drug. Presenting these conditioned stimuli without the drug also causes a decrease in that response. Therefore, drugs can also be thought of in a means-ends analysis when the concept of extinction is considered.

The proposition that seemingly ubiquitous human behavior can be explained in evolutionary terms (instincts) has led to gross overgeneralizations throughout the history of psychology (for a discussion, see Fantino \& Logan 1979, pp. 297-301). There is no doubt that the ontological biology of a person will change in response to the use of money or tokens (i.e., changes in neural circuitry will occur). But neural changes accompanying conditioning do not require Drug Theory. Tools, be they money or computers, are likely to be powerful generalized reinforcers since, as discussed above, they are paired with so many good things. A broadened concept of generalized reinforcers together with the concept of extinction can go a long way to making a dependence on Drug Theory superfluous.

\section{ACKNOWLEDGMENTS}

The image shown in Figure. 1 is "Inflation-1923.jpg," produced by AdsD der Friedrich-Ebert-Stiftung. The preparation of this commentary was supported by National Science Foundation Grant IBN-9870900.

\section{Evolutionary psychology and functionally empty metaphors}

\author{
Don Ross ${ }^{\mathrm{a}, \mathrm{b}}$ and David Spurrett ${ }^{\mathrm{c}}$ \\ ${ }^{a}$ Departments of Philosophy and Economics, University of Alabama at \\ Birmingham, Birmingham, AL 35294-1260, and ${ }^{\mathrm{b}}$ School of Economics, \\ University of Cape Town, Rondebosch 7701, South Africa; ${ }^{\mathrm{b}}$ School of \\ Philosophy and Ethics, University of KwaZulu-Natal, Howard College Campus, \\ Durban, 4041, South Africa.
}

\section{dross@commerce.uct.ac.za}

http://www.uab.edu/philosophy/ross.html; $\quad$ spurrett@ukzn.ac.za http://www.ukzn.ac.za/undphil/spurrett/

\begin{abstract}
Lea \& Webley's (L\&W's) non-exclusive distinction between tool-like and drug-like motivators is insufficiently discriminating to say much about money that is useful, as the distinction's equivocal application to sex, food, and drugs shows. Further, it appears as though the motivations of problem gamblers are non-metaphorically like those of drug addicts.
\end{abstract}

Lea \& Webley $(\mathrm{L} \& W)$ make clear that their topic is a choice of metaphors for money. They take care to distance themselves from the idea that one of their two favoured metaphors could be altogether "correct" at the expense of the other. So, arguing against them that money is not a drug but (more like) a tool, might seem to miss their point. We instead raise doubts about the value of their dichotomy of metaphors in the first place. We then say why there is indeed an interesting, but non-metaphorical, relationship between drugs and money.

L\&W's discussion depends on a distinction between motivators that directly subserve biological functions (tools) and what they call (in sect. 2.2.4) "functionless motivators" (drugs). They recognize that money serves some biological functions much of the time and so is, to that extent, a tool. But then they argue 
that it doesn't always serve this function, and even systematically subverts fitness in some circumstances (e.g., when used to facilitate transactions within families), and so is also, to that extent, a drug.

This distinction applies to too many things too easily. Most sexual activities of modern humans are recreational and costly, and so do not support, and sometimes subvert, their expected fitness. In wealthy societies, the same goes for food. Psychoactive drugs, for that matter, are also tool-like; consider the familiar sequence that begins with a drink bought in a bar and leads to the production of children. Perhaps L\&W would say that sex and food are both tool-like and drug-like, just as money is, while drugs are also tool-like. But metaphors are valuable only insofar as they discipline and structure thought. Contrasts that exclude nothing are (functionally) empty.

L\&W say things that suggest the following response. Sex and food are pre-cultural motivators, but money is not. Therefore, sex and food in general must be tools for enhancing fitness, whereas in the case of money the jury is out until we devote theoretical reflection to the matter. But L\&W have no independently stable ontology of types of motivators at their disposal. There is no human instinct for "sex in general"; there are just dispositions to particular sorts of sexual activity in particular sorts of circumstances and not any one of these dispositions is always fitness-promoting.

Our objection would be churlish if money were, like cocaine but unlike most sex, typically pathological with respect to function (fitness-enhancing or otherwise; again, sex is typically pathological with respect to fitness). But this would be so only if true miserliness - sheer hoarding of money for the sake of having it and not for status, security, and so forth-were widespread. Such miserliness is in fact extremely rare. (When they mention it in support of their argument, L\&W cite no prevalence studies, surprising or otherwise.)

The poverty of $L \& W$ 's case here is a special case of the poverty of a whole species of evolutionary psychology. This species aims to identify a restricted set of basic pre-cultural motivators. Then it hypothesizes modules for seeking and evaluating instances of these motivators. The modules, being narrow specialists, can be fooled into misevaluation by things that mimic the targets for which the modules were selected; these are drug-like rewards.

Human cognitive architecture is probably modular to some extent. But hunting for definite, cross-environmental reward types that are the agents responsible for selection of the modules reflects a simplistic and naive view of evolutionary dynamics and complexity. Such hunts can sometimes have heuristic value if they are taken with a pinch of salt and if the explanatory target has very shallow cognitive interpenetration - for example, human preferences for sweets and fats, or male heterosexual preferences for curvaceous women, the prototype instances that show off evolutionary psychology in its best light. Money isn't very much like ripe fruit or rounded hips in that respect - very little of widespread attraction to people is. So money, like almost everything, is tool-like and drug-like. Is saying this really a helpful contribution to scientific understanding?

$\mathrm{L} \& W$ twice allude to a truly powerful way of studying reward when they mention "neuroeconomics," including the study of differential brain responses to variances in reward types, frequencies, delays, and contexts. They are wrong, though, to cite neuroeconomics, specifically Glimcher (2003), as having identified a "trade module" or a distinctive neural response to traderelated stimuli. There is no such finding. What Glimcher and other neuroeconomists report are neural capacities to learn to predict values of rewards in many contexts, not in specifically trade-related contexts. In fact, the early progress in neuroeconomics is bad news for evolutionary psychology of L\&W's type, for it shows that brains nimbly learn to compare rewards across whole ranges of settings and cultural manipulations of setting (e.g., McClure et al 2004), not that they are systems that refer their input robotically back to a fixed stock of ancestral reward types and thereby get tricked in bars and casinos. Biological brains, that is, are multi-modal evaluation and resource allocation machines; it would be surprising if any creature capable of representing multiple such evaluations to itself proved incapable of latching onto money given the chance. Capuchin monkeys, for example, have been trained to use multiple fungible fiat currency (Chen et al., in press).

Study of the brains of problem gamblers suggests there is indeed an interesting relationship between drugs and money, but not one resembling L\&W's metaphor (see, e.g., Potenza et al. 2003). Problem gamblers don't appear to value money for its own sake. But they do appear to be typical, perhaps even prototypical, addicts. Cocaine addicts may not value cocaine for its own sake. Rather, gamblers and cocaine addicts have more difficulty than other people convincing their brains that they are receiving enough reward, at a fast enough rate, as a generalized target. Here reward just means: anything that mobilizes neural attention. Thus, as Rachlin (2000) has stressed, gambling and chemical stimulants are close substitutes for social interaction. Behavior with respect to money is just like behavior with respect to stereotypical drugs because money is such a reliable tool for getting what the brain is always looking for, namely, relief from boredom. But it isn't money itself that is the drug, it is gambling. Money in the gambling addict is - literally - a tool for getting drugged.

\section{Tools, drugs, and signals in the road from evolution to money}

\section{Federico Sanabria \\ Department of Psychology, Arizona State University, Tempe, AZ 85287-1104. Federico.Sanabria@asu.edu http://www.public.asu.edu/ fsanabri/}

Abstract: The problem of the biology of money is twofold: It subsumes both the identification of behavioral mechanisms that account for the power of money as an incentive, and the elucidation of the phylogeny of such mechanisms. The drugs-tool distinction, as articulated by Lea \& Webley $(\mathrm{L \& W})$ in their fascinating synthesis, is a welcome step toward their solution. Compared to the direct invocation of instinctual drives, however, conditioning processes provide a conceptually and empirically clearer road from evolution to money.

The nearly absolute displacement of weaker non-monetary modes of production by the global expansion of capitalist economies, begs the question that the authors ask: Why are people so interested in money? The answer is less trivial than it appears. The obvious answer is not incorrect, but rather, as is made crystalline in the target article, it is incomplete. To explore the shortcomings of that explanation, the authors have christened it as "Tool Theory," characterized its means-to-end connotations, and moved forward to evaluate one exciting possibility: that there is a biological rationale, beyond the mere utilitarian, for the rewarding character of money. For motivation theorists, the reality of a connection between biological functions and motives is as obvious as Tool Theory (e.g., Maslow 1943); nevertheless, biological explanations are, at best, a growing but still marginal element of economic discourse. The science of money is still disconnected from the science of life, and the target article insightfully points at issues that may bridge this gap.

The question of the biology of money is meaningful only if it inquires about how a specific motivated behavior (money seeking) is mapped to specific evolutionary demands. The conventional character of money and its short natural history, however, preclude any direct connection between money and nature. This point is well argued by the authors, who conclude that there cannot be a "money instinct." Consequently, the research question is only viable through a roundabout: Money 
must operate through basic behavioral mechanisms which themselves are related to (or, rather, must be related to) fitness maximization. The mediatory role of these presumed behavioral mechanisms breaks the problem of the biology of money into two parts: (a) what behavioral mechanisms are involved in money seeking (proximate causes)? and (b) what is the evolutionary rationale of such mechanisms (ultimate causes)? These two distinct problems are not clearly separated by the authors, as evidenced by the mechanisms selected for their synthetic theory of monetary behavior.

According to L\&W, money may be metaphorically described as a tool, or as a drug. These two functions are easily mappable to two general behavioral mechanisms familiar to behavior analysts: operant and Pavlovian conditioning. In operant terms, money may serve as the lever that, when properly manipulated, yields reinforcing consequences. In Pavlovian terms, money may serve as the cue signaling the availability of attractive stimuli, eliciting responses of approach and anticipation, among others. The tool versus drug distinction, however, does not fully match the operant versus Pavlovian dichotomy. Tools yield "real" rewards, whereas drugs are "nonfunctional" substitutes for "real" rewards. The tool-drug dichotomy presumably encompasses all possible motivational roles of stimuli like money, which in themselves are not "real" rewards. The terms in quotation marks are defined by their contribution to fitness. Certainly, operant and Pavlovian conditioning, as general mechanisms, are significant contributors to the fitness of complex organisms, and they are demonstrably facilitated by a congruency of stimuli and responses that is only attributable to evolutionary processes (e.g., Garcia \& Koelling 1966). But once operational, conditioning is agnostic of the "reality" of the reinforcement process. And so is money: it may work as a tool to obtain fitness diminishers like crack cocaine, and it may work as a "functional drug," signaling incoming food ingestion when we inspect our wallet in a restaurant. It is not clear how either one of these two cases fits the tool versus drug distinction. The completeness of the tool-drug approach is undermined when we consider the possibility of using a tool to obtain a drug, or of using a drug as a tool. The basic metaphors are conceptually close to conditioning mechanisms, but they need to reconfigure their link to selective advantage as a separate problem.

In the target article, the Skinnerian operant approach is described as a "Drug Theory" on the basis of its characterization of money as a conditioned reinforcer. Interestingly, "operant money theory" could be described also as a "Tool Theory" on the same basis, if one is of the persuasion that conditioned reinforcement derives its value from signaling the relative proximity of other reinforcing events (e.g., Preston \& Fantino 1991). If such is the case, there is no reason to agree with the authors' claim that conditioned reinforcers must work in the same way as unconditioned reinforcers. Furthermore, positive informative signals may elicit behavior completely unrelated to the signaled reinforcer (e.g., a ringing phone may signal an awaited call, but few would engage in a conversation with the phone), or very similar to the consummatory response (e.g., autoshaping in the pigeon; Allan \& Zeigler 1994). In other words, money, qua conditioned reinforcer, may be described as a tool or as a drug, and neither description appears to be exclusive. The compatibility of these descriptions is an issue that goes beyond money and into the discussion of the interaction/identity of operant and Pavlovian conditioning (e.g., Lajoie \& Bindra 1976).

Although reciprocal altruism and play may be involved in the interest for money, their invocation as instincts to explain monetary behavior is unwarranted. The connection between behavioral mechanisms and evolution is not examined to such an extent as to rule out the empirically verifiable possibility that both behaviors are derivable from general mechanisms. Consider the situation of cooperating in a prisoner's dilemma game, when playing against a perfectly reciprocating strategy (or tit-for-tat; Axelrod 1984). Sanabria et al. (2003) have demonstrated that pigeons may learn to cooperate in this game, but only if each choice between cooperation and defection produces a stimulus that is predictive of reciprocation (i.e., a conditioned reinforcer or punisher). Pigeons are obviously not hardwired to reciprocate the actions of a computer at the expense of immediate gratification, but they can learn it. Maybe money operates, partially, as an analogue of the cooperation stimulus, bridging over what we give up for money, and what we obtain for it.

The tool-drug metaphors bring economic motivations closer to their biological substratum, but they can be improved. Their symmetry with conditioning mechanisms suggests a fruitful course of action. These mechanisms may well function as mediators between evolution and some socially arranged behavior (Gutnisky \& Zanutto 2004; Skinner 1984). Such function, unlike instinctual drives directly linked to evolution, is readily verifiable in nature.

\section{ACKNOWLEDGMENTS}

Preparation of this commentary was supported by NSF IBN 0236821 and NIMH 1R01MH066860. Thanks to Peter Killeen for his feedback on early drafts of this commentary.

\section{Memetics and money}

\author{
Keith E. Stanovich \\ Department of Human Development and Applied Psychology, University of \\ Toronto, Toronto, Ontario M5S 1 V6 Canada. \\ kstanovich@oise.utoronto.ca \\ http://leo.oise.utoronto.ca/ kstanovich/index.html
}

Abstract: Lea \& Webley's (L\&W's) Drug Theory solves many puzzles surrounding money-related behavior. I explore supplementing the Drug Theory with ideas from gene-culture coevolution theory and memetic theory.

Lea \& Webley's (L\&W's) discussion of money as a drug represents an ingenious synthesis of disparate literatures. The theory is, however, specifically oriented toward explaining the origins of money ("our task is to offer the best account we can of the biological origins of the money motive"; sect. 1.4). I would like to raise the possibility that a theory that moves beyond the origins of money to focus on its ongoing manifestations might find a greater role for culture. That is, once money is in existence, the symbolic aspects of money-related behavior may function in such a way as to make them not simply classifiable as instances of the Drug Theory (as argued in sects. 3.3.2 and 5.2). To account for the ongoing manifestations of money-related behavior, I believe that the Drug Theory will need to be supplemented with ideas from gene-culture coevolution theory and memetic theory.

In L\&W's discussion, "function" always refers to biological function. This is true in both their Tool Theory and their Drug Theory. In the former, money gives indirect access to biological rewards, and in the latter, money "covers cases where it gives direct access to the systems that subserve such rewards but in an illusory, nonfunctional way" (sect. 2.3). But what about human goals and desires that have completely slipped their genetic/biological moorings? Neither the Tool nor the Drug Theory would seem to have much to say about such cases, or at least both theories need to be supplemented to encompass this situation. The alternative is to contest a fundamental assumption of most memetic theorists - that memetic goals can become detached from genetic fitness considerations and indeed can become detached from the interests of the vehicle (person) hosting them (Blackmore 1999; Dennett 1995; Stanovich 2004).

A view of money that recognizes memetic goals that are detached from genetic goals does have affinities with views in the modern sociology of money discussed by L\&W. However, 
broader notions of symbolization than those represented in the sociological literature might not be as easily subsumed under the Drug Theory - for example, notions of symbolic utility associated with Robert Nozick. Nozick defines a situation involving symbolic utility as one in which an action (or one of its outcomes) "symbolizes a certain situation, and the utility of this symbolized situation is imputed back, through the symbolic connection, to the action itself" (Nozick 1993, p. 27). Money use in highly affluent societies can often have this property. Nozick notes that we are apt to view a concern for symbolic utility as irrational when the lack of a causal link between the symbolic action and the actual outcome has become manifestly obvious, yet the symbolic action continues to be performed. Many dysfunctional interactions surrounding money seem to have this property of being detached from real-world outcomes and becoming attached to very abstract memeplexes (political memeplexes that seem to serve neither personal interests nor genetic interests come to mind). L\&W recognize the difficulty here when they acknowledge "that money is essentially a symbol, perhaps multiply symbolic (cf. Lea et al. 1987, Ch. 12), seems hard to reconcile with any kind of biological analysis of money motivation; it leads, furthermore, to a cognitive rather than a motivational analysis of behaviour towards money." This seems right, and the cognitive substrate that it relies upon would seem to be in the domains of simulation and metarepresentation (Carruthers 2002; Currie \& Ravenscroft 2002; Dienes \& Perner 1999; Nichols \& Stich 2003; Sperber 2000) - precisely the domains upon which memetic evolution is dependent.

If the origins of money are in the mechanisms outlined in the Drug Theory, then I would argue that a further exaptation has taken place in the service of memetic evolution. An exaptation for memetic purposes would likewise be consistent with the many findings of biological nonfunctionality that L\&W find supportive of the Drug Theory, and it would additionally be consistent with many findings in the heuristics and biases literature which show that interactions involving money are instrumentally irrational (Kahneman \& Tversky 2000; Raghubir \& Srivastava 2002; Shafir et al. 1997; Stanovich 1999), that they do not serve the interests of the individual (whether or not they are consistent with genetic fitness maximization; see Stanovich 2004).

In L\&W's Drug Theory, money parasitizes trading that is derived from reciprocal altruism. However, L\&W might just as easily (and additionally) have posited money parasitizing trading derived from strong reciprocity (Fehr \& Fischbacher 2003) - altruistic acts performed when no reciprocal benefit is possible. This uniquely human form of behavior is increasingly viewed as the product of gene/culture evolution (Fehr \& Fischbacher 2003; Gintis 2003; Gintis et al. 2003; Richerson \& Boyd 2005). This, in part, puts the Drug Theory on a memetic foundation as well as a biological one.

\section{Money motives, moral philosophy, and biological explanations}

\section{Adrian J. Walsh \\ Philosophy Discipline, School of Social Science, University of New England, Armidale, NSW, 2351, Australia. \\ awalsh@une.edu.au \\ www.une.edu.au/arts/Philosophy/STAFF/awalsh.htm}

Abstract: Lea \& Webley $(\mathrm{L} \& W)$ provide two alternative biological accounts of human monetary motivations, the Tool Theory and the Drug Theory. They argue that both are required for an adequate explanation. I explore the applicability of these models to philosophical discussions of how we might justify such motivations. I argue their approach is not entirely satisfactory for normative questions, since it precludes the possibility of rational non-instrumental attitudes towards money.
Lea \& Webley's (L\&W's) target article explores the important question of what the biological basis of our monetary motives might be. One obvious explanation involves their Tool Theory, according to which money is a tool and our reasons for desiring it are to be understood like our desire for any tool in terms of what other goods it is able to help us obtain (sect. 2.1). L\&W argue that while this has some intuitive appeal, a Tool Theory of money motivation fails to explain fully the strong pull of money as a motivator. A full explanation requires that we understand money as acting sometimes, in a metaphorical sense, as a drug. According to their Drug Theory, money intrudes metaphorically on the normal functioning of the nervous system: money acquires its incentive power because it mimics the psychological action of some other more natural incentive (sect. 2.2.4). Accordingly, it involves irrationality.

My interest here concerns money motives and morality. What applicability might this have to normative theories regarding the extent to which we should be motivated by money in the way that we so obviously are. For the moral philosopher, any interest here would be in justification rather than explanation. How well might L\&W's template fit onto the history of what R. H. Tawney (1926) called "economic casuistry"? Unlike more radical approaches that would cast all monetary motives as immoral, the economic casuist distinguishes between legitimate and illegitimate monetary motives.

We can discern two central schools of thought regarding money motives in this more moderate tradition. The first of these derives from the work of Immanuel Kant, and sees money as a tool or instrument which is only to be used for buying "tool-like" things. For Kant, money is a pure means. He contrasts this with persons who are ends-in-themselves and should be accorded respect in keeping with their status as persons. Kant argues that every thing has either a price or a dignity and if it has a price it cannot have a dignity (Kant 1785/1946). Although it is quite legitimate to regard mere things as means and therefore to ascribe to them a price, this is not the case with persons. Clearly, what we have here is a Tool Theory of normative evaluation. Money is a tool and it is wrong to treat persons as if they were tools.

The second great tradition is Aristotelian in origin and focuses on the role that money plays in the best possible life. Aristotle, and later philosophers such as Aquinas, regarded money as the very embodiment of an instrument and, as such, it could not be a proper end of activity (Aristotle 1952). However, immersion in commercial life often leads people to regard money as an endin-itself. For the Aristotelian this is an irrational mistake. In explaining this irrationality, Aristotelians focus on the inability of money to function as an ultimate goal. Proper activities have a realizable goal. When one aims to build a boat, one realizes one's goal when the boat is completed and ready to sail. But in the case of money there is no point at which one realizes one's goal of making money. Having no satisfaction conditions, it endlessly iterates (Walsh 2004). Obviously, this second tradition can be cast as a Drug Theory. According to the Aristotelian tradition, the person who takes the pursuit of money as their fundamental goal is irrational since the very nature of money is such that it cannot function in this way.

It appears, then, that L\&W's template fits neatly onto the two main ethical traditions in Western philosophy that seek to distinguish between legitimate or illegitimate money motives. These accounts of the moral difference conform either to the Drug model or to the Tool model, since the normatively undesirable motives here are either understood as cases of "inappropriate tool-treatment" or of irrational drug-like behavior. Built into such a model is the assumption that non-instrumental motives towards money must be irrational. We can see this assumption at work in L\&W's discussion of restrictions on money use (sect. 4.5). Money is said to function as a drug in those cases where it is "found to have a value and an emotional charge that are not predicted by its economic use" (sect. 4.11). If not a means, then the behavior belongs to the realm of irrationality. 
But should we accept this last assumption? In moral philosophy the suggestion that non-instrumental attitudes are fundamentally irrational is highly controversial. Value pluralists, such as Raz (1986) and Anderson (1993), have argued persuasively for the existence of forms of moral value that arise from the ideals and attitudes expressed in action itself, rather than its consequences. Anderson, in particular, explores how our use of money might express ideals and attitudes that in certain circumstances might be inappropriate. She claims that in such cases it is rational to refuse monetary exchanges on grounds which are fundamentally non-economic and which reflect the basic values of the agent concerned. This seems right, for surely one can refuse money for some good, no matter how much money is on offer, without being thought irrational. If this is correct, then there would appear to be cases in moral theory not covered by the Tool and Drug Models, at least as described - namely, those where one might rationally choose, on non-instrumental normative grounds, to avoid certain monetary transactions.

Although the account is insightful, my concern is that if it were to be applied in its current form to the normative realm, it would exclude rational non-instrumental attitudes towards money from the possible set of human motives in this area. This would be an undesirable outcome. A further question, which might be pursued elsewhere, concerns the extent to which rational non-instrumental attitudes towards money could have a role in biological explanations of our desire for money.

\section{Authors' Response}

\section{Money: Motivation, metaphors, and mores}

\author{
Stephen E. G. Lea and Paul Webley \\ University of Exeter, School of Psychology, Washington Singer Laboratories, \\ Exeter EX4 4QG, United Kingdom. \\ S.E.G.Lea@exeter.ac.uk P.Webley@exeter.ac.uk \\ http://www.exeter.ac.uk/ SEGLea \\ http://www.exeter.ac.uk/ pwebley
}

\begin{abstract}
Our response amplifies our case that money is best seen as both a drug and a tool. Some commentators challenge our core assumptions: In this response we, therefore, explain in more detail why we assume that money is an exceptionally strong motivator, and that a biological explanation of money motivation is required. We also provide evidence to support those assumptions. Other commentators criticise our use of the drug metaphor, particularly arguing that it is empirically empty; and in our response we seek to show how it can be submitted to test - aided by some commentaries which suggest such tests. In addition, we explain, with evidence, why we do not think that the notion of money as a generalised conditioned reinforcer provides a satisfactory alternative to the tool/drug account. The largest group of commentaries suggests alternative instincts on which the drug-like effects of money might be based, other than the reciprocation and play instincts we propose; in our response, we explain why we still prefer our original proposals, but we accept that alternative or additional instincts may indeed underlie money motivation. A final group of commentaries carries the argument further, suggesting extensions to the tool/drug model, in ways with which we are broadly in sympathy. The purpose of the tool and drug metaphors is to encourage reflection on the biological origins of money motivation, and to that extent at least we believe that they have succeeded.
\end{abstract}

\section{R1. Introduction}

Our target article started from four core assumptions (sect. 1): (1) For humans (but not for other species), money has an extraordinary incentive power, similar to that of other motivators such as food and sex. (2) Whereas the incentive power of food, sex, and most other motivators is easily understood in biological terms, that of money is not. (3) A biological explanation of the incentive power of money therefore needs to be provided because "the science of money is still disconnected from the science of life" (to use Sanabria's elegant expression), and the gap needs to be bridged. (4) This task has hitherto been neglected.

From those assumptions we argued, through a consideration of past theories and current data, to three conclusions (sect. 5.4): (i) The "obvious" Tool Theory of money motivation, according to which money is valued because it enables us to fulfil other biologically explicable instincts, is inadequate; (ii) the inadequacies of a Tool Theory can be overcome by combining it with a Drug Theory, according to which money provides illusory fulfilment of other instincts; and (iii) the instincts for which money particularly provides illusory fulfilment are the instincts to trade and to play.

We predicted (sect. 5.4) that our three conclusions would find decreasing levels of acceptance, and a reading of the commentaries bears this out. Similarly, not all of our assumptions were challenged: everyone pretty much agrees that the biological explanation of the money motive has been neglected. However, by no means does everyone agree that such an explanation is needed; some commentators clearly feel that the biology of money has been neglected, is continuing to be neglected, and ought to be neglected further.

Hence, we can divide the arguments in the commentaries into those that challenge our assumptions; those that (broadly) agree with our assumptions but challenge our conclusions, because they challenge the arguments by which we reached them; and those that accept our assumptions and our conclusions as far as they go, but seek to extend them in various ways. Naturally, several of the commentaries involve elements of all three of those positions. In responding to the commentaries, therefore, we reflect on these three approaches in succession, rather than taking each commentary in turn. We start with a response to critiques of our assumptions.

\section{R2. Money is an important human motivator}

Several commentators (e.g., Burghardt, Glassman) challenge our assumption that the money motivation is unique. To some extent these challenges miss the point of our article. For example, we have no problem with the fact that human sexual motivation is decoupled from procreation (Ross \& Spurrett); that does not undermine its biological continuity in the terms in which we define it (sect. 1.4). A more serious challenge, however, is Furnham's claim that money is not in fact a very powerful motivator. Furnham argues that money is actually a hygiene factor (in the sense of Herzberg et al. 1967) rather than a motivator. In support of this claim, he points out that at least some affective associations with money are in fact negative, 
and that this is not what one would expect from a cognitive drug, nor from something that is a strong motivator.

It is fundamental to our argument that money is a powerful motivator. Accordingly, at the risk of belabouring the obvious, we need to briefly review some of the evidence that supports our position. Such evidence comes from everyday discourse, the stylised facts of the ordinary labour market, empirical studies of some less usual markets, and finally from direct experiment. The culturally invasive nature of money, which we discuss in section R4.1 of this response, provides additional evidence.

\section{R2.1. Everyday discourse: Proverbs, aphorisms, and familiar quotations}

Both formal literature and traditional wisdom contain large numbers of aphorisms and comments referring to money. Indeed, there are so many that Furnham and Argyle (1998) are able to open each of their chapters with a list, and Jackson (1995) has collected a comprehensive anthology. Formal analyses of such lists have been carried out: for example, Doyle and Li's (2001) comparison of Chinese and Japanese proverbs about money.

Examination of lists of such aphorisms suggests that they fall into two types, which we call the cynical and the sceptical. Cynical aphorisms assert the power of money, in the face of explicit or implicit protestations to the contrary. Sceptical aphorisms assert the limitations of the power of money, in the face of an assumed consensus that such limitations barely exist. It might be thought that the two groups cancel each other out. However, given the social function of aphorisms, it is clear that both types are evidence that there is a widely held belief in the power of money.

Examples of cynical aphorisms include: "[Money] is the sovereign queen of all delights: for her the lawyer pleads; the soldier fights" (R. Barnfield, spelling modernised from the 1598 original); "What makes all doctrines plain and clear? - About two hundred pounds a year" (Butler); "Wine maketh merry; but money answereth all things" (Ecclesiastes 10:19) (all quotations from Benham 1935).

On the more sceptical side we have, from the same collection (Benham 1935): "No man's fortune could be an end worthy of his being" (F. Bacon); "A good name is rather to be chosen than great riches" (Proverbs 22:1); "Honour and money are not found in the same purse" (Spanish proverb).

Of course, literature as such is not evidence. But these sayings are evidence that people have long believed money to be a powerful force, and that some people have believed it to be a dangerously powerful force in people's lives.

\section{R2.2. Stylised facts: The labour market and crime}

The second line of evidence for the power of the money motive again comes from the realm of everyday experience, though it belongs to the academic disciplines of labour economics and occupational psychology and partly to criminology. Put crudely, there is no job so unpleasant, hazardous, or immoral that no one will take it if the pay is right.

This generalisation may seem questionable. In any society, there are some people who refuse to take the only jobs offered them for the pay they are offered, preferring to become marginalised or outcast, or to work in the subsistence economy. There are jobs that people take only with great reluctance, and where the pay has to be at a premium because of their non-pecuniary disadvantages: prostitution and related occupations such as topless dancing are the obvious examples (see Reynolds 1986; Thompson et al. 2003). But the evidence of labour market history is that there is no job that absolutely no one could be induced to do, if sufficient money was offered. And beyond legitimate employment, it is clear that if a crime is apparently profitable, there is no level of punishment, up to and including death, that will completely eliminate it so long as there is some chance of escaping detection. In the right circumstances, then, money has the capacity to overwhelm all other motivations.

We are not saying that the money motive is all-powerful. We are not saying that anyone can be persuaded to perform any act for enough money: some people are able to resist bribery. But the same is true of other powerful motives; the power of hunger or sex are not disputed because some people manage to fast and many people are sexually faithful.

\section{R2.3. Empirical studies: Unusual markets}

Just as some people will, under some circumstances, do almost anything for money, so also some people, under some circumstances, will sell almost anything for money. The most discussed example in the recent literature is the sale of organs for transplantation, particularly kidneys, and there is extensive discussion in the medical ethics and policy literature as to whether this should be encouraged or not (e.g., Kahn \& Delmonico 2004). Significant numbers of people have made this kind of sale: Goyal et al. (2002) found more than 300 individuals who had done so in one city in India - about . $05 \%$ of the population.

In everyday speech, someone who would do anything for money is described as being ready to sell his grandmother. There is no formal evidence that people do exactly that, but they will certainly sell their children. The widespread tradition of brideprice is, objectively, a matter of selling a daughter, though it might be thought a relatively innocuous example. The public concern about international adoption in recent years has partly been driven by the possibility that it can lead to the sale of children (Hollingsworth 2003). It is also claimed that child prostitution in developing countries often involves the sale of children by their parents. Some widely circulated stories (see, e.g., Flowers 2001) are hard to document, but even authors who are sceptical of them recognise that there are parents in some of these countries who are willing, however reluctantly, to be supported by their adolescent daughters' earnings from the sex trade (Bagley 1999).

As in the case of crime, the existence of these markets does not mean that people are universally or even commonly willing to sell their body parts, or their children, for money. What it does show is that in the right circumstances, the money motive will overwhelm even the motives to preserve one's own body and one's own descendants. Biologically speaking, that places the money motive at the highest level there is. 


\section{R2.4. A formal demonstration of the strength of the money motive}

Few experimental psychologists have thought it necessary to demonstrate the strength of the money motive. However, Schwab (1953) has reported an experiment in which he asked patients to hang from a horizontal bar in a gymnasium for as long as they possibly could, which turned out to be about 45 seconds. If he subjected them to "suggestion and strong urging (hypnosis in some cases)," they managed to hang on for somewhat longer, about 75 seconds. But if he held out a $\$ 5$ bill (worth around $\$ 30$ at today's prices), and told them they could have it if they beat their previous records, they managed to hang on for an average of 110 seconds. Any incentive that enables someone to perform at tasks at $250 \%$ of their previous best level has, we argue, some right to be regarded as strong.

\section{R2.5. Is money a uniquely human motivator?}

While not questioning the strength of the money motive for humans, Ross \& Spurrett raise the possibility that animals other than humans can also acquire the motivation to use money. They cite the results of Chen et al. (in press), showing that capuchins would trade tokens with an experimenter in exchange for food reward. Impressive as these results are, they do not add anything in principle to other demonstrations of conditioned reinforcement in animals. A number of other commentators have also suggested that conditioned reinforcement provides an adequate alternative biological explanation of the money motive. We respond to this argument later, in section R6.2.

\section{R3. Money motivation is unusually difficult to explain biologically}

Few if any commentators suggest that money is easy to explain biologically. However, some commentators question whether it poses a special or unique difficulty. Essentially they argue that many or even all human motivations are so transformed by our uniquely cultural biology that they are as detached from any obvious function as money is. As we have pointed out in the preceding section (R2), however, this is to misunderstand what we mean by biological continuity. Continuity does not require that a human function is identical to that of other primates. It does require that there should be a plausible path of evolutionary and historical development from the kind of motivations seen in other animals (and, therefore, presumably shown by our prehuman ancestors) to those seen in modern humans. There is a plausible path from chimpanzees' monkey hunting (Teleki 1973) to "Laughing Stock Farm pork cooked two-ways with winter squash and red wine panade and Belgian endive" at Chez Panisse; but there is no such path to the platinum American Express card with which we might pay for the dish. We do not even know where such a path would start.

\section{R4. The culture and biology of money}

Commentators differ sharply on whether there is a real need for a biological explanation for money in the sense in which we mean such an explanation. A number of commentators express concerns about our biological approach to money, feeling that in taking this approach we had paid insufficient attention to cultural and social explanations. This view is expressed most forcefully by Belk, who claims that money motivations are learned along with civilising rituals that overcome rather than indulge basic motivations. Others (Jorion, Kniffen) have drawn attention to the significance of money as a marker of status. The general issue here is the nature of the relationship between biology and culture: behaviours may be largely determined by genes, there may be gene-culture coevolution, or behaviours may be "off-the-leash" and basically culturally determined.

\section{R4.1. Is money purely cultural?}

The most radical alternative to our kind of biological explanation is the one that we identified early in the target article (sect. 2.3): money must be understood purely at a cultural level, detached from human biology except insofar as biological evolution has given humans the capacity to be cultural beings. The position taken by Belk seems to us to fall within this camp; where we see drug-like effects, he sees the effects of social ritual. The trouble with this position, as we have argued elsewhere (Lea \& Webley 2005), is that, like nineteenth- and twentieth-century economic theory, it "abolishes the body" (Gagnier \& Dupré 1999). Of course, we cannot abolish culture either: we are not proposing, as Belk seems to suggest, that children come into the world desiring money. We entirely agree that they have to learn the desire for money - that is precisely why it is biologically problematic. As economic psychologists we have a responsibility to account for tastes, in Becker's (1996) phrase: we have to explain why this particular desire is learned when other possible desires are not, and why this desire becomes so strong. If money motivation is indeed learned in the same way as manners are learned (as Belk argues), then either people should be a lot less interested in money, or we should be a lot better mannered. To put it another way, if money is a pure cultural artefact and behaviour towards it a pure function of ritual, then its presence or absence in societies, the forms it takes, and the taboos about it, would be essentially arbitrary, constrained only by history. They are not, and the evidence on the cultural history of money shows that they are not.

Money is not an inevitable result of human culture. A great many of the world's cultures did not use any form of money until they came into contact with the European or East Asian cultures that had invented the kinds of money we are familiar with. Complex economies could be sustained by other means, such as systems of ritual (see, e.g., Dole \& Carneiro 1958) or barter (Chapman 1980; Humphrey \& Hugh-Jones 1992). A large number of "primitive" societies did use money, however, and studies in economic anthropology have shown that their moneys included a wide range of materials. Some examples are listed by Einzig (1966) and they include familiar examples such as cows and cowrie shells, but also less likely sounding objects such as bolts of cloth, granite boulders, pearl necklaces, and woodpecker scalps. Compared with this rich array of different money substances, the number of independent inventions of money seems to have been quite small, probably fewer than twenty 
(Grierson 1978). So all the different money-using societies must have acquired the idea of money from this relatively small number of roots, with subsequent cultural radiation of the actual substances used as money. This shows that the money idea is culturally highly contagious, or, to put it another way, powerful. If a money-using society and a non-money-using society come into contact, it is likely that the non-money-using society will adopt money; it is unheard of for a money-using society to stop using money. Furthermore, the developed world's style of money, using coins, notes, and bank accounts, seems to be as dominant within money use as money use is over other exchange systems. When modern money makes contact with a more primitive money system, even though there may be some initial resistance, the modern form quite quickly displaces its primitive competitor.

We conclude from this evidence that money in general, and modern forms of money in particular, are culturally invasive. This in turn suggests that they are not arbitrary; rather, they are peculiarly compatible with enduring features of human nature, and it follows that if we are to understand money fully, we must understand its biological as well as its cultural history.

\section{R4.2. What kind of biological explanation should we have?}

Some commentators accept, to a greater or less extent, that a biological explanation is needed, but disagree with the particular kind of biological explanation we seek to provide. We are accused of peddling a style of evolutionary psychology which is universalistic (Agassi), or intellectually feeble; of relying on modular explanations (Ross \& Spurrett); of not being part of a naturalistic evolutionary science (Burghardt); or of believing that brains can use coins as neurotransmitters (Booth).

We will turn to Burghardt's and Booth's comments in sect.R4.4 below. On the issue of modularity in human cognition (or motivation), our target article takes no explicit position. As a matter of fact, we prefer to construe evolutionary psychology in the broad sense rather than the narrow sense: we are much more persuaded by the assumption that modern human behaviour can be interpreted in the light of evolutionary theory, than by the details of Tooby and Cosmides" "adaptive toolbox" (Lea, in press; for the distinction between broad and narrow constructions of evolutionary psychology, see Buller 2005). We might argue that the idea of a restricted set of pre-cultural modules is more plausible in the motivational than the cognitive realm, but we would be quite happy with the idea that money motivation arose as a flexible extension from some other human motivation that has a convincing biological basis. However, the case for that idea has yet to be made. We argued in the target article (sect. 5.1) that the Drug Theory of money is feeble unless we can specify what biologically-grounded motives money mimics. The same is equally true of any alternative that is offered: If money motivation is to be explained as a result of the flexibility and situationdependency of human motivation (cf. Ross \& Spurrett), that argument needs to be filled out with specific and testable proposals as to what flexibility, applied to what motivations, in what situations, has produced modern levels of motivation towards money.

\section{R4.3. Gene-culture coevolution}

Stanovich takes a more radical, and to us a more interesting, approach to biological explanation: he argues that, in order to explain current behaviour with money, a biological approach needs to be supplemented by a cultural approach (specifically ideas from gene-culture coevolution and mimetic theory). He believes that there are a number of human goals and desires that have "slipped their genetic/biological moorings," that money is one of these, and that this leads to situations where money becomes attached to abstract "memeplexes." Although we might wish to disagree with some of the details of Stanovich's proposals, we agree with the general position that human behaviour has to be understood in terms of gene-culture coevolution, and that this applies to economic behaviour as much as to any other behaviour (cf. Lea \& Newson 2005). In our view, nature-nurture arguments are sterile, and in arguing for a biological basis for money motivation we certainly are not arguing against a cultural basis for the expression of that motivation. Neither could exist without the other. Therefore, we agree with Jorion's position that analysing money as a cultural phenomenon does not preclude tracing it back to its biological basis, though we disagree with his conclusions from that position (see sect. R5).

\section{R4.4. The problem with instinct}

Finally, and inevitably, we need to explain again our use of the term "instinct." Both Behrendt and Burghardt seem to misunderstand it. Although we have no quarrel with the Lorenzian concept of fixed action patterns, or with ritualisation as a possible account of their emergence, we are not talking about this kind of microinstinct (cf. Lea 1984) but about instinct in the sense of a reasonably universal human motive of plausibly biological origin. Behrendt has no problem with a biological approach as such; for other commentators (e.g., Booth), using the term "instinct" seems to suggest that our argument can be dismissed as biological determinism. But, as we point out repeatedly (e.g., sect. 1.4 of the target article and sect. R4.3 above) and as most commentators (e.g., Agassi) understood, we are fully of the view that culture plays an essential and codetermining role in human behaviour. It is hard to understand how Booth, for example, can think that we would deny that acculturation is involved in pornography, when we proceed to discuss pornographic texts. Does he think we believe that children are born with an instinct to speak English or French? The idea of an instinct, however, remains essential for distinguishing between motivations like hunger, that do have obvious biological origins and are universal or nearly so, and those like the desire for money, that are not universal and have no obvious biological origins.

\section{R5. Is Tool Theory enough?}

We turn now to those arguments that (to a greater or less extent) accept our initial assumptions, but reject our conclusions. We consider first a set of critiques that essentially argue that a tool theory, suitably modified, can provide an adequate biological account of money motivation. 
Among these arguments we classify those put forward by Jorion. He makes three main claims: (a) that "for anyone below the poverty line, cash remains foremost the means to the essential end of subsistence," and therefore, that no explanation of the desire for money is needed for the very poor; (b) that the drive to acquire money is a special case of the drive for recognition (for the desire of desire); and (c) that people who are admired (desired) extend the range of their partners - in other words, that cash is a universal tool for reproductive advantage. It is useful to consider Kniffen's complementary commentary at the same time. He claims that the distinction between money and status cannot be made easily and that the importance of status in an evolutionary context deserves looking at (status can motivate individuals, relatively high status then translates into reproductive fitness).

We disagree with the first of Jorion's points. The fact that money is spent on food does not mean that no explanation of the desire for money is needed - in our terms, what Jorion is saying is that among very poor people, the desire for money is fully explained by its use as a tool. We do not find this convincing because for most of history money has not been used by poor people to obtain subsistence, nor was it even very useful for doing so. Until the mass urbanisation of the twentieth century, for most people in the world (and especially for most poor people) cash was not in fact important for subsistence. Food was something one farmed or hunted, and most other things that provided for people's basic needs were not part of the cash economy. This is still true in many parts of the world, if not for the majority of the population. So the desire to have money seems to have no necessary connection with the need for subsistence. Furthermore, Jorion's second and third points (and those of Kniffen) essentially claim that money equals status. Put simply, people want money for the goods they can obtain, goods give them status, and status leads to higher inclusive fitness. This is very clearly a tool theory of money. In the target article we devoted much space to showing that tool theories as a class are not wrong but inadequate, because money has an emotional value that is not predicted by its role as a tool.

We agree with the idea that status leads to greater inclusive fitness, and money (representing overall assets) obviously plays a part both in signalling status and in securing its benefits. But we find it hard to believe that this is where the biological roots of the desire for money are to be found. Two points are relevant here: the idea of spheres of exchange (discussed in the target article) and the role of money in subsistence societies. On spheres of exchange, it is arguable that money does not provide access to women, whereas other status markers do (Bohannan 1959). On the role of money, there are many societies that have had money in some form for centuries or even millenia, but where the cash economy is a very recent development. Polynesia is a good example: the core of Polynesian society was land and the sea (and their products), not cash. And it was chiefs, not the market, who controlled and distributed land and produce.

\section{R6. Critiques of Tool/Drug Theory}

The majority of commentators accept that a pure Tool Theory will not do. However, many do not agree with our second conclusion, that its inadequacies are best remedied by supplementing it with Drug Theory (of course, some welcome this conclusion, e.g., Ainslie; Dewitte; Markman, Blok, Dennis, Goldwater, Kim, Laux, Narvaez \& Rein [Markman et al.] and some others share our belief that money is valued for more than its exchange value even if they do not find the tool/ drug dichotomy helpful, e.g., Behrendt). Two classes of critique emerged: attacks on the tool/drug metaphors as such, and alternative proposals for overcoming the deficiencies of Tool Theory, of which by far the most significant is the proposal that operant conditioning could bridge the gap between biology and money motivation.

\section{R6.1. The use and abuse of metaphor}

The most trenchant comments on the tool and drug metaphors are those from Ross \& Spurrett and Burghardt. Both claim that the distinction between tool-like and drug-like motivators is vacuous and could be applied to virtually anything that is desired (e.g., automobiles, clothing, sex, food). Furnham claims that anyway, Tool/Drug Theory is simply a classificatory device for all other theories and has very limited incremental validity; furthermore, he disputes our classification of historic theories as "tool" or "drug," implying that the distinction is not well defined. Other commentators feel that our notion of a cognitive drug is poorly specified (Belk) or incoherent

\section{(Booth).}

It is important to be clear about what we are claiming in the target article. Tool Theory and Drug Theory are indeed broad classes of theories rather than theories in themselves. (Furnham is right that this is a classificatory device.) They are two distinct general ways of explaining money and, as Walsh says, this is a distinction that fits neatly into the two main ethical traditions in Western thought as they try to distinguish between legitimate and illegitimate uses of money. On the one hand, Kant asserts that money is a "pure means" - in our terms, a tool - whereas persons are "ends in themselves," and ethical rules about the roles of money in society derive from the fact that, in Walsh's words, "Money is a tool and it is wrong to treat persons as if they were tools." On the other hand, Aristotle recognises that some people pursue money as an end in itself (as Walsh notes, a Drug theory), but condemns such people as irrational because in reality money can only be the means to an end and not the end in itself. According to a Kantian analysis, therefore, drug-like uses of money are wrong because money is a tool and to use it as a drug offends against the dignity of persons. And according to an Aristotelean analysis, money can be a drug but to use it as one is wrong because it is irrational. We are not claiming that these classes of theory are unique to money, and in fact it would be surprising if they were. Just like money, clothing and cars can be either a means to an end (clothes might help you get a job, a car might help you get a partner) or an end in themselves (clothes keep you warm or dry, cars get you from A to B as Burghardt's professor pointed out). So we agree that our tool/drug distinction could be applied to other areas; indeed, in the target article we cite Mintz's (1986) argument that sugar should be regarded as a "drug food." But we are not aware of a wide range of car or clothing behaviour that needs to be explained, or car 
and clothing theories that need to be classified, whereas money motivation is in serious need of deeper explanation than it currently receives.

The idea of a cognitive drug was felt by some to be weak. According to Booth, the only cognitive drug we mention is pornographic pictures and text - and "there is little or no evidence for innate sexual arousal at the sight of the real thing." What we actually say (sect. 2.2.3) is that we can be emotionally engaged by many kinds of text and that any such text can be thought of as a cognitive drug. Pornography is just an extreme example. Fiction and film are more general examples: these elicit responses (tears, laughter, fear) without the effects that make these responses adaptive.

On one point, we entirely agree with these critiques of Drug Theory. As we argue in section 5.1, a drug theory of money is only useful if one can specify what the natural incentives are that money mimics (see sect. R4.2). Tool/Drug Theory as such may well be difficult to falsify, an issue that bothered Bouissac and Ross \& Spurrett, though Kemp \& Grace manage to derive a testable prediction from it. However, what Drug Theory does is to direct attention to the question: What more ancient motivations is money motivation related to? Hypotheses of this kind - specific drug theories, if you will - are potentially falsifiable, though, like all evolutionary hypotheses, they need to be specified in a disciplined manner.

\section{R6.2. Is operant psychology enough?}

Three commentaries (Romanowich, Fantino \& StolarzFantino [Romanowich et al.]; Sanabria; and Kemp \& Grace), in rather different ways, make the case that operant psychology could provide the necessary link between evolution and socially maintained behaviours, such as those associated with money. For these commentators, the idea that money functions as a powerful generalized conditioned reinforcer is not a pure drug theory (as we claim in sect. 3.2.2 of the target article) but can encompass all the phenomena we attribute to both drug and tool theories - especially if the phenomena of negative reinforcement and extinction are properly taken into account. If this argument is correct, it would make our tool/drug distinction redundant. The argument of these commentators is attractive because it appears to place the biology of money within a well-established framework of experimental facts about conditioned and token reinforcement. However, the evidential base for the claim that conditioned reinforcement can explain human interest in money is in fact much weaker than is often claimed. It rests on unproved assertions about animal behaviour, and unproved generalisations from animal behaviour to human behaviour.

The basic assumptions required to underpin the assertion that conditioned reinforcement can provide a biological account of human money motivation are the following:

1. Arbitrary stimuli (including physical tokens) associated with reinforcers can acquire reinforcing power, and are then called conditioned reinforcers.

2. When stimuli such as tokens are paired with multiple unconditioned reinforcers, they can become associated with all of them.

3. Conditioned reinforcers associated with multiple unconditioned reinforcers will show a reinforcing effect regardless of whether the subject is motivated to obtain any particular associated unconditioned reinforcer.

4. Such functionally autonomous conditioned reinforcers will be unusually powerful.

5. These phenomena are shown in a wide range of species and thus result from biological processes that are common to humans and our prehuman ancestors.

If all these assumptions were true, conditioned reinforcement would indeed do the job that the commentators want it to do. Kemp \& Grace furthermore point out that if the conditioned reinforcing effect was based on avoidance learning, we might expect it to be highly resistant to extinction, and we agree that that could happen. Nor do we question proposition (1): conditioned reinforcement is a real phenomenon (and both Kemp \& Grace and Chandrasekharan present physiological data that offer a mechanism by which it might work). The problem is that (1) is the only one of the five propositions that is well supported by data from any species other than humans. Virtually all studies of token reinforcement (or other kinds of conditioned reinforcement) involve pairing the token with a single type of unconditioned reinforcer. Under these circumstances, the incentive value of the token then varies as a function of deprivation states that affect the incentive value of the unconditioned reinforcer. This is as true of modern demonstrations of token exchange in an avowedly economic context (e.g., Chen et al., in press) as it is of the classic operant experiments on token reinforcement described, for example, by Kelleher (1957; 1958). Even proposition (2) fails: it has proved very difficult to link conditioned reinforcers to more than one unconditional reinforcer at all (Lea \& Midgley 1989; Midgley et al. 1989). Consequently, there is no evidence to support (3) or (4).

Furthermore, in relation to proposition (5), the simple application of principles of animal operant psychology to human behaviour has been proved to be highly problematic (e.g., Horne \& Lowe 1993). We therefore need to look for direct evidence of functional independence in human conditioned reinforcement. But the evidence for conditioned reinforcement from studies with human participants is slender. It is certainly true that token reinforcement systems can work very powerfully with humans, as in the classic studies of token economies (e.g., Ayllon \& Azrin 1968); however, in all such studies, it is entirely possible that it was the clients' prior understanding of money that allowed the token economy to work, rather than the success of token economies providing evidence for a Skinnerian explanation of money. In sum, the explanation of money as a generalised conditioned reinforcer is at present no more than a plausible speculation.

For these reasons, we do not believe that the conditioned reinforcement theory can replace the Tool/ Drug Theory, at least in the present state of the evidence. Nonetheless, it remains one of the best articulated accounts of money motivation, and because it is strongly grounded in empirical ideas it does lead to interesting elaborations and falsifiable hypotheses.

\section{R6.3. In support of Tool/Drug Theory}

Some commentators provided additional evidence in support of Tool/Drug Theory. For example, Kemp \& Grace reinterpret our tool/drug distinction as an analogy to that between discriminative and hedonic properties of 
conditioned reinforcers (and give some recent neurophysiological evidence to support this). They also deploy the tool/drug distinction to make a prediction about behaviour towards near monies, and furthermore the prediction turns out to be correct: people do in general overvalue money (as when they are willing to pay $£ 23$ for 100 air miles that are actually worth $£ 7-12$ ). Kniffin agrees that users of near-moneys may pay more than they are worth. Similarly, Lefebvre interprets the well-established "contrafreeloading" phenomenon to argue that for animals (like humans) certain forms of utility are different (Lefebvre uses the term "sacred") in that the animal will work in some areas for smaller rewards than in others. He thus argues that "the sacral aspect of money has deep biological roots"; while we would not necessarily agree with his interpretation of contrafreeloading, if it is accepted, it tends to support the idea of a dual motivational role for money.

\section{R7. Human instincts: Some alternative candidates for the biological underpinnings of money}

In a key section of the target article (sect. 5) we proposed two instincts (or motives) that we believe are universal among humans and that are manifested in modern culture as a desire for money. We do not claim, and we certainly do not take for granted (pace Agassi), that these are the only possibilities. The commentators have enthusiastically put forward several additional or alternative specific candidates. We shall explain in this section why we prefer our original choices to these specific alternatives, but we should say at the outset that if the general structure of our argument is accepted, it is more likely than not that there will be changes or additions to be made to the list of more basic instincts on which the drug-like aspects of the money motive depend. In the end we may even arrive at a list as long as that offered by Ainslie, though he basically argues that there need not be any specific underlying motives, so we leave discussion of his proposal to section R8.

At the outset, too, it is important to note Mouras's observations on the neural correlates of monetary award. Mouras provides an fMRI perspective and reviews a range of imaging data to show that neural circuits linked to natural addictive/rewarding processes are involved in monetary reward. In other words, money has been found to induce brain activations in areas that overlap those induced by cocaine, and several brain areas are involved in both monetary reward and sexual motivation. Studies have also shown different areas being activated at different phases of a task. What one can deduce from this (though this is not spelled out by Mouras) is that money mimics a range of natural incentives, some of which are clearly "druglike" in form (the cocaine example). If this is the case, further fMRI work may help clarify what are the natural incentives that money mimics.

Some of the commentators put forward objections to our two proposed underlying instincts. Burghardt, for example, argues on the one hand, that trading is not as we suggested unique to humans, and on the other, that the question of whether play is an independent motive is still open. We agree with both these arguments up to a point. Indeed, we pointed out (sect. 5.2) that barter can be induced in laboratory animals. But we are not convinced that either this, or the examples of ritual presentation that Burghardt gives, really constitute the integration of division of labour into a system of trade, which is how we characterised human trading (sect. 5.2). On play, our own reading of the evidence is that, however much the adaptive value of play may come from other motivational systems such as aggression, within the life of the individual organism it is motivationally independent from them.

An impressive list of alternative instinctual origins for the drug aspects of money is produced. We consider first the proposal that a wholly asocial motivational system may be a sufficient explanation. Bouissac and Booth both argue that natural selection favoured the evolution of a hoarding "instinct" and an inhibitory system, and both point out that such instincts are found quite widely in the animal kingdom and commonly show a dissociation from their obvious functions. Here they diverge, however, with Bouissac making money essentially a cultural index for resources (corresponding to other commentators who seek to explain money motivation in terms of status and power), and Booth linking money motivation to the general tendency of humans to collect things for their own sake. This idea seems strange to us: most people are not collectors of money - in general, as Katona (1975) pointed out, we save less than we intend or think desirable. Misers are interesting, but as Ross \& Spurrett point out, they are also unusual.

Several commentators seek to root a money instinct in social motivations other than the trading instinct that we propose. There are many differences among these approaches, but we draw them together here because they all point to instincts that are more competitive than cooperative. Agassi claims that people desire wide options (and that is what they want money for), and also that money provides power. What Agassi appears to be proposing is that the natural incentives that money mimic are not just trading and play, but curiosity and power. Curiosity seems to us to be rooted in the play instinct, so this does not add to our synthetic account, though it might provide an alternative way of looking at it. Agassi's emphasis on power, however, allies him with other commentators who see the major origin of money motivation in the drive to social status (e.g., Jorion, Kniffin; see also Dewitte's idea that money serves as a signal for the intrinsic quality of the owner). Dewitte argues for a second similar motivation, the need for autonomy. Behrendt proposes that the pursuit of money is a "culturally ritualised expression of the aggressive instinct." He further suggests that money is used as a tool to obtain status, which in turn allows the aggressive instinct to be expressed, and he suggests that the function of money may be related to suppressed envy in a psychoanalytic sense. Kniffin argues that status itself has many drug-like properties.

Status, power, and the desire for freedom from constraint and control over one's own behaviour and fate are certainly powerful human motivators, and money undoubtedly facilitates them in a modern society. But we are not convinced that their links with money transactions are direct enough for them to be plausible as the origins of money motivation. For an instinct to underlie money motivation, it is not enough for it to be strong: 
there also has to be a reasonable evolutionary and historical pathway from it to the money motivation. Money is directly concerned with trading, but only indirectly with power, status, or autonomy, and this is why we favour a trading instinct as the most likely candidate to underlie the money motive. As for Behrendt's arguments from Lorenzian drive-depletion theory and psychoanalysis, we do not find these persuasive as general systems and there seems no particular reason to apply them to money.

To us, the most interesting suggestion for an alternative instinct on which the money motive might be based comes from Dewitte. Like us, he argues for multiple instincts underlying the drug effect of money. We have noted his argument for an autonomy instinct earlier, and we are not persuaded by it. However, like us, Dewitte sees reciprocation as also involved. But he makes the interesting observation that giving and receiving, credit and debt, though logically interdependent, are not psychologically equivalent. This is undoubtedly true; when we first started to investigate the psychology of debt (see Lea et al. 1993), we expected it to be the mirror image of the psychology of saving (see Wärneryd 1999), but we found little relation between the two. Furthermore, Dewitte's observation gains support from evidence cited by Mouras that monetary gain and loss have different neurophysiological effects. However, we disagree with Dewitte's interpretations of the observations he lists (which partly depend on his idea that the key instinct for understanding money is the need for autonomy). To take in turn three of the observations he draws attention to:

(a) The persistent asymmetry in monetary gifts between parents and children, which Dewitte argues continues until children gain psychological autonomy from their parents. We would argue that the asymmetry is based (in the first instance) simply on the fact that there is an asymmetry between the amount of money parents and children have. If the relative financial situations are reversed (as when a young adult wins the lottery), giving money to parents is perfectly acceptable.

(b) Intrinsic savings motives, which Dewitte argues do not make sense from a reciprocity perspective but are easily explained by a need for autonomy. A number of distinct savings motives have been identified. Some are indeed related to autonomy: Canova et al. (2005) found that autonomy was one of three superordinate goals for saving. But people also save in order to provide money for their children and in order to be able to lend money to friends (which makes a lot of sense from a reciprocity perspective).

(c) Borrowing whilst owing money. We disagree with Dewitte's view that this is hard to understand from a reciprocity perspective. Since both borrowing and lending build up social networks and patterns of obligations, we would expect people to both borrow and save.

Dewitte also argues that people are willing to live on credit, and that this disagrees with the reciprocity principle. However, this observation is at odds with the data marshalled by Prelec and Loewenstein (1998) showing that people generally prefer to prepay, at least for ephemeral commodities, and hence that they like to keep their mental accounts in credit. Prepay cards are in fact quite common, though they usually occur in near-money situations such as pay-as-you-go cellphones or multi-trip transit tickets.

While we have explained here why we favour our original hypothesis about the instincts supporting the drug effect of money, we do welcome these alternative suggestions. The drug metaphor will have served its purpose if it sparks an empirically driven debate about the origins of the money motive, whatever conclusion that debate then comes to.

\section{R8. Some extensions}

Finally, we turn to some commentaries that take our basic argument and seek to extend it. Ainslie's thoughtful and insightful contribution argues that whilst money clearly has an emotional value over and above its value in exchange, this need not be linked to particular underlying instincts like play and reciprocal altruism (indeed, he believes this approach is unnecessarily specific). Second, he claims that money gains its emotional power through being authenticated as a "prize"- but that money is not special in this respect. This is also true for a wide range of other facts through which we pace our emotions, such as sporting feats or news items - in fact anything that is scarce, which links his view to that of Ascoli \& McCabe. They argue that scarcity is an excellent explanation for the drug-like properties of money-but also for the drug-like properties of food and other generalised reinforcers. Because both barter and food have been hard to obtain throughout human history, and because (crucially) future availability of both is uncertain, it makes good sense that people are addicted (i.e., want too much of) both food and money. In an affluent society, one consequence is that people eat more than is good for them (they get obese and have shorter life expectancies) and (by extension) work more than is good for them to obtain more money. This corresponds to our view that money needs to be conceived of as a drug, but places emphasis on trading (barter) rather than play, and puts the ecology of early man (when barter was scarce) at the heart of the explanation. However, in an interesting reverse of the conditioned reinforcement account, Ascoli \& McCabe see money as a reinforcement for barter. Like the operant psychologists, we would expect the relationship to run in the opposite direction.

Both of these contributions seem to us to be valuable extensions of our argument. As Romanowich et al. remind us, we have known since Premack (1965) that relative scarcity can turn anything into a reinforcer. However, we do want to defend the idea of looking for specific instincts on which the money motive is based, because without that specificity Drug Theory becomes dangerously vague. It can also be argued that money is not a particularly good prize, for some of the same reasons that it is not a particularly good gift: it is not special (i.e., scarce) enough, even if it is difficult to acquire a lot of it.

Two commentaries suggest mechanisms that might account for the drug effects of money. Chandrasekharan uses his concept of epistemic structure and shows how it could explain the origin of money and the tendency to acquire money, given a general "tiredness" or avoidanceof-effort motive. This links well to the classic economic observation that money makes exchanges easier, which we see as part of the tool account, but also explains how something that provides epistemic structure might come to be independently valued. We are not convinced, however, that this adds more than some useful labels to 
fairly standard evolutionary arguments. Glassman makes the valuable points that every evolved feature of a living system originated as something else-it achieves autonomy as it evolves - and that a sub-system naturally accumulates additional functions, thereby becoming more and more robust. Like conditioned reinforcement theory, Glassman's concept of "entification" provides a more explicit alternative for Allport's underspecified concept of functional autonomy. It thus locates money as a special case of a more general phenomenon - other examples being music or reading (echoing Ainslie's suggestion).

Markman et al. extend the drug/tool distinction in a different way, by mapping it into a dimension of motivationally active uses or cool uses: to them, motivationally active uses of money exemplify Drug Theory and motivationally cool uses fit Tool Theory, and they cite experimental evidence in support of this. We find this interesting, and we support their empirical argument - we too have evidence that transactions such as repaying neighbourly help with money can be taboo (Webley \& Lea 1993a). However, we are concerned about too easy an identification of "tool" with "rational" and "drug" with "irrational" (we have a similar issue with Walsh's argument). Tool uses of money are, perhaps, rational by definition if we adopt a descriptive sense of rationality - they involve valuing money strictly for what it can be used for. But that, as Simon (1978) long ago pointed out, need not imply that behaviour is governed by a rational process, nor need drug effects of money imply irrational processes.

Finally, Kniffin gives the argument one more twist by pointing out that money is itself a protean metaphor, used to give value to near-moneys and other commodities; we must recognise that if the money motive is built on more basic instincts, additional motives may still be built on to the money motive.

\section{R9. Envoi}

By responding first to those who challenged even the foundations of our argument, we have constructed this response on a steadily rising plane of agreement. However, we would not wish it to appear that we are searching for affirmation. The commentaries have included much that is complimentary of our argument, along with many challenges. But the comment that gave us most pleasure came in the Note to the contribution by Glassman, who thanked a student class which had had an enlivening discussion of the target article. The tool and drug metaphors for money motivation may continue to be discussed, or they may not. But they will have served their purpose if they stimulate discussion: discussion among those whose profession is to understand money, about the origins of our interest in it; and discussion among those whose profession is to understand origins, about our interest in money.

\section{References}

[The letters " $a$ " and " $r$ " before author's initials stand for target and response article references, respectively.]

Agassi, J. (1977) Towards a rational philosophical anthropology. Martinus Nijhoff. [JA]

Ainslie, G. (2001) Breakdown of will. Cambridge University Press. [GA]
(2003) Uncertainty as wealth. Behavioural Processes 64:369-85. [GA] (2005) Précis of Breakdown of will. Behavioral and Brain Sciences 28(5): 635-73. [GA]

Aldona, J., ed. (1991) Chiefly feasts: The enduring Kwakiutl potlatch. University of Washington Press. [aSEGL]

Allan, R. W. \& Zeigler, H. P. (1994) Autoshaping the pigeon's gape response: Acquisition and topography as a function of reinforcer type and magnitude. Journal of the Experimental Analysis of Behavior 62:201-23. [FS]

Allison, D. B., Miller, R. A., Austad, S. N., Bouchard, C., Leibel, R., Klebanov, S., Johnson, T. \& Harrison, D. E. (2001) Genetic variability in responses to caloric restriction in animals and in regulation of metabolism and obesity in humans. Journal of Gerontology A 56:550-65. [GAA]

Allport, G. W. (1937) Personality: A psychological interpretation. Holt. [RBG, aSEGL]

Amato, P. R. \& Rogers, S. J. (1997) A longitudinal study of marital problems and subsequent divorce. Journal of Marriage and the Family 59:612-24. [aSEGL]

Anderson, E. (1993) Value in ethics and economics. Harvard University Press. [AJW]

Anderson, N. H. (1981) Foundation of information integration theory. Academic Press. [aSEGL]

Anderson, S. W., Damasio, H. \& Damasio, A. R. (2005) A neural basis for collecting behaviour in humans. Brain 128:201-12. [DAB, PB]

Aristotle (1952) Politics, ed. J. Warrington. Heron Books. [AJW]

Axelrod, R. (1984) The evolution of cooperation. Basic Books. [SD, FS]

Ayllon, T. \& Azrin, N. H. (1968) The token economy: A motivational system for therapy and rehabilitation. Appleton-Century-Crofts. [rSEGL]

Bagley, C. (1999) Adolescent prostitution in Canada and the Philippines: Statistical comparisons, an ethnographic account and policy options. International Social Work 42:445-69. [rSEGL]

Baldwin, J. W. (1959) The medieval theories of the just price: Romanists, canonists and theologians of the twelfth and thirteenth century. The American Philosophical Society. [AJW]

Baum, W. M. (1974a) Chained concurrent schedules: Reinforcement as situation transition. Journal of the Experimental Analysis of Behavior 22:91-101. [SK] (1974b) On two types of deviation from the matching law: Bias and undermatching. Journal of the Experimental Analysis of Behavior 22: 231-42. [VAL]

(2002) From molecular to molar: A paradigm shift in behavior analysis. Journal of the Experimental Analysis of Behavior 78:95-116. [VAL]

Becker, G. S. (1996) Accounting for tastes. Harvard University Press. [rSEGL]

Belk, R. W. (1984) Three scales to measure constructs related to materialism:

Reliability, validity, and relationships to measures of happiness. Advances in Consumer Research 11:291-97. [aSEGL]

(1996) The perfect gift. In: Gift giving: A research anthology, ed. C. Otnes \& R. Beltramini. Bowling Green University Popular Press. [RB]

(2005) Exchange taboos from an interpretive perspective. Journal of Consumer Psychology 15:16-21. [RB]

Belk, R. W. \& Coon, G. (1993) Gift-giving as agapic love: An alternative to the exchange paradigm based on dating experiences. Journal of Consumer Research 20:393-417. [RB]

Belk, R. W. \& Wallendorf, M. (1990) The sacred meanings of money. Journal of Economic Psychology 11:35-67. [aSEGL]

Belk, R. W., Sherry, J. F. \& Wallendorf, M. (1988) A naturalistic inquiry into buyer and seller behavior at a swap meet. Journal of Consumer Research 14:44970. [aSEGL]

Bell, S. (2001) The role of the state and the hierarchy of money. Cambridge Journal of Economics 25:149-63. [aSEGL]

Benham, W. G. (1935) Cassell's classified quotations, $4^{\text {th }}$ edition. Cassell. [rSEGL] Berlyne, D. E. (1960) Conflict, arousal and curiosity. McGraw Hill. [aSEGL]

Black, D. W. (1996) Compulsive buying: A review. Journal of Clinical Psychiatry 57:50-5. [aSEGL]

Blackmore, S. (1999) The meme machine. Oxford University Press. [KES]

Bohannan, P. (1959) The impact of money on an African subsistence economy. Journal of Economic History 19:455-61. [rSEGL]

Booth, D. A., Lovett, D. \& McSherry, G. M. (1972) Postingestive modulation of the sweetness preference gradient in the rat. Journal of Comparative and Physiological Psychology 78:485-512. [DAB]

Booth, D. A., Thompson, A. L. \& Shahedian, B. (1983) A robust, brief measure of an individual's most preferred level of salt in an ordinary foodstuff. Appetite 4:301-12. [DAB]

Borneman, J. \& Fowler, N. (1997) Europeanization. Annual Review of Anthropology 26:487-514. [aSEGL]

Bornemann, E. (1976) The psychoanalysis of money. Urizen. [aSEGL]

Boulding, K. E. (1981) Evolutionary economics. Sage. [aSEGL]

Boundy, D. (1993) When money is the drug: The compulsion for credit, cash, and chronic debt. Harper. [aSEGL]

Bown, N. J., Read, D. \& Summers, B. (2003) The lure of choice. Journal of Behavioral Decision Making 16:297-308. [SD] 
References/Lea \& Webley: Money as tool, money as drug

Braver, T. S. \& Cohen, J. D. (2000) On the control of control: The role of dopamine in regulating prefrontal function and working memory. In: Control of cognitive processes: Attention and performance XVIII, ed. S. Monsell \& J. Driver, pp. 713-37. MIT Press. [SC]

Brehm, J.W. (1966) A theory of psychological reactance. Academic Press. [SD]

Breiter, H. C., Aharon, I., Kahneman, D., Dale, A. \& Shizgal, P. (2001) Functional imaging of neural responses to expectancy and experience of monetary gains and losses. Neuron 30(2):619-39. [HM]

Breiter, H. C., Becerra, L., Gonzaels, R. G., Jenkins, L., Huffman, E., Harter, K., Comite, A. \& Borsook, D. (2000) Morphine induced reward and pain circuitry activation in drug naïve humans. Poster presented at the 19th Annual Meeting of the American Pain Society, Atlanta, GA, November 2-5, 2000. [HM]

Breiter, H. C., Gollub, R. L., Weisskoff, R. M., Kennedy, D. N., Makris, N., Berke, J. D., Goodman, J. M., Kantor, H. L., Gastfriend, D. R., Riorden, J. P., Mathew, R. T., Rosen, B. R. \& Hyman, S. E. (1997) Acute effects of cocaine on human brain activity and emotion. Neuron 19(3):591-611. [HM]

Brendl, C. M., Markman, A. B. \& Higgins, E. T. (1998) Mentale Buchhaltung als Selbst-Regulation: Representativität für ziel-geleitete Kategorien [Mental accounting as self-regulation: Representativeness to goal-derived categories]. Zeitschrift fuer Sozialpsychologie 29:89-104. [ABM]

Brendl, C. M., Markman, A. B. \& Messner, C. (2003) Devaluation of goal-unrelated choice options. Journal of Consumer Research 29:463-73. [ABM]

Brooks, J. (1981) Showing off in America. Little, Brown. [RBG]

Brooks, J. L., Mark, L, Sakai, R. \& Crowe, C. (producers) (1996) Jerry Maguire [Motion picture], directed by C. Crowe. United States: Columbia/TriStar Studios. [KMK]

Bruner, J. S. \& Goodman, C. C. (1947) Value and need as organising factors in perception. Journal of Abnormal and Social Psychology 42:33-44. [aSEGL]

Brysbaert, M. \& d'Ydewalle, G. (1989) Why Belgian coins grow smaller. Psychologica Belgica 29:109-18. [aSEGL]

B+S Card Service GmbH (2005) Online service available at: http://www.bs-cardservice.com/english/becoming-a-partner/card-settlement/payment-cards/ [SD]

Buchan, J. (1997) Frozen desire. Picador. [aSEGL]

Buller, D. J. (2005) Adapting minds. MIT Press. [rSEGL]

Burdett, K., Trejos, A. \& Wright, R. (2001) Cigarette money. Journal of Economic Theory 99:117-42. [aSEGL]

Burghardt, G. M. (2001) Play: Attributes and neural substrates. In: Handbook of behavioral neurobiology, vol. 13: Developmental psychobiology, developmental neurobiology and behavioral ecology: Mechanisms and early principles, ed. E. M. Blass, pp. 327-66. Kluwer Academic/Plenum. [GMB] (2005) The genesis of animal play: Testing the limits. MIT Press. [GMB]

Burgoyne, C. B. (1990) Money in marriage: How patterns of allocation both reflect and conceal power. Sociological Review 38:634-65. [aSEGL]

Burgoyne, C. B. \& Routh, D. A. (1991) Constraints on the use of money as a gift at Christmas: The role of status and intimacy. Journal of Economic Psychology 12:47-69. [aSEGL]

Burroughs, J. E. \& Rindfleisch, A. (2002) Materialism and well-being: A conflicting values perspective. Journal of Consumer Research 29:348-70. [aSEGL]

Cameron, J. \& Bryan, M. (1992) Money drunk/money sober. Ballentine Wellspring. [aSEGL]

Campbell, C. (1987) The romantic ethic and the spirit of modern consumerism. Blackwell. [RB]

Campbell, D. T. (1974a) Evolutionary epistemology. In: The philosophy of Karl Popper. Vol. 14, I \& II. The library of living philosophers, ed. P. A. Schilpp, pp. 413-463. Open Court. [RBG]

(1974b) Unjustified variation and selective retention in scientific discovery. In Studies in the philosophy of biology, ed. F. J. Ayala \& T. Dobzhansky, pp. 139-61. University of California Press. [RBG] (1976) On the conflicts between biological and social evolution and between psychology and moral tradition. American Psychologist 30:110326. [RBG]

Canova, L., Rattazzi, A. M. M. \& Webley, P. (2005) The hierarchical structure of saving motives. Journal of Economic Psychology 26:21-34. [rSEGL]

Card, S. K., Moran, T. P. \& Newell, A. (1983) The psychology of human-computer interaction. Erlbaum. [aSEGL]

Carruthers, B. \& Babb, S. (1996) The color of money and the nature of value: Greenbacks and gold in postbellum America. American Journal of Sociology 101:1556-91. [aSEGL]

Carruthers, B. G. \& Espeland, W. N. (1998) Money, meaning and morality. American Behavioral Scientist 41:1384-408. [aSEGL]

Carruthers, P. (2002) The cognitive functions of language. Behavioral and Brain Sciences 25:657-726. [KES]

Case, D. A. \& Fantino, E. (1981) The delay-reduction hypothesis of conditioned reinforcement and punishment: Observing behavior. Journal of the Experimental Analysis of Behavior 35:93-108. [aSEGL]

Caskey, J. P. \& St Laurent, S. (1994) The Susan B. Anthony dollar and the theory of coin/note substitutions. Journal of Money, Credit and Banking 26:495-510. [aSEGL]
Catania, A. C. (1975) Freedom and knowledge: An experimental analysis of preference in pigeons. Journal of the Experimental Analysis of Behavior 24:89-106. [aSEGL]

Chandrasekharan, S. (2005) Epistemic structure: An inquiry into how agents change the world for cognitive congeniality. Ph.D. thesis, Carleton University, Ottawa, Canada. Available as a Carleton University Cognitive Science Technical Report at: http://www.carleton.ca/iis/TechReports/files/2005-02.pdf. [SC]

Chandrasekharan, S. \& Stewart, T. (2004) Reactive agents learn to add epistemic structures to the world. In: Proceedings of the 26th Annual Meeting of the Cognitive Science Society, CogSci2004, Chicago, ed. K. D. Forbus, D. Gentner \& T. Regier. Erlbaum. Available at: http://www.sce.carleton.ca/ schandra/ papers/simulation-cogsci-final.pdf. [SC]

Chapman, A. (1980) Barter as a universal mode of exchange. Homme 20:3383. [rSEGL]

Check, E. (2005) Patchwork people. Nature 437:1084-86. [PB]

Chen, G. H., Wang, Y. J., Wang, X. M., Zhou, J. N. \& Liu, R. Y. (2005) Effect of aging on species-typical behaviors in senescence accelerated mouse. Physiology and Behavior 85:536-45. [DAB]

Chen, M. K., Lakshminarayanan, V. \& Santos, L. (in press) How basic are behavioral biases? Evidence from capuchin-monkey trading behavior. Journal of Political Economy. [rSEGL, DR]

Christopher, A. N., Ryan, D. M., Marek, P., Troisi, J. D., Jones, J. R. \& Reinhar, D. F. (2005) Affluence cues and first impressions: Does it matter how the affluence was acquired? Journal of Economic Psychology 26:187-200. [SD]

Cohen, J. D., Botvinick, M. \& Carter, C. S. (2000) Anterior cingulate and prefrontal cortex: Who's in control? Nature Neuroscience 3:421-23. [GAA]

Conner, M. T., Haddon, A. V., Pickering, E. S. \& Booth, D. A. (1988) Sweet tooth demonstrated: Individual differences in preference for both sweet foods and foods highly sweetened. Journal of Applied Psychology 73:27580. [DAB]

Crump, T. (1981) The phenomenon of money. Routledge and Kegan Paul. [aSEGL]

Currie, G. \& Ravenscroft, I. (2002) Recreative minds. Oxford University Press. [KES]

Davies, G. (2002) A history of money from ancient times to the present day, 3rd edition. University of Wales Press. [aSEGL]

Dawkins, R. (1976) The selfish gene. Oxford University Press. [RBG, aSEGL]

De Boeck, F. (1998) Domesticating diamonds and dollars: Identity, expenditure and sharing in southwestern Zaire (1984-1997). Development and Change 29:777-810. [aSEGL]

Deci, E. L. \& Ryan, R. M. (1985) Intrinsic motivation and self-determination in human behavior. Plenum Press. [SD]

Deci, E. L., Koestner, R. \& Ryan, R. M.(1999) A meta-analytic review of experiments: Examining the effects of extrinsic rewards on intrinsic motivation. Psychological Bulletin 125: 627-68. [AF]

Deflem, M. (2003) The sociology of the sociology of money. Journal of Classical Sociology 3:67-96. [aSEGL]

Dennett, D. C. (1995) Darwin's dangerous idea: Evolution and the meanings of life. Simon \& Schuster. [KES]

De Roover, R. (1967) San Bernadino of Siena and Sant'antonino of Florence: The two great economic thinkers of the middle ages. Baker Library. [AJW]

Desforges, L. (2001) Tourism consumption and the imagination of money. Transactions of the Institute of British Geographers 26:353-64. [aSEGL]

de Waal, F. (1982) Chimpanzee politics. Jonathan Cape. [aSEGL] (1996) Good natured/ Harvard University Press. [aSEGL]

Dickerson, M. (1984) Compulsive gamblers. Longman. [aSEGL]

Dienes, Z. \& Perner, J. (1999) A theory of implicit and explicit knowledge. Behavioral and Brain Sciences 22:735-808. [KES]

Dodd, N. (1994) The sociology of money: Economics, reason and contemporary society. Continuum. [aSEGL]

Dole, G. E. \& Carneiro, R. L. (1958) A mechanism for mobilizing labor among the Kuikuru of Central Brazil. Transactions of the New York Academy of Sciences 21:58-60. [rSEGL]

Dowd, K. (1992) The demand for nondurable goods and endogenous labor supply. Applied Economics 24:1199-202. [aSEGL]

Doyle, K. O. (1998) The social meanings of money and property. Sage. [aSEGL] (2001) Introduction: Ethnicity and money. American Behavioral Scientist 45:181-90. [aSEGL]

Doyle, K. O. \& Li, Y. L. (2001) A within-continent content analysis - Meanings of money in Chinese and Japanese proverbs. American Behavioral Scientist 45:307-12. [rSEGL]

Eibl-Eibesfeldt, I. (1970) Ethology, the biology of behavior. Holt, Rinehart and Winston. [RBG]

Einzig, P (1966) Primitive money, 2nd edition. Pergamon. [arSEGL]

Elias, N. (1994) The civilizing process. Blackwell. [aSEGL]

Ernst, M., Nelson, E. E., McClure, E. B., Monk, C. S., Munson, S., Eshel, N., Zarahn, E., Leibenluft, E., Zametkin, A., Towbin, K., Blair, J., Charney, D. \& 
Pine, D. S. (2004) Choice selection and reward anticipation: An fMRI study. Neuropsychologia 42(12):1585-97. [HM]

Falk, P. \& Campbell, C., eds. (1997) The shopping experience. Sage. [RB]

Fantino, E. (2000) Delay-reduction theory - the case for temporal context: Comment on Grace and Savastano (2000). Journal of Experimental Psychology: General 129(4):444-46. [PR]

Fantino, E. \& Logan, C.A. (1979) The experimental analysis of behavior: A biological perspective. W.H. Freeman. [PR]

Fehr, E. \& Fischbacher, U. (2003) The nature of human altruism. Nature 425:785-91. [KES]

Fehr, E. \& Tyran, J.-R. (2001) Does money illusion matter? American Economic Review 91:1239-62. [aSEGL]

Ferenczi, S. (1914/1976) The ontogenesis of the interest in money. In: The psychoanalysis of money, ed. E. Bornemann. Urizen. (Originally published in 1914). [aSEGL]

Fiorillo, C. D., Tobler, P. N. \& Schultz, W. (2003) Discrete coding of reward probability and uncertainty by dopamine neurons. Science 299:18981902. [SK]

Fisher, I. (1928) The money illusion. Adelphi. [aSEGL]

Fiske, A. P. \& Tetlock, P. E. (1997) Taboo trade-offs: Reactions to transactions that transgress the spheres of justice. Political Psychology 18:255-97. [aSEGL]

Flowers, R. B. (2001) The sex trade industry's worldwide exploitation of children. Annals of the American Academy of Political and Social Science 575:14757. [rSEGL]

Forman, N. (1987) Mind over money. Doubleday. [aSEGL]

Foster, G. (1972) The anatomy of envy: A study in symbolic behavior. Current Anthropology 13:165-82. [RB]

Frank, R. H. (1985) Choosing the right pond: Human behavior and the quest for status. Oxford University Press. [KMK]

Franke, G. R. (1994) United States cigarette demand, 1961-1990: Econometric issues, evidence, and implications. Journal of Business Research 30:3341. [aSEGL]

Freeman, R. P. J., Richardson, N. J., Kendal-Reed, M. S. \& Booth, D. A. (1993) Bases of a cognitive technology for food quality. British Food Journal 95 (9): 37-44. [DAB]

Freud, S. (1959) Character and anal eroticism. In: The standard edition of the complete psychological works of Freud, vol. IX, ed. J. Strachey. Hogarth. [aSEGL]

Frost, R. O., Steketee, G. \& Williams, L. (2002) Compulsive buying, compulsive hoarding, and obsessive-compulsive disorder. Behavior Therapy 33:20114. [aSEGL]

Furby, L. (1978) Sharing: Decisions and moral judgments about letting others use one’s possessions. Psychological Reports 43:595-609. [RB]

Furnham, A. (1983) Inflation and the estimated sizes of notes. Journal of Economic Psychology 4:349-52. [aSEGL]

Furnham, A. (1984) Many sides of the coin: The psychology of money usage. Personality and Individual Differences 5:501-9. [aSEGL]

(1990) A content, correlational, and factor analytic study of 7 questionnaire measures of the Protestant work-ethic. Human Relations 43:38399. [aSEGL]

Furnham, A. \& Argyle, M. (1998) The psychology of money. Routledge. [AF, arSEGL]

Gagnier, R. \& Dupré, J. (1999) Reply to Amariglio and Ruccio "literary/cultural 'economies,' economic discourse, and the question of marxism." In: New economic criticism, ed. M. Woodmansee \& M. Osteen, pp. 401-407. Routledge. [rSEGL]

Gamble, A., Garling, T., Charlton, J. \& Ranyard, R. (2002) Euro-illusion: Psychological insights into price evaluations with a unitary currency. European Psychologist 7:302-311. [aSEGL]

Garcia, J. \& Koelling, R. A. (1966) Relation of cue to consequence in avoidance learning. Psychonomic Science 4:123-24. [FS]

Gerhart, B. \& Rynes, S. L. (2003) Compensation: Theory, evidence, and strategic implications. Sage. [KMK]

Gintis, H. (2003) The hitchhiker's guide to altruism: Genes, culture, and the internalization of norms. Journal of Theoretical Biology 220:407-18. [KES]

Gintis, H., Bowles, S., Boyd, R. \& Fehr, E. (2003) Explaining altruistic behavior in humans. Evolution and Human Behavior 24:153-72. [KES]

Glassman, R. B. (1973) Persistence and loose coupling in living systems. Behavioral Science 18:83-98. [RBG]

Glassman, R. B. \& Wimsatt, W. C. (1984) Evolutionary advantages and limitations of early plasticity. In: Early brain damage, Vol. 1: Research orientations and clinical observations, ed. C. R. Almi \& S. Finger, pp. 35-58. Academic Press. [RBG]

Glimcher, P. W. (2003) Decisions, uncertainty, and the brain: The science of neuroeconomics. MIT Press. [aSEGL, DR]

Glimcher, P. W. \& Rustichini, A. (2004) Neuroeconomics: The consilience of brain and decision. Science 306(5695): 447-52. [HM]
Goldberg, H. \& Lewis, R. T. (1978) Money madne: The psychology of saving, spending, loving, and hating money. Morrow. [aSEGL]

Goldin, R. F. (2005) Will a few extra pounds lead to a longer life? STATS News (available online at: http://www.stats.org/ record.jsp?type $=$ news\&ID $=501) . \quad[\mathrm{GAA}]$

Goyal, M., Mehta, R. L., Schneiderman, L. J. \& Sehgal, A. R. (2002) Economic and health consequences of selling a kidney in India. JAMA: Journal of the American Medical Association 288:1589-93. [rSEGL]

Granovetter, M. (1985) Economic action and social structure: The problem of embeddedness. American Journal of Sociology 91:481-510. [aSEGL]

Green, L. \& Myerson, J. (2004) A discounting framework for choice with delayed and probabilistic rewards. Psychological Bulletin 130:769-92. [GA]

Grierson, P. (1978) The origins of money. Research in Economic Anthropology $1: 1-35$. [arSEGL]

Grilo, C. M. (2004) Factor structure of DSM-IV criteria for obsessive compulsive personality disorder in patients with binge eating disorder. Acta Psychiatrica Scandinavica 109:64-9. [aSEGL]

Grisham, J. R. \& Barlow, D. H. (2005) Compulsive hoarding: Current research and theory. Journal of Psychopathology and Behavioral Assessment 27:45-52. [DAB]

Guidotti, P. E. \& Rodriguez, C. A. (1992) Dollarization in Latin America: Gresham law in reverse. International Monetary Fund Staff Papers 39:51844. [aSEGL]

Guilford, T., Roberts, S. \& Biro, D. (2004) Positional entropy during pigeon homing II: Navigational interpretation of Bayesian latent state models. Journal of Theoretical Biology 227(1):25-38. [SC]

Gutnisky, D. A. \& Zanutto, B. S. (2004) Cooperation in the iterated prisoner's dilemma is learned by operant conditioning mechanisms. Artificial Life 10:433-61. [FS]

Hadley, E. C., Dutta, C., Finkelstein, J., Harris, T. B., Lane, M. A., Roth, G. S., Sherman, S. S. \& Starke-Reed, P. E. (2001) Human implications of caloric restriction's effects on aging in laboratory animals: An overview of opportunities for research. Journal of Gerontology A 56:5-6. [GAA]

Hamilton, W. D. (1963) The evolution of altruistic behavior. American Naturalist 97: 354-6. [aSEGL]

Hamon, C. \& Quilliec, B. (2005) Hoards from the Neolithic to the metal ages in Europe: Technical and codified practices. In: Programme and Abstracts of the European Association of Archaeologists 11th Annual Meeting, 5-11 September, 2005, Cork, Ireland, ed. E. Twohig. pp. 86-90. University of Cork. [PB]

Hanson, T. L., Garfinkel, I., McLanahan, S. S. \& Miller, C. K. (1996) Trends in child support outcomes. Demography 33: 483-96. [aSEGL]

Harpaz, I. \& Snir, R. (2003) Workaholism: Its definition and nature. Human Relations 56:291-319. [aSEGL]

Hegel, G. W. F. (1807/1949) Phenomenology, trans. J. B. Baillie, Rev. 2nd edition. George Allen \& Unwin. (Original work published in 1807). [PJ]

Heidegger, M. (1927/1962) Being and time, new edition, trans. J. Macquarrie \& E. Robinson. Blackwell. (Originally published, 1927). [aSEGL]

Hendry, D. P., ed. (1969a) Conditioned reinforcement. Dorsey. [aSEGL]

Hendry, D. P. (1969b) Reinforcing value of information: Fixed-ratio schedules. In: Conditioned reinforcement, ed. D. P. Hendry. Dorsey. [aSEGL]

Henry, S. (1978) The hidden economy. Martin Robertson. [aSEGL]

Herzberg, F., Mausner, B. \& Snyderman, B. (1967) The motivation to work, 2nd edition. Wiley. [rSEGL]

Higgins, S. T., Wong, C. J., Badger, G. J., Ogden, D. E. \& Dantona, R. L. (2000) Contingent reinforcement increases cocaine abstinence during outpatient treatment and 1 year of follow-up. Journal of Consultation and Clinical Psychology 68:64-72. [GAA]

Hollingsworth, L. D. (2003) International adoption among families in the United States: Considerations of social justice. Social Work 48:209-17. [rSEGL]

Holt, D. B. \& Searls, K. (1994) The impact of modernity on consumption: Simmel's philosophy of money. Advances in Consumer Research 21:65-69. [aSEGL]

Horne, P. J. \& Lowe, C. F. (1993) Determinants of human performance on concurrent schedules. Journal of the Experimental Analysis of Behavior 59:29-60. [rSEGL]

Humphrey, C. \& Hugh-Jones, S. (1992) Barter, exchange and value: An anthropological approach. Cambridge University Press. [rSEGL]

Humphrey, D. B. (2004) Replacement of cash by cards in US consumer payments. Journal of Economics and Business 56:211-225. [aSEGL]

Hussein, G. (1985) Is money an acceptable gift in Cyprus? Perceptual and Motor Skills 61:1074. [aSEGL]

Hyatt, C. W. \& Hopkins, W. D. (1998) Interspecies object exchange: Bartering in apes? Behavioural Processes 42:177-87. [aSEGL]

Ingham, G. (1996) Money is a social relation. Review of Social Economy 54:507-29. [aSEGL]

(2001) Fundamentals of a theory of money: Untangling Fine, Lapavitsas and Zelizer. Economy and Society 30:304-23. [aSEGL]

Innis, R. E. (1984) Technics and the bias of perception. Philosophy and Social Criticism 11:7-89. [aSEGL] 
Iyengar, S. S. \& Lepper, M. R. (2000) When choice is demotivating: Can one desire too much of a good thing? Journal of Personality and Social Psychology 79:995-1006. [SD]

Jackson, K. (1995) The Oxford book of money. Oxford University Press. [rSEGL]

James, S., Jordan, B. \& Redley, M. (1992) The wife's employment family fit. In: New directions in economic psychology, ed. S. E. G. Lea, P. Webley \& B. M. Young Edward Elgar. [aSEGL]

James, W. (1890) The principles of psychology, vol. 2. Harvard University Press/ Henry Holt/Dover. [PB, RBG]

Jinkings, N. (2000) Brazilian bank tellers: Between the fetishism of money and the cult of excellence. Latin American Perspectives 27:45-64. [aSEGL]

Joseph, B. (1986) Envy in everyday life. Psychoanalytic Psychotherapy 2:1322. [R-PB]

Judson, O. (2002) Dr. Tatiana's sex advice for all creation. Henry Holt. [GMB]

Kahn, J. P. \& Delmonico, F. L. (2004) The consequences of public policy to buy and sell organs for transplantation. American Journal of Transplantation 4:17880. [rSEGL]

Kahneman, D. \& Tversky, A., eds. (2000) Choices, values, and frames. Cambridge University Press. [KES]

Kant, I. (1785/1946) The moral law or Kant's groundwork of the metaphysics of morals, trans. and ed. H. J. Paton (with commentary). Hutchinson. [AJW]

Katona, G. (1975) Psychological economics. Elsevier. [rSEGL]

Kehtarnavaz, N. \& Kim, N. (2005) Digital signal processing system-level design using LabVIEW. Newnes/Elsevier. [RBG]

Kelleher, R. T. (1957) Conditioned reinforcement in chimpanzees. Journal of Comparative and Physiological Psychology 49:571-75. [rSEGL]

(1958) Fixed-ratio schedules of conditioned reinforcement with chimpanzees. Journal of the Experimental Analysis of Behavior 1:281-89. [rSEGL]

Kemp, S. (2005) Investigations of the consumer psychology of near-money. In: Consumers, policy and the environment: A tribute to Folke Ölander, ed. K. Grunert \& J. Thorgersen, pp. 251-64. Springer. [SK]

Kim, K.-M. (2001) Nested hierarchies of vicarious selectors. In: Selection theory and social construction: The evolutionary naturalistic epistemology of Donald T. Campbell, ed. C. Heyes \& D. L. Hull, pp. 101-18. State University of New York Press. [RBG]

Kirby, K. N. (1997) Bidding on the future: Evidence against normative discounting of delayed rewards. Journal of Experimental Psychology: General 126:5470. [GA]

Kirsh, D. (1996) Adapting the environment instead of oneself. Adaptive Behavior $4(3 / 4): 415-52 . \quad[\mathrm{SC}]$

Knauft, B. M. (1997) Gender identity, political economy and modernity in Melanesia and Amazonia. Journal of the Royal Anthropological Institute 3:23359. [aSEGL]

Knutson, B., Adams, C. M., Fong, G. W. \& Hommer, D. (2001a) Anticipation of increasing monetary reward selectively recruits nucleus accumbens. Journal of Neuroscience 21(16):RC159. [HM]

Knutson, B., Fong, G. W., Adams, C. M., Varner, J. L. \& Hommer, D. (2001b) Dissociation of reward anticipation and outcome with event-related fMRI. NeuroReport 12(17):3683-87. [GAA, HM]

Knutson, B., Fong, G. W., Bennett, S. M., Adams, C. M. \& Hommer, D. (2003) A region of mesial prefrontal cortex tracks monetarily rewarding outcomes: Characterization with rapid event-related fMRI. Neuroimage 18(2):26372. [HM]

Kohn, A. (1993) Punished by rewards. Houghton Mifflin. [AF]

Kojève, A. (1969) Introduction to the reading of Hegel, trans. J. H. Nichols, Jr., ed. A. Bloom. Agora Paperback Editions. [PJ]

Kooreman, P., Faber, R. P. \& Hofmans, H. M. J. (2004) Charity donations and the euro introduction: Some quasi-experimental evidence on money illusion. Journal of Money, Credit and Banking 36:1121-24. [aSEGL]

Lai, K. Y., Tari, Z. \& Bertok, P. (2005) Improving data accessibility for mobile clients through cooperative hoarding. Proceedings of the 21st International Conference on Data Engineering 415-16 (abstract). [DAB]

Lajoie, J. \& Bindra, D. (1976) An interpretation of autoshaping and related phenomena in terms of stimulus-incentive contingencies alone. Canadian Journal of Psychology 30:157-72. [FS]

Lea, S. E. G. (1981) Inflation, decimalization and the estimated size of coins. Journal of Economic Psychology 1:79-81. [aSEGL]

(1984) Instinct, environment and behaviour. Methuen. [arSEGL] (1994) The evolutionary biology of economic behavior. In: Essays in economic psychology, ed. H. Brandstätter \& W. Güth. Springer. [aSEGL]

(in press) Evolutionary psychology and economic psychology. In: The Cambridge handbook of psychology and economic behaviour, ed. A. Lewis. Cambridge University Press. [rSEGL]

Lea, S. E. G. \& Midgley, M. (1989) La biologie de la monnaie. Communications de l'EHESS 50:121-36. [arSEGL]

Lea, S. E. G. \& Newson, L. (2005) Evolutionary economic psychology. Paper read at the Conference of the International Association for Research in Economic Psychology, Prague, September 2005. [rSEGL]
References/Lea \& Webley: Money as tool, money as drug

Lea, S. E. G. \& Webley, P. (2005) In search of the economic self. Journal of SocioEconomics 34:585-604. [rSEGL]

Lea, S. E. G., Tarpy, R. M. \& Webley, P. (1987) The individual in the economy: A survey of economic psychology. Cambridge University Press. [SK, aSEGL]

Lea, S. E. G., Webley, P. \& Levine, R. M. (1993) The economic psychology of consumer debt. Journal of Economic Psychology 14:85-119. [rSEGL]

Lefebvre, V. A. (2003) Mentalism and behaviorism: Merging? Reflexive Processes and Control 2(2):56-76. [VAL]

(2004) Bipolarity, choice, and entro-field. Proceedings of the 8th world multiconference on systemics, cybernetics and informatics, vol. IV, ed. N. Calaos. pp. 95-99. International Institute of Informatics and Systemics. [VAL]

Leiser, D. \& Izak, G. (1987) The money size illusion as a barometer of confidence: The case of high inflation in Israel. Journal of Economic Psychology 8:34756. [aSEGL]

Liston-Heyes, C. (2002) Real versus perceived values of air miles. Journal of Consumer Policy 25:1-26. [SK]

Lorenz, K. (1963/2002) On aggression. Routledge. [R-PB]

Lorenz, K. Z. (1966) On aggression, second edition. Harcourt, Brace \& World. [RBG]

(1969) Innate bases of learning. In: On the biology oflearning, ed. K. H. Pribram, pp. 11-93. Harcourt, Brace \& World. [RBG]

Luna-Arocas, R. \& Tang, T. L. P. (2004) The love of money, satisfaction, and the Protestant work ethic: Money profiles among university professors in the USA and Spain. Journal of Business Ethics 50:329-54. [aSEGL]

Machauer, A. \& Weber, M. (1998) Bank behavior based on internal credit ratings of borrowers. Journal of Banking \& Finance 22:1355-83. [aSEGL]

Maital, S. (1982) Minds, markets and money. Basic Books. [aSEGL]

Malinowski, B. (1922) Argonauts of the western Pacific. Routledge and Kegan Paul. [aSEGL]

Margolin, M. (2003) The Ohlone way. Heydey. (Originally published 1978). [aSEGL]

Markman, A. B. \& Brendl, C. M. (2005) Goals, policies, preferences, and actions. In: Applying social cognition to consumer-focused strategy, ed. F. R. Kardes, P. M. Herr \& J. Nantel, pp. 183-200. Erlbaum. [ABM]

Marx, K. (1932) Capital. Dent. (Originally published 1867). [aSEGL]

Maslow, A. H. (1943) A theory of human motivation. Psychological Review 50:370-96. [FS]

Mattson, M. P. (2002) Brain evolution and lifespan regulation: Conservation of signal transduction pathways that regulate energy metabolism. Mechanisms of Ageing and Development 123:947-53. [GAA]

(2005) Energy intake, meal frequency, and health: A neurobiological perspective. Annual Review of Nutrition 25:237-60. [GAA]

Mauss, M. (1954) The gift: Forms and functions of exchange in archaic societies. Routledge \& Kegan Paul. (Originally published 1925). [aSEGL]

Mayer, M. L. \& Rozier, R. G. (2000) Money illusion among health care providers: Should we adjust for inflation in analyses of provider behavior? Social Science \& Medicine 51:395-405. [aSEGL]

Mazur, A. \& Booth, A. (1998) Testosterone and dominance in men. Behavioral and Brain Sciences 21:353-63. [KMK]

McCabe, K. (1989) Fiat money as a store of value in an experimental market. Journal of Economic Behavior and Organizations 12:215-31. [GAA] (2003) A cognitive theory of reciprocal exchange. In: Trust and reciprocity: Interdisciplinary lessons from empirical research, ed. E. Ostrom \& J. Walker, pp. 147-69. Russell Sage Foundation. [GAA]

McClure, S. M., Laibson, D. I., Loewenstein, G. \& Cohen, J. D. (2004) The grasshopper and the ant: Separate neural systems value immediate and delayed monetary rewards. Science 306:503-507. [GA, aSEGL]

McClure, S. M., Li, J., Tomlin, D., Cypert, K. S., Montague, L. M. \& Montague, R. M. (2004) Neural correlates of behavioral preference for culturally familiar drinks. Neuron 44:379-87. [DR]

McDougall, W. (1924) An outline of psychology, 2nd edition. Methuen. [R-PB]

McGraw, A. \& Tetlock, P. (2005) Taboo trade-offs, relational framing and the acceptability of exchanges. Journal of Consumer Psychology 15(1):215. $[\mathrm{RB}, \mathrm{ABM}]$

Mennell, S., Murcott, A. \& van Otterloo, A. H. (1992) The sociology of food: Eating, diet and culture. Sage. [aSEGL]

Mesterton-Gibbons, M. \& Dugatkin, L. A. (1999) On the evolution of delayed recruitment to food bonanzas. Behaviural Ecology 10:377-90. [aSEGL]

Midgley, M., Lea, S. E. G. \& Kirby, R. M. (1989) Algorithmic shaping and misbehavior in the acquisition of token deposit by rats. Journal of the Experimental Analysis of Behavior 52:27-40. [rSEGL]

Miller, R. \& Schulman, E. (1999) Money illusion revisited: Linking inflation to asset return correlations. Journal of Portfolio Management 25(3):45-54. [aSEGL]

Millman, M. (1991) Warm hearts and cold cash. Free Press. [aSEGL]

Mintz, S. W. (1986) Sweetness and power. Penguin. [arSEGL]

Mishkin, F. S. (1992) The economics of money, banking and financial markets, 3rd edition. Harper Collins. [aSEGL] 
Mobbs, C. V., Bray, G. A., Atkinson, R. L., Bartke, A., Finch, C. E., Maratos-Flier, E., Crawley, J. N. \& Nelson, J. F. (2001) Neuroendocrine and pharmacological manipulations to assess how caloric restriction increases life span. Journal of Gerontology A 56:34-44. [GAA]

Modigliani, F. \& Cohn, R. A. (1979) Inflation, rational valuation and the market. Financial Analysts Journal 35(2):24-44. [aSEGL]

Mook, D. G. (1987) Motivation: The organisation of action. Norton. [aSEGL]

Montague, P. R., Dayan, P. \& Sejnowski, T. K. (1996). A framework for mesencephalic dopamine systems based on predictive Hebbian learning. Journal of Neuroscience 16:1936-47. [SC]

Morgan, C. T., Stellar, E. \& Johnson, O. (1943) Food-deprivation and hoarding in rats. Journal of Comparative Psychology 36:47-55. [DAB]

Motel, A. \& Szydlik, M. (1999) Private Transfers zwischen den Generationen. Zeitschrift für Soziologie 28:3-22. [aSEGL]

Mouras, H. \& Stoléru, S. (in press) Functional neuroanatomy of sexual arousal. In: Male sexual dysfunction: Pathophysiology and treatment, ed. F. Kandeel, T. Lue, J. Pryor \& R. Swerdloff. Marcel Dekker. [HM]

Munro, D., Thomas, D. W. \& Humphries, M. M. (2005) Torpor patterns of hibernating eastern chipmunks Tamias striatus vary in response to the size and fatty acid composition of food hoards. Journal of Animal Ecology 74:692700. [DAB]

Needleman, J. (1994) Money and the meaning of life. Doubleday. [aSEGL]

Newton, T. (2003) Credit and civilization. British Journal of Sociology $54: 347-71$. [aSEGL]

Nichols, S. \& Stich, S. P. (2003) Mindreading: An integrated account of pretence, self-awareness, and understanding other minds. Oxford University Press. [KES]

North, D. (1990) Institutions, institutional change and economic performance. Cambridge University Press. [GAA]

Nozick, R. (1993) The nature of rationality. Princeton University Press. [KES]

O’Daly, M., Angulo, S., Gipson, C. \& Fantino, E. (in press) Influence of temporal context on value in the multiple chains and successive-encounters procedures. Journal of the Experimental Analysis of Behavior. [PR]

O’Doherty, J., Dayan, P., Schultz, J., Deichmann, R., Friston, K. \& Dolan, R. J. (2004) Dissociable roles of ventral and dorsal striatum in instrumental conditioning. Science 304:452-54. [GAA]

Offer, A. (1997) Between the gift and the market: The economy of regard. Economic History Review 50:450-76. [aSEGL]

Oliven, R. G. (1998) Looking at money in America. Critique of Anthropology 18:35-59. [aSEGL]

Pahl, J. (1989) Money and marriage. Macmillan. [aSEGL]

(1995) His money, her money: Recent research on financial organisation in marriage. Journal of Economic Psychology 16:361-76. [aSEGL]

Pavlov, I. P. (1927) Conditioned reflexes. Oxford University Press. [SK]

Pelchat, M. L., Johnson, A., Chan, R., Valdez, J. \& Ragland, J. D. (2004) Images of desire: Food-craving activation during fMRI. Neuroimage 23:148693. [GAA]

Perlman, M. (1986) The bullionist controversy revisited. Journal of Political Economy 94:745-62. [aSEGL]

Petroski, H. (1985) To engineer is human. St Martin’s Press. [RBG]

Pieters, R. \& Robben, H. (1999) Consumer evaluation of money as a gift: A twoutility model and an empirical test. Kyklos 52:173-200. [aSEGL]

Potenza, M. N., Steinberg, M. A., Skudlarski, P., Fulbright, R. K., Lacadie, C. M., Wilber, M. K., Rounsaville, B. J., Gore, J. C. \& Wexler, B. E. (2003) Gambling urges in pathological gambling: A functional magnetic resonance imaging study, Archives of General Psychiatry 60:828-36. [DR]

Prasad, M. (1999) The morality of market exchange: Love, money, and contractual justice. Sociological Perspectives 42:181-213. [aSEGL]

Prelec, D. \& Loewenstein, G. (1998) The red and the black: Mental accounting of savings and debt. Marketing Science 17(1):4-28. [SD, rSEGL]

Prelec, D. \& Simester, D. (2001) Always leave home without it: A further investigation of the credit-card effect on willingness to pay. Marketing Letters 12:512. [aSEGL]

Premack, D. (1965) Reinforcement theory. In: Nebraska symposium on motivation, vol. 13, ed. D. Levine, pp. 123-80. University of Nebraska Press. [rSEGL]

Preston, R. A. \& Fantino, E. (1991) Conditioned reinforcement value and choice. Journal of the Experimental Analysis of Behavior 55:155-75. [FS]

Rachlin, H. (1976) Behavior and learning. Freeman. [SK

(2000) The science of self control. Harvard University Press. [DR]

(2002) Altruism and selfishness. Behavioral and Brain Sciences 25:239-96. [RB]

Raghubir, P. \& Srivastava, J. (2002) Effect of face value on product valuation in foreign currencies. Journal of Consumer Research 29:335-47. [KES]

Ramnani, N., Elliott, R., Athwal, B. S. \& Passingham, R. E. (2004) Prediction error for free monetary reward in the human prefrontal cortex. Neuroimage 23(3):777-86. [HM]

Raz, J. (1986) The morality of freedom. Clarendon Press. [AJW]

Reynolds, H. (1986) The economics of prostitution. Thomas. [rSEGL]
Richerson, P. J. \& Boyd, R. (2005) Not by genes alone: How culture transformed human evolution. University of Chicago Press. [KES]

Richins, M. L. (2004) The material values scale: Measurement properties and development of a short form. Journal of Consumer Research 31:209-19. [aSEGL]

Ridley, M. (1997) The origins of virtue. Penguin. [aSEGL]

Roth, M. S. (1988) Knowing and history. Appropriations of Hegel in twentieth-century France. Cornell University Press. [PJ]

Routh, D. A. \& Burgoyne, C. B. (1998) Being in two minds about a single currency: A UK perspective on the euro. Journal of Economic Psychology 19:741-54. [aSEGL]

Rudmin, F. W. (1991) To have possessions. Select Press. [aSEGL]

Sahlins, M. (1974) Stone age economics. Tavistock. [aSEGL]

Sanabria, F., Baker, F. \& Rachlin, H. (2003) Learning by pigeons playing against tit-for-tat in an operant prisoner's dilemma. Learning and Behavior 31:318-31. [FS]

Sartre, J.-P. (1943) Being and nothingness: A phenomenological essay on ontology. Philosophical Library. [RB]

Saugstad, P. \& Schioldborg, P. (1966) Value and size perception. Scandinavian Journal of Psychology 7:102-14. [aSEGL]

Schor, J. B. (1998) The overspent American. Basic Books. [aSEGL]

Schultz, W. (1992) Activity of dopamine neurons in the behaving primate. Seminars in Neurosciences 4:129-38. [SC]

(2004) Neural coding of basic reward terms of animal learning theory, game theory, microeconomics and behavioural ecology. Current Opinion in Neurobiology 14:139-47. [SK]

Schultz, W., Dayan, P. \& Montague, R. (1997) A neural substrate of prediction and reward. Science 275:1593-99. [GAA]

Schumpeter, J. A. (1994) History of economic analysis. Oxford University Press. (Originally published 1954). [aSEGL]

Schwab, R. S. (1953) Motivation in measurements of fatigue. In: Fatigue, ed. W. F. Floyd \& A. T. Welford, pp. 143-48. Lewis. [rSEGL]

Schwartz, B., Ward, A., Lyubomirsky, S., Monterosso, J., White, K. \& Lehman, D. R. (2002) Maximizing versus satisficing: Happiness is a matter of choice. Journal of Personality and Social Psychology 83:1178-97. [KMK]

Schweingruber, D. \& Berns, N. (2003) Doing money work in a door-to-door sales organization. Symbolic Interaction 26:447-71. [aSEGL]

Scitovsky, T. (1976) The joyless economy. Oxford University Press. [aSEGL]

Seaford, R. (2004) Money and the early Greek mind. Cambridge University Press. [aSEGL]

Shafir, E., Diamond, P. \& Tversky, A. (1997) Money illusion. Quarterly Journal of Economics 112:341-74. [aSEGL, KES]

Shefrin, H. M. \& Thaler, R. H. (1988) The behavioral life-cycle hypothesis. Economic Inquiry 26(4):609-43. [SD]

(1992) Mental accounting, saving, and self-control. In: Choice over time, ed. G. Loewenstein \& J. Elster, pp. 287-330. Russell Sage Foundation. $[\mathrm{ABM}]$

Shell, M. (1982) Money, language and thought. University of California Press. [aSEGL]

Sherry, D. F. (1985) Food storage by birds and mammals. Advanced Studies in Behavior 15:153-88. [PB]

Silberman, S. (2003) The bacteria whisperer. Wired 11.04, April 2003. [SC]

Simmel, G. (1900/1978) The philosophy of money, 2nd enlarged edition, trans. T. Bottomore \& D. Frisby. Routledge and Kegan Paul. (Originally published in 1900). [R-PB, aSEGL]

Simon, H. A. (1978) Rationality as a process and as a product of thought. American Economic Review 68(2):1-16. [rSEGL]

(1996) The sciences of the artificial, 3rd edition. MIT Press. [RBG]

Simpson, B. (1997) On gifts, payments and disputes: Divorce and changing family structures in contemporary Britain. Journal of the Royal Anthropological Institute 3:731-45. [aSEGL]

Singh, S. (1996) Money, marriage and the computer. Marriage and Family Review 24:369-98. [aSEGL]

Skinner, B. F. (1953) Science and human behavior. Macmillan. [aSEGL] (1966) Phylogeny and ontogeny of behavior. Science 153:1205-13. [GMB] (1984) Selection by consequences. Behavioral and Brain Sciences 7:477510. [FS]

Slater, P. E. (1980) Wealth addiction. Dutton. [aSEGL]

Smith, A. (1776/1908) An enquiry into the nature and causes of the wealth of nations. Bell. (Original work published in 1776).

Smith, C. C. \& Reichman, O. J. (1984) The evolution of food caching by birds and mammals. Annual Review of Ecology and Systematics 15:329-51. [PB]

Smith, E. A. (2004) Why do good hunters have higher reproductive success? Human Nature 15:343-64. [KMK]

Snelders, H. M. J. J., Lea, S. E. G., Webley, P. \& Hussein, G. (1992) The polymorphous concept of money. Journal of Economic Psychology 13:71-92. [aSEGL] 
Snellman, J. S., Vesala, J. M. \& Humphrey, D. B. (2001) Substitution of noncash payment instruments for cash in Europe. Journal of Financial Services Research 19:131-45. [aSEGL]

Snodgrass, J. G. (2002) A tale of goddesses, money, and other terribly wonderful things: Spirit possession, commodity fetishism, and the narrative of capitalism in Rajasthan, India. American Ethnologist 29:602-36. [aSEGL]

Solomon, R. L., Kamin, L. J. \& Wynne, L. C. (1953) Traumatic avoidance learning: The outcomes of several extinction procedures with dogs. Journal of Abnormal and Social Psychology 48:291-302. [SK]

Soman, D. \& Cheema A. (2002) The effect of credit on spending decisions: The role of the credit limit and credibility. Marketing Science 21:32-53. [SD]

Sperber, D. (2000) Metarepresentations in evolutionary perspective. In: Metarepresentations: A multidisciplinary perspective, ed. D. Sperber, pp. 117-37. Oxford University Press. [KES]

Spillius, E. B. (1993) Varieties of envious experience. International Journal of Psychoanalysis 74:1199-1212. [R-PB]

Stanovich, K. E. (1999) Who is rational? Studies of individual differences in reasoning. Erlbaum. [KES]

(2004) The robot's rebellion: Finding meaning in the age of Darwin. University of Chicago Press. [KES]

Stoléru, S. \& Mouras, H. (in press) Brain functional imaging studies of sexual desire and arousal in human males. In: The psychophysiology of sex, ed. E. Janssen. Indiana University Press. [HM]

Stopka, P. \& Macdonald, D. W. (2003) Way-marking behavior: An aid to spatial navigation in the wood mouse (Apodemus sylvaticus). BMC Ecology, published online: http://www.biomedcentral.com/1472-6785/3/3. [SC]

Sutton, R. \& Barto, A. (1998) Reinforcement learning. MIT Press. [GAA]

Suzuki, S. (1997) Effects of number of alternatives on choice in humans. Behavioural Processes 39:205-14. [SD]

Symons, D. (1979) The evolution of human sexuality. Oxford University Press. [aSEGL]

Tang, T. L. P. (1995) The development of a short money ethic scale: Attitudes toward money and pay satisfaction revisited. Personality and Individual Differences 19:809-16. [aSEGL]

Tang, T. L. P. \& Chiu, R. K. (2003) Income, money ethic, pay satisfaction, commitment, and unethical behavior: Is the love of money the root of evil for Hong Kong employees? Journal of Business Ethics 46:13-30. [aSEGL]

Tang, T. L. P. \& Gilbert, P. R. (1995) Attitudes toward money as related to intrinsic and extrinsic job-satisfaction, stress and work-related attitudes. Personality and Individual Differences 19:327-32. [aSEGL]

Tataranni, P. A., Gautier, J. F., Chen, K., Uecker, A., Bandy, D., Salbe, A. D., Pratley, R. E., Lawson, M., Reiman, E. M. \& Ravussin, A. E. (1999) Neuroanatomical correlates of hunger and satiation in humans using positron emission tomography. Proceedings of the National Academy of Sciences USA 96:4569-74. [GAA]

Tawney, R. H. (1926) Religion and the rise of capitalism. John Murray. [AJW]

Teleki, G. (1973) The predatory behavior of wild chimpanzees. Bucknell University Press. [rSEGL]

Tetlock, P. E., Kristel, O. V., Elson, S. B., Green, M. C. \& Lerner, J. S. (2000) The psychology of the unthinkable: Taboo trade-offs, forbidden base rates, and heretical counterfactuals. Journal of Personality and Social Psychology $78(5): 853-70 . \quad[\mathrm{ABM}]$

Thompson, T. I. (1963) Visual reinforcement in Siamese fighting fish. Science 141:55-57. [aSEGL]

Thompson, W. E., Harred, J. L. \& Burks, B. E. (2003) Managing the stigma of topless dancing: A decade later. Deviant Behavior 24:551-70. [arSEGL]

Tinbergen, N. (1951) The study of instinct. Oxford University Press. [GMB, aSEGL]

Tooby, J. \& Cosmides, L. (1992) Cognitive adaptations for social exchange. In: The adapted mind. Evolutionary psychology and the generation of culture, ed. J. H. Barkow, L. Cosmides \& J. Tooby, pp.163-228. Oxford University Press. [SD]

Trivers, R. L. (1971) The evolution of reciprocal altruism. Quarterly Review of Biology 46:35-57. [aSEGL]

Trope, Y. \& Fishbach, A. (2000) Counteractive self-control in overcoming temptation. Journal of Personality and Social Psychology 79:493-506. [SD]

Truman, G. E., Sandoe, K., \& Rifkin, T. (2003) An empirical study of smart card technology. Information and Management 40:591-606. [aSEGL].
References/Lea \& Webley: Money as tool, money as drug

van der Geest, S. (1997) Money and respect: The changing value of old age in rural Ghana. Africa 67:534-59. [aSEGL]

Van Veldhoven, G. M. M. (1985) Economic-psychological aspects of money: An overview. In: Economic Psychology, ed. H. Brandstätter \& E. Kirchler. Trauner. [aSEGL]

Veblen, T. (1979) The theory of the leisure class, Penguin. (Originally published 1899). [aSEGL]

Vogler, C. (1998) Money in the household: Some underlying issues of power. Sociological Review 46:687-713. [aSEGL]

Volkow, N. D. \& Wise, R. A. (2005) How can drug addiction help us understand obesity? Nature Neuroscience 8:555-60. [GAA]

Walsh, A. J. (2004) The morality of the market and the medieval schoolmen. Politics, Philosophy and Economics 3(2):241-59. [AJW]

Ward, P. \& Zahavi, A. (1973) The importance of certain assemblages of birds as "information-centres" for food-finding. Ibis 115:517-34. [aSEGL]

Wärneryd, K.-E. (1999) The psychology of saving: A study on economic psychology. Edward Elgar. [SD, rSEGL]

Watson, J. B. (1924) Behaviorism. The Peoples Institute. [GA]

Weber, M. (1976) The Protestant ethic and the spirit of capitalism, trans. T. Parsons, 2nd edition. Allen \& Unwin. (Originally published 1904). [aSEGL]

Webley P. (2004) Children's understanding of economics. In: Children's understanding of society, ed. M. Barrett \& E. Buchanan-Barrow. Psychology Press. [aSEGL]

Webley, P. \& Lea, S. E. G. (1993a) The partial unacceptability of money in repayment for neighborly help. Human Relations 46: 65-76. [arSEGL] (1993b) Towards a more realistic psychology of economic socialization. Journal of Economic Psychology 14:461-72. [aSEGL]

Webley, P. \& Webley, E. (1990) The playground economy. In: Applied economic psychology in the 1990s, ed. S. E. G. Lea, P. Webley \& B. M. Young. Washington Singer Press. [aSEGL]

Webley, P. \& Wilson, R. (1989) Social relationships and the unacceptability of money as a gift. Journal of Social Psychology 129:85-91. [aSEGL]

Webley, P., Burgoyne, C. B., Lea, S. E. G. \& Young, B. M. (2001) The economic psychology of everyday life. Psychology Press. [aSEGL]

Webley, P., Lea, S. E. G. \& Portalska, R. (1983) The unacceptability of money as a gift. Journal of Economic Psychology 4:223-38. [aSEGL]

Weiner, B. (1992) Human motivation: Metaphors, theories and research. Sage Wordsworth. [aSEGL]

Wike, E. L., ed. (1966) Secondary reinforcement: Selected experiments. Harper and Row. [aSEGL]

Wilden, A. (1968) The language of the self: The function of language in psychoanalysis. Johns Hopkins Press. [PJ]

Williams, Z. M., Bush, G., Rauch, S. L., Cosgrove, G. R. \& Eskandar, E. N. (2004) Human anterior cingulate neurons and the integration of monetary reward with motor responses. Nature Neuroscience 7(12):1370-75. Epub: 21 November 2004. [HM]

Wilson, E. O. (1975) Sociobiology. Harvard University Press. [RBG]

Wojcicki, J. M. (2002) Commercial sex work or ukuphanda? Sex-for-money exchange in Soweto and Hammanskraal area, South Africa. Culture Medicine and Psychiatry 26:339-70. [aSEGL]

Wolf, E. (1988) Treating the self: Elements of clinical self psychology. Guilford Press. [R-PB]

Woodruff, D. M. (1999) Money unmade: Barter and the fate of Russian capitalism. Cornell University Press. [aSEGL]

Wynn, T. (2002) Archeology and cognitive evolution. Behavioral and Brain Sciences 25:389-402. [DAB]

Yamauchi, K. T. \& Templer, D. I. (1982) The development of a Money Attitudes Scale. Journal of Personality Assessment 46:522-8. [aSEGL]

Zahavi, A. \& Zahavi, A. (1997) The handicap principle: A missing piece of Darwin's puzzle. Oxford University Press. [PB, SC]

Zelizer, V. A. (1989) The social meaning of money: "Special monies". American Journal of Sociology 95:342-77. [aSEGL]

(1994a) The creation of domestic currencies. American Economic Review 84:138-42. [aSEGL]

(1994b) The social meaning of money. Basic Books. [ABM]

(1996) Payments and social ties. Sociological Forum 11:481-95. [aSEGL]

Zink, C. F., Pagnoni, G., Martin-Skurski, M. E., Chappelow, J. C. \& Berns, G. S. (2004) Human striatal responses to monetary reward depend on saliency. Neuron 42:509-17. [aSEGL] 